Cochrane Database of Systematic Reviews

\title{
Graduated compression stockings for prevention of deep vein thrombosis (Review)
}

Sachdeva A, Dalton M, Lees T

Sachdeva A, Dalton M, Lees T.

Graduated compression stockings for prevention of deep vein thrombosis.

Cochrane Database of Systematic Reviews 2018, Issue 11. Art. No.: CD001484. DOI: 10.1002/14651858.CD001484.pub4.

www.cochranelibrary.com 
TABLE OF CONTENTS

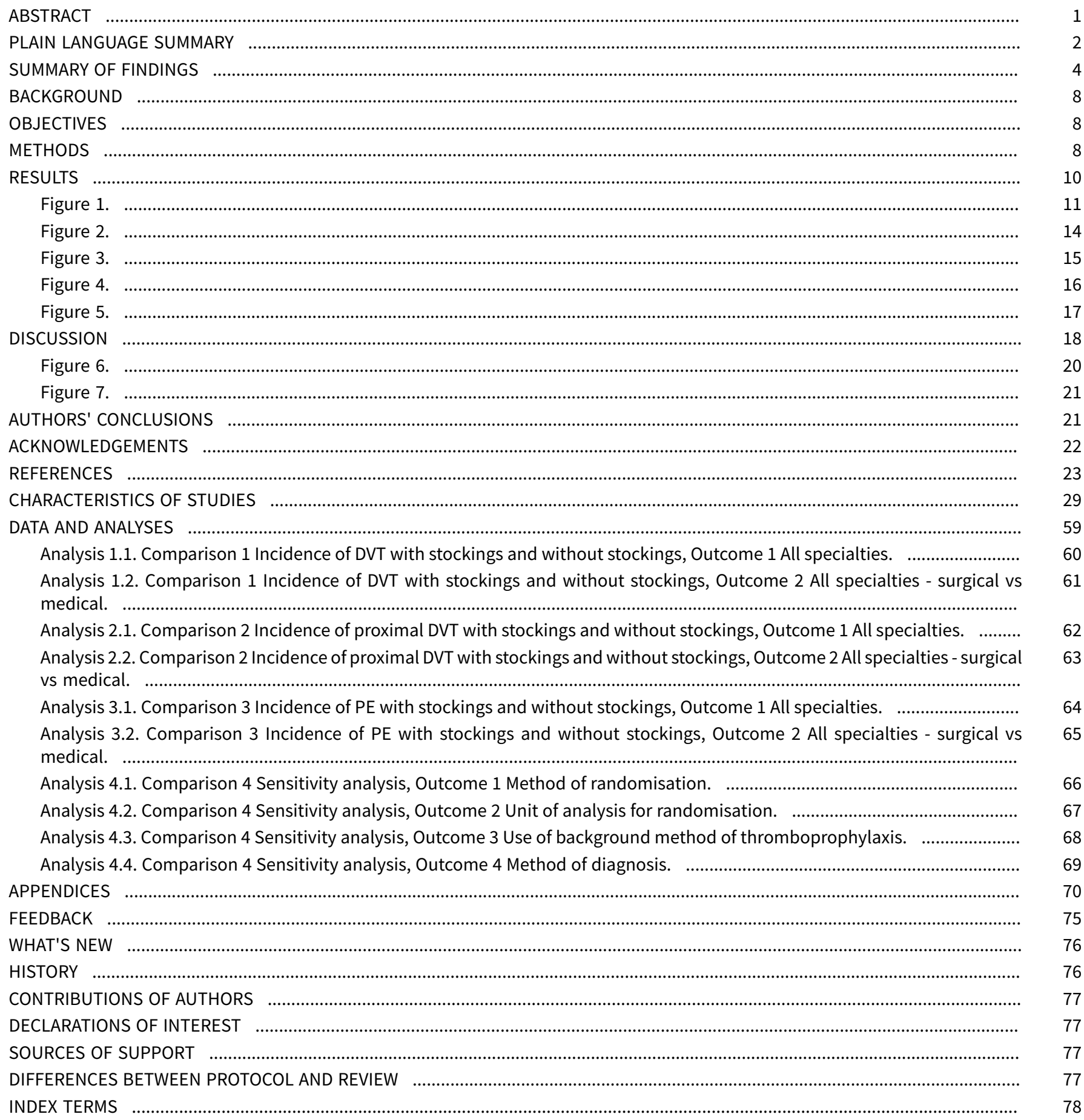


[Intervention Review]

\title{
Graduated compression stockings for prevention of deep vein thrombosis
}

Ashwin Sachdeva1 ${ }^{1}$, Mark Dalton², Timothy Lees ${ }^{3}$

1Wellcome Centre for Mitochondrial Research, Newcastle University, Newcastle upon Tyne, UK. 2Department of Anaesthetics, Royal Victoria Infirmary, Newcastle upon Tyne, UK. ${ }^{3}$ NMC Royal Hospital, Abu Dhabi, United Arab Emirates

Contact: Timothy Lees, NMC Royal Hospital, Khalifa City, Abu Dhabi, United Arab Emirates. Timlees@doctors.org.uk.

Editorial group: Cochrane Vascular Group.

Publication status and date: Edited (no change to conclusions), published in Issue 4, 2019.

Citation: Sachdeva A, Dalton M, Lees T. Graduated compression stockings for prevention of deep vein thrombosis. Cochrane Database of Systematic Reviews 2018, Issue 11. Art. No.: CD001484. DOI: 10.1002/14651858.CD001484.pub4.

Copyright $@ 2019$ The Cochrane Collaboration. Published by John Wiley \& Sons, Ltd.

\begin{abstract}
A B S T R A C T

\section{Background}

Hospitalised patients are at increased risk of developing deep vein thrombosis (DVT) in the lower limb and pelvic veins, on a background of prolonged immobilisation associated with their medical or surgical illness. Patients with DVT are at increased risk of developing a pulmonary embolism (PE). The use of graduated compression stockings (GCS) in hospitalised patients has been proposed to decrease the risk of DVT. This is an update of a Cochrane Review first published in 2000, and last updated in 2014.
\end{abstract}

\section{Objectives}

To evaluate the effectiveness and safety of graduated compression stockings in preventing deep vein thrombosis in various groups of hospitalised patients.

\section{Search methods}

For this review the Cochrane Vascular Information Specialist searched the Cochrane Vascular Specialised Register, the Cochrane Central Register of Controlled Trials (CENTRAL), and trials registries on 21 March 2017; and the Cochrane Vascular Specialised Register, CENTRAL, MEDLINE Ovid, Embase Ovid, CINAHL Ebsco, AMED Ovid, and trials registries on 12 June 2018.

\section{Selection criteria}

Randomised controlled trials (RCTs) involving GCS alone, or GCS used on a background of any other DVT prophylactic method. We combined results from both of these groups of trials.

\section{Data collection and analysis}

Two review authors (AS, MD) assessed potentially eligible trials for inclusion. One review author (AS) extracted the data, which a second review author (MD) cross-checked and authenticated. Two review authors (AS, MD) assessed the methodological quality of trials with the Cochrane 'Risk of bias' tool. Any disagreements were resolved by discussion with the senior review author (TL). For dichotomous outcomes, we calculated the Peto odds ratio and corresponding 95\% confidence interval. We pooled data using a fixed-effect model. We used the GRADE system to evaluate the overall quality of the evidence supporting the outcomes assessed in this review.

\section{Main results}

We included 20 RCTs involving a total of 1681 individual participants and 1172 individual legs (2853 analytic units). Of these 20 trials, 10 included patients undergoing general surgery; six included patients undergoing orthopaedic surgery; three individual trials included patients undergoing neurosurgery, cardiac surgery, and gynaecological surgery, respectively; and only one trial included medical patients. Graduated compression stockings were applied on the day before surgery or on the day of surgery and were worn up until discharge or until 
the participants were fully mobile. In the majority of the included studies DVT was identified by the radioactive I125 uptake test. Duration of follow-up ranged from seven to 14 days. The included studies were at an overall low risk of bias.

We were able to pool the data from 20 studies reporting the incidence of DVT. In the GCS group, 134 of 1445 units developed DVT (9\%) in comparison to the control group (without GCS), in which 290 of 1408 units developed DVT ( $21 \%)$. The Peto odds ratio (OR) was 0.35 (95\% confidence interval ( $\mathrm{Cl}) 0.28$ to 0.43 ; 20 studies; 2853 units; high-quality evidence), showing an overall effect favouring treatment with GCS $(P<0.001)$.

Based on results from eight included studies, the incidence of proximal DVT was 7 of $517(1 \%)$ units in the GCS group and 28 of 518 (5\%) units in the control group. The Peto OR was 0.26 ( $95 \% \mathrm{Cl} 0.13$ to $0.53 ; 8$ studies; 1035 units; moderate-quality evidence) with an overall effect favouring treatment with GCS $(P<0.001)$. Combining results from five studies, all based on surgical patients, the incidence of $P E$ was 5 of $283(2 \%)$ participants in the GCS group and 14 of $286(5 \%)$ in the control group. The Peto OR was $0.38(95 \% \mathrm{Cl} 0.15$ to $0.96 ; 5$ studies; 569 participants; low-quality evidence) with an overall effect favouring treatment with GCS $(P=0.04)$. We downgraded the quality of the evidence for proximal DVT and PE due to low event rate (imprecision) and lack of routine screening for PE (inconsistency).

We carried out subgroup analysis by speciality (surgical or medical patients). Combining results from 19 trials focusing on surgical patients, 134 of $1365(9.8 \%)$ units developed DVT in the GCS group compared to 282 of $1328(21.2 \%)$ units in the control group. The Peto OR was 0.35 (95\% Cl 0.28 to 0.44 ; high-quality evidence), with an overall effect favouring treatment with GCS $(P<0.001)$. Based on results from seven included studies, the incidence of proximal DVT was 7 of 437 units (1.6\%) in the GCS group and 28 of $438(6.4 \%)$ in the control group. The Peto OR was 0.26 ( $95 \% \mathrm{Cl} 0.13$ to 0.53 ; 875 units; moderate-quality evidence) with an overall effect favouring treatment with GCS (P< 0.001). We downgraded the evidence for proximal DVT due to low event rate (imprecision).

Based on the results from one trial focusing on medical patients admitted following acute myocardial infarction, 0 of 80 ( $0 \%$ ) legs developed DVT in the GCS group and 8 of $80(10 \%)$ legs developed DVT in the control group. The Peto OR was $0.12(95 \% \mathrm{Cl} 0.03$ to 0.51 ; low-quality evidence) with an overall effect favouring treatment with GCS $(P=0.004)$. None of the medical patients in either group developed a proximal DVT, and the incidence of PE was not reported.

Limited data were available to accurately assess the incidence of adverse effects and complications with the use of GCS as these were not routinely quantitatively reported in the included studies.

\section{Authors' conclusions}

There is high-quality evidence that GCS are effective in reducing the risk of DVT in hospitalised patients who have undergone general and orthopaedic surgery, with or without other methods of background thromboprophylaxis, where clinically appropriate. There is moderatequality evidence that GCS probably reduce the risk of proximal DVT, and low-quality evidence that GCS may reduce the risk of PE. However, there remains a paucity of evidence to assess the effectiveness of GCS in diminishing the risk of DVT in medical patients.

\section{PLAIN LANGUAGE SUMMARY}

\section{Graduated compression stockings for prevention of deep vein thrombosis during a hospital stay}

\section{Background}

Deep vein thrombosis (DVT) is a blood clot that forms in a vein deep in the body, usually in the leg or pelvic veins. A number of factors such as reduced mobility, older age, obesity, active cancer, major surgery, major injuries, history of previous DVT, family history of DVT, and recent period of illness may increase the risk of developing a DVT. Hospital patients, who often have one or more of these risk factors, are at particular risk of developing DVT, either immediately after surgery or if they are immobile due to a medical illness.

Symptoms of DVT vary from none to pain and swelling in the legs. A blood clot can move from the leg to the lungs, with the danger of pulmonary embolism (PE) and death. The main treatment for DVT includes the use of blood-thinning drugs (anticoagulation). Deep vein thrombosis usually resolves, but it can have long-term effects such as high venous pressure in the leg, leg pain, swelling, darkening of the skin, and inflammation.

Deep vein thrombosis can be prevented with the use of compression or drugs. Drugs can cause bleeding, which is a particular concern in surgical patients. Graduated compression stockings (GCS) help prevent the formation of blood clots in the legs by applying varying amounts of pressure to different parts of the leg.

\section{Study characteristics and key results}

We identified 20 randomised controlled trials (studies in which participants are assigned to a treatment group using a random method) (2853 analytic units consisting of 1681 individual patients and 1172 individual legs) in our most recent search on 12 June 2018 . Nine trials compared wearing stockings to no stockings, and 11 compared stockings plus another method with that method alone. The other methods used were dextran 70, aspirin, heparin, and mechanical sequential compression. Of the 20 trials, 10 included patients undergoing general surgery; six included patients undergoing orthopaedic surgery; three individual trials included patients undergoing neurosurgery, cardiac surgery, and gynaecological surgery, respectively; and only one trial included medical patients (patients who were admitted to the hospital 
for reasons other than surgery). The compression stockings were applied on the day before surgery or on the day of surgery and were worn up until discharge or until the patients were fully mobile. Thigh-length stockings were used in the vast majority of included studies. The included studies were of good quality overall. We found that wearing GCS reduced the overall risk of developing DVT, and probably also DVT in the thighs. We found that GCS may also reduce the risk of PE amongst patients undergoing surgery. As only one trial included medical patients, results for this population are limited. The occurrence of problems associated with wearing GCS was poorly reported in the included studies.

\section{Quality of the evidence}

Our review confirmed that GCS are effective in reducing the risk of DVT in hospitalised surgical patients (high-quality evidence). It also demonstrated that GCS probably reduce the risk of developing DVT in the thighs (proximal DVT, moderate-quality evidence) and PE (lowquality evidence). Reasons for downgrading the quality of the evidence included low event rate (i.e. small number of participants who developed DVT) and uncertainty due to only a small number of patients being routinely screened for proximal DVT or PE. Limited evidence was available for hospitalised medical patients, with only one study suggesting that GCS may prevent DVT in such patients. 


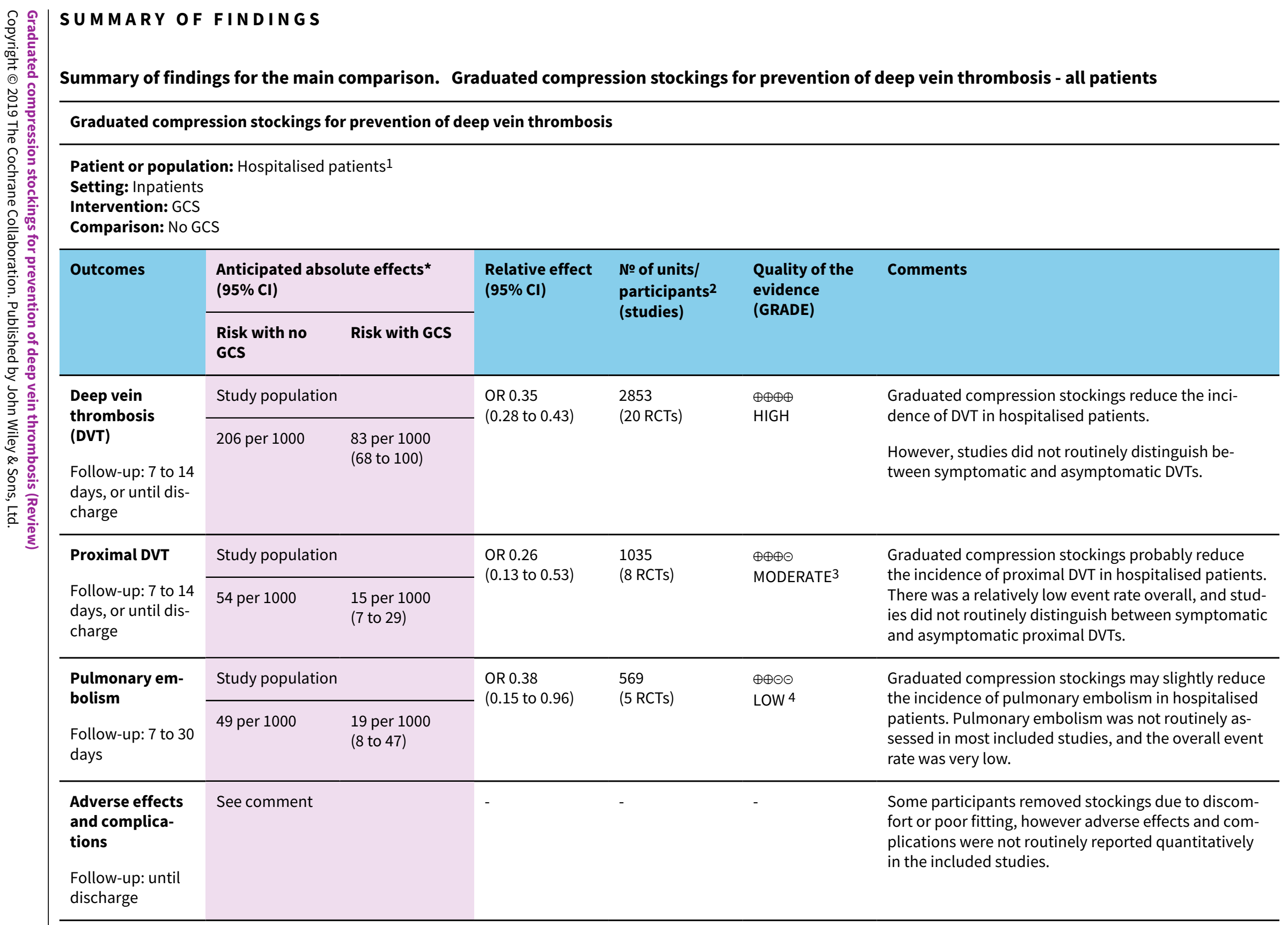

Patient or population: Hospitalised patients 
*The risk in the intervention group (and its $95 \%$ confidence interval) is based on the assumed risk in the comparison group and the relative effect of the intervention (and its $95 \% \mathrm{Cl})$.

CI: confidence interval; DVT: deep vein thrombosis; GCS: graduated compression stockings; OR: odds ratio; RCT: randomised controlled trial

\section{GRADE Working Group grades of evidence}

High quality: We are very confident that the true effect lies close to that of the estimate of the effect.

Moderate quality: We are moderately confident in the effect estimate: the true effect is likely to be close to the estimate of the effect, but there is a possibility that it is substantially different.

Low quality: Our confidence in the effect estimate is limited: the true effect may be substantially different from the estimate of the effect.

Very low quality: We have very little confidence in the effect estimate: the true effect is likely to be substantially different from the estimate of effect.

1Included patients admitted for surgical procedures (including abdominal, orthopaedic, neurosurgical, gynaecological surgery) and medical illness (acute myocardial infarction). 2Numbers refer to number of analytic units (either individual legs or individual participants).

3 We downgraded the quality of the evidence by one step due to the low event rate in the GCS group (imprecision).

${ }^{4}$ We downgraded the quality of the evidence by two steps as routine screening for pulmonary embolism was done in only two of the five RCTs, and the Cls were wide (inconsistency).

\section{Summary of findings 2. Graduated compression stockings for prevention of deep vein thrombosis in surgical patients}

\section{Graduated compression stockings for prevention of deep vein thrombosis}

Patient or population: Patients hospitalised for surgical procedures ${ }^{1}$

Setting: Inpatients

Intervention: GCS

Comparison: No GCS

\begin{tabular}{|c|c|c|c|c|c|c|}
\hline \multirow[t]{2}{*}{ Outcomes } & \multicolumn{2}{|c|}{$\begin{array}{l}\text { Anticipated absolute effects } \\
(95 \% \mathrm{Cl})\end{array}$} & \multirow[t]{2}{*}{$\begin{array}{l}\text { Relative effect } \\
(95 \% \mathrm{Cl})\end{array}$} & \multirow{2}{*}{$\begin{array}{l}\text { № of units/ } \\
\text { participants } 2 \\
\text { (studies) }\end{array}$} & \multirow{2}{*}{$\begin{array}{l}\text { Quality of the } \\
\text { evidence } \\
\text { (GRADE) }\end{array}$} & \multirow[t]{2}{*}{ Comments } \\
\hline & $\begin{array}{l}\text { Risk with no } \\
\text { GCS }\end{array}$ & Risk with GCS & & & & \\
\hline Deep vein throm- & \multicolumn{2}{|c|}{ Study population } & \multirow{2}{*}{$\begin{array}{l}\text { OR } 0.35 \\
(0.28 \text { to } 0.44)\end{array}$} & \multirow{2}{*}{$\begin{array}{l}2693 \\
(19 \mathrm{RCTs})\end{array}$} & \multirow{2}{*}{$\begin{array}{l}\oplus \oplus \oplus \oplus \\
\mathrm{HIGH}\end{array}$} & \multirow{2}{*}{$\begin{array}{l}\text { Graduated compression stockings reduce the inci- } \\
\text { dence of DVT in hospitalised surgical patients. How- } \\
\text { ever, studies did not routinely distinguish between } \\
\text { symptomatic and asymptomatic DVTs. }\end{array}$} \\
\hline $\begin{array}{l}\text { Follow-up: } 7 \text { to } 14 \\
\text { days, or until dis- } \\
\text { charge }\end{array}$ & 212 per 1000 & $\begin{array}{l}86 \text { per } 1000 \\
(70 \text { to } 106)\end{array}$ & & & & \\
\hline \multirow[t]{2}{*}{ Proximal DVT } & \multicolumn{2}{|c|}{ Study population } & OR 0.26 & 875 & $\oplus \oplus \oplus \ominus$ & Graduated compression stockings probably reduce \\
\hline & 64 per 1000 & 17 per 1000 & (0.13 to 0.53$)$ & (7 RCTs) & & cal patients. However, studies did not routinely dis- \\
\hline
\end{tabular}


Follow-up: 7 to 14 days, or until discharge
(9 to 35$)$

\section{Pulmonary em-}

bolism

Follow-up: 7 to 30

days, or until dis-

charge

Adverse effects

and complications

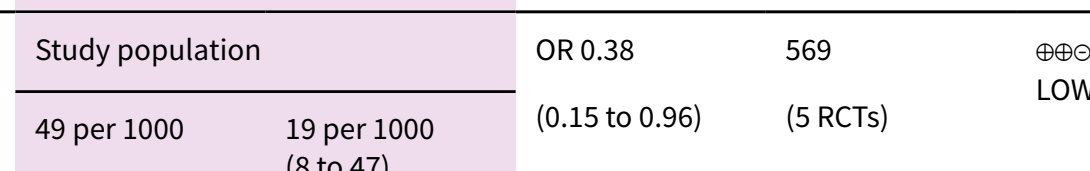

$\oplus \odot \odot$

(8 to 47 ) tinguish between symptomatic and asymptomatic proximal DVTs. There was a relatively low event rate overall.

Graduated compression stockings may slightly reduce the incidence of pulmonary embolism in hospitalised surgical patients. However, pulmonary embolism was not routinely assessed in most included studies, and the overall event rate was very low.

Some participants removed stockings due to discomfort or poor fitting however adverse effects and complications associated with wearing GCS were not routinely reported quantitatively in the included studies.

Follow-up: until

discharge

See comment

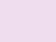

${ }^{*}$ The risk in the intervention group (and its 95\% confidence interval) is based on the assumed risk in the comparison group and the relative effect of the intervention (and its $95 \% \mathrm{Cl})$.

CI: confidence interval; DVT: deep vein thrombosis; GCS: graduated compression stockings; OR: odds ratio; RCT: randomised controlled trial

\section{GRADE Working Group grades of evidence}

High quality: We are very confident that the true effect lies close to that of the estimate of the effect.

Moderate quality: We are moderately confident in the effect estimate: the true effect is likely to be close to the estimate of the effect, but there is a possibility that it is substantially different.

Low quality: Our confidence in the effect estimate is limited: the true effect may be substantially different from the estimate of the effect.

Very low quality: We have very little confidence in the effect estimate: the true effect is likely to be substantially different from the estimate of effect.

${ }_{1}^{1}$ ncluded patients admitted for surgical procedures (including abdominal, orthopaedic, neurosurgical, gynaecological surgery).

2Numbers refer to number of analytic units (either individual legs or individual participants).

3 We downgraded the quality of the evidence by one step due to the low event rate in the GCS group (imprecision).

${ }^{4}$ We downgraded the quality of the evidence by two steps as routine screening for pulmonary embolism was done in only two of the five RCTs, and the Cls were wide (inconsistency).

\section{Summary of findings 3. Graduated compression stockings for prevention of deep vein thrombosis in medical patients}

\section{Graduated compression stockings for prevention of deep vein thrombosis}

Patient or population: Patients hospitalised following acute myocardial infarction

Setting: Inpatients

Intervention: GCS

Comparison: No GCS 


\begin{tabular}{|c|c|c|c|c|c|c|}
\hline \multirow[t]{2}{*}{ Outcomes } & \multicolumn{2}{|c|}{$\begin{array}{l}\text { Anticipated absolute effects* } \\
(95 \% \mathrm{CI})\end{array}$} & \multirow[t]{2}{*}{$\begin{array}{l}\text { Relative effect } \\
(95 \% \mathrm{CI})\end{array}$} & \multirow[t]{2}{*}{$\begin{array}{l}\text { № of units } \\
\text { (studies) }\end{array}$} & \multirow{2}{*}{$\begin{array}{l}\text { Quality of the } \\
\text { evidence } \\
\text { (GRADE) }\end{array}$} & \multirow[t]{2}{*}{ Comments } \\
\hline & $\begin{array}{l}\text { Risk with no } \\
\text { GCS }\end{array}$ & Risk with GCS & & & & \\
\hline \multirow{2}{*}{$\begin{array}{l}\text { Deep vein thrombo- } \\
\text { sis (DVT) } \\
\text { Follow-up: } 8 \text { days or } \\
\text { discharge or until de- } \\
\text { velopment of DVT }\end{array}$} & \multicolumn{2}{|c|}{ Study population } & \multirow{2}{*}{$\begin{array}{l}\text { OR } 0.12 \\
\text { (0.03 to } 0.51)\end{array}$} & \multirow{2}{*}{$\begin{array}{l}160 \\
(1 \mathrm{RCT})\end{array}$} & \multirow{2}{*}{$\begin{array}{l}\oplus \oplus \odot \odot \\
\text { LOW } 1\end{array}$} & \multirow{2}{*}{$\begin{array}{l}\text { Graduated compression stockings may reduce in- } \\
\text { cidence of DVT in hospitalised medical patients. } \\
\text { However, results are based on a single study on } \\
\text { medical patients hospitalised following acute my- } \\
\text { ocardial infarction (Kierkegaard 1993). }\end{array}$} \\
\hline & 100 per 1000 & $\begin{array}{l}13 \text { per } 1000 \\
\text { ( } 3 \text { to } 54)\end{array}$ & & & & \\
\hline \multirow{2}{*}{$\begin{array}{l}\text { Proximal DVT } \\
\text { Follow-up: } 8 \text { days or } \\
\text { discharge or until de- } \\
\text { velopment of DVT }\end{array}$} & \multicolumn{2}{|c|}{ Study population } & \multirow[t]{2}{*}{ Not estimable } & \multirow{2}{*}{$\begin{array}{l}160 \\
(1 \mathrm{RCT})\end{array}$} & \multirow[t]{2}{*}{-} & \multirow{2}{*}{$\begin{array}{l}\text { None of the participants in either group of this sin- } \\
\text { gle RCT with a small sample size developed proxi- } \\
\text { mal DVT. }\end{array}$} \\
\hline & 0 per 1000 & $\begin{array}{l}0 \text { per } 1000(0 \text { to } \\
0)\end{array}$ & & & & \\
\hline $\begin{array}{l}\text { Pulmonary em- } \\
\text { bolism }\end{array}$ & See comment & & - & - & - & $\begin{array}{l}\text { No studies reported on this outcome. There is } \\
\text { paucity of evidence to evaluate the effect of GCS } \\
\text { on reducing incidence of pulmonary embolism in } \\
\text { hospitalised medical patients. }\end{array}$ \\
\hline $\begin{array}{l}\text { Adverse effects and } \\
\text { complications }\end{array}$ & See comment & & - & $\begin{array}{l}160 \\
(1 \mathrm{RCT})\end{array}$ & - & $\begin{array}{l}\text { There are rare reports of post-thrombotic changes } \\
\text { in participants who developed DVT in the single in- } \\
\text { cluded RCT. }\end{array}$ \\
\hline
\end{tabular}

${ }^{\star}$ The risk in the intervention group (and its $95 \%$ confidence interval) is based on the assumed risk in the comparison group and the relative effect of the intervention (and its $95 \% \mathrm{Cl})$.

CI: confidence interval; DVT: deep vein thrombosis; GCS: graduated compression stockings; OR: odds ratio; RCT: randomised controlled trial

\section{GRADE Working Group grades of evidence}

High quality: We are very confident that the true effect lies close to that of the estimate of the effect.

Moderate quality: We are moderately confident in the effect estimate: the true effect is likely to be close to the estimate of the effect, but there is a possibility that it is substantially different.

Low quality: Our confidence in the effect estimate is limited: the true effect may be substantially different from the estimate of the effect.

Very low quality: We have very little confidence in the effect estimate: the true effect is likely to be substantially different from the estimate of effect.

1We downgraded the quality of the evidence by two steps as there was only one study and a low event rate in the GCS group (imprecision). 


\section{B A C K G R O U N D}

\section{Description of the condition}

The occurrence of one or more factors of Virchow's triad (stasis of blood, endothelial injury, and hypercoagulability of blood) in the venous system often leads to deep vein thrombosis (DVT) (Virchow 1858). Diagnosis of DVT is difficult as the patient history is not specific, and symptoms vary from no symptoms to pain and swelling in the legs. The sequelae of DVT vary from complete resolution of the clot without any ill effects through to death due to pulmonary embolism (PE).

Risk factors associated with the development of DVT include age over 60 years, active cancer, obesity, major surgery, major trauma, prolonged immobilisation, pregnancy, history of thromboembolic disease, and acute medical illness. Thromboembolic risk factors are particularly common amongst hospitalised patients, with baseline incidence of DVT in $29 \%$ of surgical patients and $24 \%$ in medical patients, and incidence of symptomatic PE of $3 \%$ and $1 \%$, respectively, without the use of thromboprophylaxis (NICE 2010).

Morbidity due to DVT includes post-thrombotic syndrome (PTS), which encompasses chronic venous hypertension causing limb pain, swelling, hyperpigmentation (darkening of the skin), dermatitis (inflammation of the skin), ulcers, and lipodermatosclerosis (a hardening of the skin that may gain a red or brown pigmentation and is accompanied by wasting of the subcutaneous fat). Data from a prospective multicentre cohort study found that $43 \%$ of patients with symptomatic DVT developed features of PTS at two-year follow-up (Kahn 2008).

Mortality associated with DVT is greatest in the first 30 days, at $3 \%$ to $6 \%$, though the risk of death remains increased even at long-term follow-up (Søgaard 2014). Various reports suggest that $28 \%$ to $41 \%$ of patients with DVT subsequently develop a $\mathrm{PE}$, which is associated with an increase in risk of 30-day mortality to approximately $12 \%$ (White 2003).

Patients who are at risk of developing DVT are categorised into three groups of low, moderate, and high risk according to the International Consensus Statement and Thromboembolic Risk Factor (THRIFT) consensus group guidelines (ICS 2013; THRIFT 1992). However, guidelines on prophylaxis of venous thromboembolism from the National Institute for Health and Care Excellence and the Scottish Intercollegiate Guidelines Network no longer categorise patients into low-, moderate-, and high-risk groups (NICE 2010; SIGN 2010), instead looking at risk factors for developing DVT in hospitalised patients on an individual basis.

\section{Description of the intervention}

Both mechanical and pharmacological methods are used in the prevention of DVT. Pharmacological methods alter the blood coagulation profile; the major disadvantage of this is the risk of bleeding, which may be of particular concern in surgical patients. For example, the altered coagulation may lead to joint haematomas following joint replacement surgery and intracranial haemorrhage following head injury or neurosurgery. Mechanical methods include techniques such as intermittent pneumatic compression (IPC) and wearing of graduated compression stockings (GCS).

\section{How the intervention might work}

The exact mechanism by which GCS function is unknown. However, there is evidence to suggest that they exert graded circumferential pressure distally to proximally and, when combined with muscular activity in the limb, are thought to displace blood from the superficial to the deep venous system via the perforating veins. It is argued that this effectively increases the velocity and volume of flow in the deep system thereby potentially preventing thrombosis (Benko 2001).

\section{Why it is important to do this review}

Despite the theoretical effectiveness and widespread use of compression stockings, their clinical effectiveness needs further appraisal. Improper application of stockings may potentially cause complications such as discomfort, oedema of the legs, DVT, and arterial ischaemia. Stockings may also be contraindicated for medical reasons. The extent to which the leg profile of patients may limit effectiveness has not been addressed. This review did not address the recommendations regarding the ideal length of stockings (knee length versus thigh length), which are assessed by a separate Cochrane Review (Sajid 2012).

The use of GCS amongst surgical patients is estimated to cost the National Health Service (NHS) GBP 63.1 million annually (GAPS). A strong evidence base is therefore needed to justify the routine use of GCS amongst hospitalised patients.

\section{O B J E C T IVES}

To evaluate the effectiveness and safety of graduated compression stockings in preventing deep vein thrombosis in various groups of hospitalised patients.

We tested the following hypotheses:

- compression stockings are effective in preventing DVT in hospitalised patients (excluding stroke);

- in all moderate-risk patients, compression stockings alone are adequate for DVT prophylaxis, except for patients for whom stockings are specifically contraindicated;

- stockings are unnecessary in low-risk patients;

- complications are associated with the use of compression stockings.

\section{METHODS}

\section{Criteria for considering studies for this review}

\section{Types of studies}

We included only randomised controlled trials (RCTs) that involved the use of compression stockings for DVT prophylaxis.

\section{Types of participants}

We included patients of either sex and any age hospitalised for conditions other than stroke.

\section{Types of interventions}

We included trials in which the use of graduated compression stockings (GCS) was compared with no prophylaxis, and those studies in which the use of GCS was compared with no stockings on a background of another method of DVT prophylaxis in both the 
treatment and control group (e.g. aspirin, heparin). We analysed both groups of trials together in this update as they both assessed the same treatment effect (i.e. GCS versus no GCS).

\section{Types of outcome measures}

\section{Primary outcomes}

- Diagnosis of DVT, either all DVT or proximal DVT, identified by ultrasound, venogram, or isotope studies

\section{Secondary outcomes}

- Diagnosis of PE, identified by a ventilation perfusion lung scan, pulmonary angiogram, or postmortem examination

- Complications and adverse effects arising from the use of GCS

\section{Search methods for identification of studies}

We placed no restrictions on language or publication status.

\section{Electronic searches}

For this update, the Cochrane Vascular Information Specialist (CIS) searched the following databases for relevant trials:

- the Cochrane Vascular Specialised Register (21 March 2017);

- the Cochrane Central Register of Controlled Trials (CENTRAL (2017, Issue 2)) via the Cochrane Register of Studies Online (21 March 2017).

See Appendix 1 for details of the search strategy used to search CENTRAL.

The Cochrane Vascular Specialised Register is maintained by the CIS and is constructed from weekly electronic searches of MEDLINE Ovid, Embase Ovid, CINAHL Ebsco (Cumulative Index to Nursing and Allied Health Literature), AMED Ovid (Allied and Complementary Medicine), and through handsearching relevant journals.

The CIS also searched the following trial registries for details of ongoing and unpublished studies (21 March 2017):

- US National Institutes of Health Ongoing Trials Register ClinicalTrials.gov (www.clinicaltrials.gov);

- World Health Organization International Clinical Trials Registry Platform (WHO ICTRP) (www.who.int/trialsearch);

- ISRCTN register (www.isrctn.com/).

See Appendix 2 for details of the search strategies used.

The CIS subsequently performed a top-up search on 12 June 2018, searching the Cochrane Vascular Specialised Register, CENTRAL, MEDLINE Ovid (2017 and 2018 only), Embase Ovid (2017 and 2018 only), CINAHL Ebsco (2017 and 2018 only), AMED Ovid (2017 and 2018 only), and the trials registries ClinicalTrials.gov and WHO ICTRP. See Appendix 3 for details of the search strategies.

\section{Searching other resources}

We searched the reference lists of all potentially eligible studies identified from the electronic searches to find additional trials.

\section{Data collection and analysis}

\section{Selection of studies}

We have specified the criteria for the selection of trials above. Two review authors (AS, MD) carried out the selection of trials for inclusion in this update, which the senior review author (TL) checked and approved.

One review author (AS) carried out the initial screening of all retrieved studies based on titles and abstracts in order to identify obvious exclusions (i.e. studies not relevant to the review). Where there was uncertainty regarding the relevance of a particular study, a second review author (MD) was consulted. Two review authors (AS, MD) independently assessed the remaining records so as to avoid exclusion of any relevant articles. Next, full papers were extracted for the remaining articles, which two review authors (AS, MD) independently assessed for inclusion (see Criteria for considering studies for this review). In case of disagreement between review authors, consensus was reached by discussion with a third review author (TL). Finally, all eligible, relevant studies based on the abovementioned criteria were included in the review.

\section{Data extraction and management}

For this update, one review author (AS) performed data extraction and entered data onto a data extraction form. Another review author (MD) then cross-checked the data. We extracted the following information.

- Age

- Sex

- DVT risk groups to which participants belonged

- Duration of application of stockings

- Types and length of stockings

- Incidence of DVT

- PE

- Adverse effects

- Investigations used to make the diagnoses

\section{Assessment of risk of bias in included studies}

Two review authors (AS, MD) independently assessed the risk of bias for all the included studies based on six domains: random sequence generation, allocation concealment, blinding (participant and assessor), incomplete outcome data, selective reporting, and other biases. We used the 'Risk of bias' assessment tool outlined in the Cochrane Handbook for Systematic Reviews of Interventions to determine whether studies were free of potential bias, assessing studies as at low risk, high risk, or unclear risk of bias if the available information was inadequate (Higgins 2011). Any discrepancies in opinion were discussed and consensus reached. Blinding of participants to their treatment group (i.e. whether they wore GCS or not) was inherently difficult, therefore blinding of assessors to treatment groups was deemed the most appropriate method to minimise risk of bias.

\section{Measures of treatment effect}

The effectiveness of treatment (i.e. the use of GCS) was assessed by recording the incidence of DVT in the treatment (stockinged) group compared to that in the control (non-stockinged) group. Deep vein thrombosis was diagnosed using an objective method of 
assessment such as ultrasound, venogram, or isotope studies. We did not combine individual patient data from different trials.

We performed analysis of the cumulative data using Peto's odds ratio (OR) with $95 \%$ confidence interval $(\mathrm{Cl})$ employing a fixedeffect model. We used fixed-effect analysis since the vast majority of included studies were based on surgical patients at medium or high risk of developing DVT. Furthermore, we also considered that fixed-effect analysis would help minimise bias due to the low event rate amongst a number of included studies with a small sample size. We used Review Manager 5, the statistical package provided by Cochrane, for cumulative analysis of the included trials (RevMan 2012).

\section{Unit of analysis issues}

Individual patients were the analytic units except in seven trials (Bergqvist 1984; Kierkegaard 1993; Mellbring 1986; Scurr 1977; Scurr 1987; Shirai 1985; Torngren 1980), where one limb was randomised to act as control and the other was treated.

Since a thrombus can embolise from either the control or stockinged leg, trials randomising individual legs could not be used to compare the incidence of $\mathrm{PE}$, therefore where data were available, individual patients were used as the unit of analysis for comparing incidence of $\mathrm{PE}$.

\section{Dealing with missing data}

Complete primary outcome data were available for participants excluded postrandomisation in only four trials (Allan 1983; Scurr 1977; Torngren 1980; Wille-Jorgensen 1991). Participants had been excluded postrandomisation in an additional eight trials (Bergqvist 1984; Fredin 1989; Holford 1976; Hui 1996; Kalodiki 1996; Mellbring 1986; Ohlund 1983; Wille-Jorgensen 1985), though the confirmation of the presence or absence of DVT amongst these excluded participants was not reported. We were unable to assess Shirai 1985 for missing data, as it was only published in Japanese. There were no reported exclusions postrandomisation in the remaining seven trials (Barnes 1978; Chin 2009; Kierkegaard 1993; Scurr 1987; Tsapogas 1971; Turner 1984; Turpie 1989). Due to the small number of trials reporting outcome data for participants excluded postrandomisation, we performed a perprotocol analysis.

Similarly, complete outcome data were unavailable for secondary outcomes, therefore we performed a per-protocol analysis.

\section{Assessment of heterogeneity}

We used the $1^{2}$ statistic to quantify heterogeneity. We considered heterogeneity to be statistically significant for a $\mathrm{P}<0.1$.

\section{Assessment of reporting biases}

We assessed reporting bias by visual inspection of funnel plots.

\section{Data synthesis}

In previous versions of this review, we performed data synthesis based on two groups as follows.
- Group 1: GCS only in the treatment group and no prophylaxis in the control group.

- Group 2: GCS in the treatment group and another method of DVT prophylaxis in both the treatment and control groups.

Since both of these groups test the same treatment effect (i.e. with stockings versus without stockings), we merged all trials in the 2014 update to increase the power of the review.

We tested comparisons of results using a fixed-effect model for the meta-analysis.

\section{Subgroup analysis and investigation of heterogeneity}

We subgrouped trials based on the speciality under which the participant had been hospitalised. Most participants underwent either general surgical or orthopaedic surgical procedures. We undertook subgroup analyses in Review Manager 5 using the method described by Deeks 2001.

\section{Sensitivity analysis}

We performed sensitivity analyses to assess the effect of the following three potential areas of bias on the robustness of decisions made during the review process.

- Method of randomisation: trials reporting use of an appropriate method of randomisation versus use of an unclear method of randomisation.

- Unit of analysis of randomisation: individual legs versus individual participants.

- Use of a background method of thromboprophylaxis.

- Method of diagnosis of DVT.

\section{'Summary of findings' table}

We presented the main findings of this update in 'Summary of findings' tables. We considered the quality of evidence, magnitude of effect of interventions examined, and the sum of available data for all outcomes of this review (DVT, proximal DVT, PE, adverse events and complications). We presented the findings for all patients (Summary of findings for the main comparison), surgical patients (Summary of findings 2), and medical patients (Summary of findings 3) according to GRADE principles, as described by Higgins 2011 and Atkins 2004. We evaluated evidence on the basis of risk of bias of the included studies, inconsistency, indirectness, imprecision of data, and publication bias. We used GRADEpro GDT software to prepare the 'Summary of findings' tables and the Ryan 2016 publication to prepare GRADE ratings (GRADEpro GDT 2015).

\section{RES U L T S}

\section{Description of studies}

\section{Results of the search}

See Figure 1. 
Figure 1. Study flow diagram.

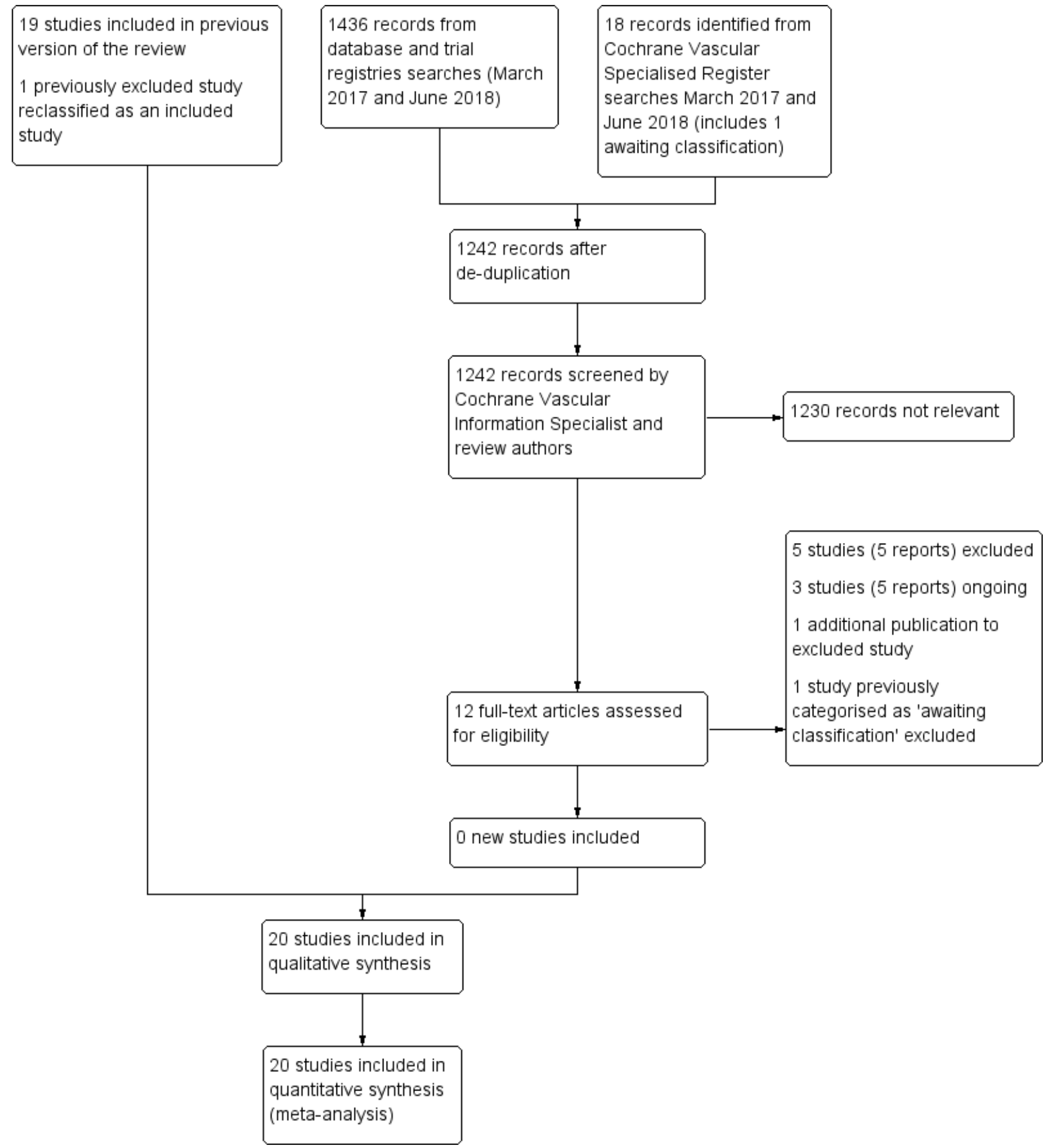

\section{Included studies}

We added one additional study in the 2018 update (Mellbring 1986), resulting in a total of 20 RCTs that met the inclusion criteria (Allan 1983; Barnes 1978; Bergqvist 1984; Chin 2009; Fredin 1989; Holford 1976; Hui 1996; Kalodiki 1996; Kierkegaard 1993; Mellbring 1986; Ohlund 1983; Scurr 1977; Scurr 1987; Shirai 1985; Torngren 1980; Tsapogas 1971; Turner 1984; Turpie 1989; Wille-Jorgensen 1985; Wille-Jorgensen 1991). See the Characteristics of included studies table. Mellbring 1986 had previously been excluded due to data issues which were overcome for this update.

\section{All trials}

The 20 included RCTs provided a total of 2853 analytic units (1681 participants and 1172 legs). Specialties involved: 
- general surgery, 10 trials (Allan 1983; Bergqvist 1984; Holford 1976; Mellbring 1986; Scurr 1977; Scurr 1987; Torngren 1980; Tsapogas 1971; Wille-Jorgensen 1985; Wille-Jorgensen 1991);

- orthopaedics, six trials (Barnes 1978; Chin 2009; Fredin 1989; Hui 1996; Kalodiki 1996; Ohlund 1983);

- neurosurgery, one trial (Turpie 1989);

- cardiac surgery, one trial (Shirai 1985);

- obstetrics and gynaecology, one trial (Turner 1984); and

- cardiology, one trial (Kierkegaard 1993).

Patients undergoing general surgery formed the largest group (1486 of 2853 analytic units, 52\%), followed by patients undergoing orthopaedic surgery (598 of 2853 analytic units, $21 \%$ ).

All participants in the treatment groups received GCS as the method of DVT prophylaxis, with or without an additional background method of thromboprophylaxis. In nine included trials, participants in the control group received no DVT prophylaxis (Allan 1983; Chin 2009; Holford 1976; Hui 1996; Scurr 1977; Shirai 1985; Tsapogas 1971; Turner 1984; Turpie 1989). In the remaining 11 included trials, where stockings were used over a background method of thromboprophylaxis, participants in the control group received either:

- dextran 70 (Bergqvist 1984; Fredin 1989; Ohlund 1983);

- subcutaneous heparin (Torngren 1980; Wille-Jorgensen 1985; Wille-Jorgensen 1991);

- aspirin (Barnes 1978; Kierkegaard 1993);

- low molecular weight heparin (Kalodiki 1996; Mellbring 1986); or

- sequential compression (Mellbring 1986; Scurr 1987).

Participants in the treatment group also received GCS.

\section{Methodological differences between trials}

In all but one of the RCTs participants were aged 35 years and above. The exception was Turpie 1989, which involved neurosurgical patients aged 16 years and above. One trial involved participants with myocardial infarction who were aged 70 years and over (Kierkegaard 1993), and one trial involved participants undergoing cardiac surgery who were aged 18 to 81 years (Shirai 1985).

All trials used thigh-length GCS, except Hui 1996, in which one group used thigh-length stockings and another used knee-length stockings. We combined these groups for the purposes of this review. One participant in the trial by Turpie 1989 wore knee-length stockings due to obesity. Five trials did not mention the length of the stockings used (Allan 1983; Chin 2009; Ohlund 1983; Turner 1984; Wille-Jorgensen 1991).

In all trials GCS were applied either on the day of admission or on the day of operation. This was not critically evaluated on the assumption that all participants were fully mobile prior to surgery. In all but two of the trials the stockings were worn until the day of discharge or until the participants were fully mobile; participants in the remaining two studies wore GCS for 14 days or until discharge (Fredin 1989; Turpie 1989).

Most RCTs (16 of 20 trials) used the radioactive 125 fibrinogen uptake (FUT) assay to screen for DVT postoperatively and phlebography to confirm the diagnosis. One trial used Doppler ultrasonography for screening and phlebography for confirmation of DVT (Barnes 1978); two trials used only phlebography (Hui 1996; Kalodiki 1996); and one trial used only duplex ultrasonography for diagnosis of DVT (Chin 2009).

\section{Excluded studies}

We excluded a further six studies in the 2018 update (Barinov 2014; NCT01234064; NCT01935414; Sultan 2014; Wille-Jorgensen 1986; Zheng 2014), bringing the total number of excluded studies to 56 . We excluded studies for the following reasons.

- Thirty-five studies did not have appropriate control arms (Ayhan 2013; Barinov 2014; Caprini 1983; Chandhoke 1991; Fasting 1985; Gao 2012; Hansberry 1991; KANT study; Koopmann 1985; Lacut 2005; Lee 1989; Lobastov 2013; Maksimovic 1996; Marston 1995; Maxwell 2000; NCT00333021; NCT01935414; Necioglu 2008; Norgren 1996; Nurmohamed 1996; Orken 2009; Porteous 1989; Rabe 2013; Ryan 2002; Sakon 2012; Serin 2010; Shilpa 2013; Silbersack 2004; Sobieraj-Teague 2012; Sultan 2014; Vignon 2013; Wille-Jorgensen 1986; Yang 2009; Zhang 2011; Zheng 2014).

- Two studies were not designed to assess the effectiveness of stockings in preventing DVT (Ido 1995; Rocca 2012).

- In six studies DVT was not diagnosed or assessed appropriately (Cohen 2007; Ibegbuna 1997; Manella 1981; Rasmussen 1988; Wilkins 1952; Wilson 1994).

- Five studies did not use the correct type of GCS (Flanc 1969; Patel 1988; Ramos 1996; Rosengarten 1970; Westrich 1996). Two trials used pneumatic compression (Ramos 1996; Westrich 1996); one trial used Tubigrip (Rosengarten 1970); and one trial used thick elastic compression stockings (Flanc 1969). In one French trial the type of stocking used was not clear (Patel 1988).

- Three studies did not meet the inclusion criteria of this review based on types of patients included (Belcaro 1993; CLOTS 2009; Muir 2000). One study appeared to evaluate people with recurrent DVT in the community (Belcaro 1993). Two studies evaluated people with acute stroke (CLOTS 2009; Muir 2000); these trials have been included in a separate Cochrane Review focusing on people with acute stroke (Naccarato 2010). The rationale for this is as follows: stockings reduce the crosssectional area of the deep veins, making the calf muscle pump more effectively and thereby improving blood flow. The authors of the CLOTS trial have suggested that severe leg weakness in people with acute stroke may therefore account for the ineffectiveness of stockings in this patient group (CLOTS 2009).

- Five studies were only published as abstracts, making it difficult to accurately assess their methodology and to extract data (Bolton 1978; Brunkwall 1991; NCT01234064; Perkins 1999; Sultan 2011). Further information provided by the authors of the Sultan 2011 trial showed that not all participants in this trial had been hospitalised, therefore it did not meet our inclusion criteria.

See the Characteristics of excluded studies table for further details.

\section{Studies awaiting classification and ongoing studies}

We could not adequately assess the study design for Celebi 2001 as the report was not published in English, therefore we have categorised it as awaiting classification. See the Characteristics of studies awaiting classification table for further details. 
We identified three ongoing studies (ChiCTR1800014257; GAPS; IRCT2017080935594N1), of which two trials are scheduled to conclude in 2019 (GAPS; IRCT2017080935594N1), and one trial in late 2020 (ChiCTR1800014257). See Characteristics of ongoing studies table for further details.

\section{Risk of bias in included studies}

Details regarding risk of bias are provided in the Characteristics of included studies table and are represented in Figure 2 and Figure 3. 
Figure 2. Methodological quality summary: review authors' judgements about each methodological quality item for each included study.

\begin{tabular}{|c|c|c|c|c|c|c|}
\hline & 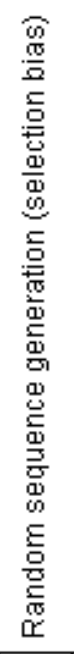 & 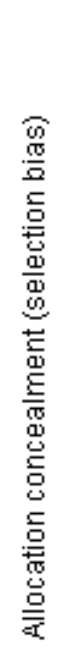 & 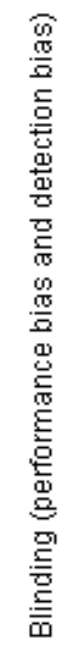 & 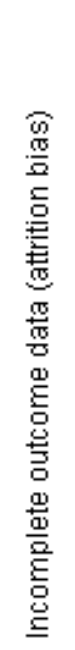 & 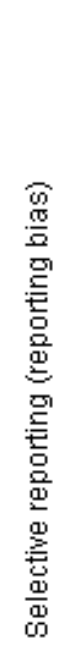 & 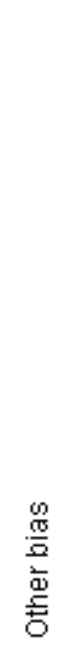 \\
\hline Allan 1983 & $\odot$ & $?$ & + & $\odot$ & $\odot$ & + \\
\hline Barnes 1978 & $?$ & + & $?$ & $\odot$ & $\odot$ & $\odot$ \\
\hline Bergqvist 1984 & $\odot$ & $?$ & $\odot$ & $\odot$ & $\odot$ & $?$ \\
\hline Chin 2009 & $?$ & $?$ & $\odot$ & $\odot$ & $\odot$ & $\odot$ \\
\hline Fredin 1989 & $?$ & ? & $\odot$ & $\odot$ & $\odot$ & $\odot$ \\
\hline Holford 1976 & $?$ & + & $?$ & $\odot$ & + & 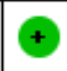 \\
\hline Hui 1996 & $?$ & $?$ & $?$ & $\odot$ & + & $?$ \\
\hline Kalodiki 1996 & + & + & + & $\odot$ & + & $?$ \\
\hline Kierkegaard 1993 & $?$ & $?$ & $\odot$ & $\odot$ & + & + \\
\hline Mellbring 1986 & $?$ & + & $?$ & $\odot$ & + & + \\
\hline Ohlund 1983 & $?$ & $?$ & $?$ & $\odot$ & + & + \\
\hline Scurr 1977 & 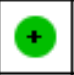 & $?$ & $?$ & $\odot$ & 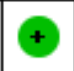 & + \\
\hline Scurr 1987 & $?$ & $?$ & $?$ & $\odot$ & $\odot$ & $?$ \\
\hline Shirai 1985 & $?$ & $?$ & $?$ & $?$ & $?$ & $?$ \\
\hline Torngren 1980 & $\odot$ & $?$ & $?$ & $\odot$ & + & + \\
\hline Tsapogas 1971 & + & $?$ & $?$ & $\odot$ & + & $?$ \\
\hline Turner 1984 & + & $?$ & + & $\odot$ & + & + \\
\hline Turpie 1989 & $?$ & + & $\odot$ & $\odot$ & $\odot$ & + \\
\hline Wille-Jorgensen 1985 & 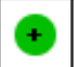 & $?$ & $\odot$ & + & + & + \\
\hline Wille-Jorgensen 1991 & + & + & $?$ & $\odot$ & $\odot$ & $?$ \\
\hline
\end{tabular}


Figure 3. Methodological quality graph: review authors' judgements about each methodological quality item presented as percentages across all included studies.

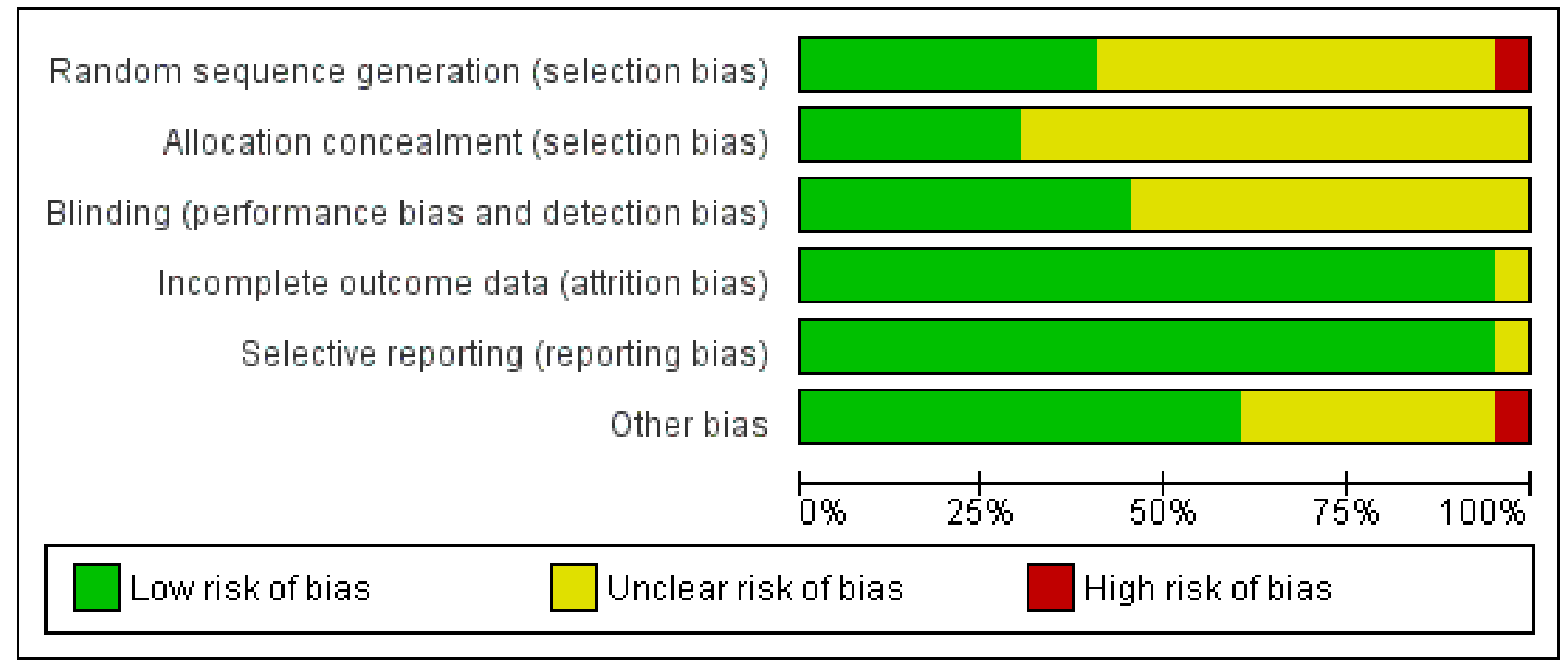

\section{Allocation}

Nine trials described the method of randomisation of participants to treatment and control groups, which was done using:

- random number tables in six trials (Allan 1983; Bergqvist 1984; Tsapogas 1971; Turner 1984; Wille-Jorgensen 1985; WilleJorgensen 1991);

- coin toss in one trial (Scurr 1977);

- consecutively numbered boxes in one trial (Kalodiki 1996);

- date of birth in one trial (Torngren 1980), which we deemed to be an inadequate method of randomisation, and so we judged the study to be at high risk of bias.

In Tsapogas 1971, participants were randomised using a random allocation table (low risk of bias). However, there was a discrepancy between the numbers of participants randomised to the treatment and control groups, therefore we deemed this trial to be at unclear risk of bias likely due to unclear allocation concealment.

The method of randomisation was not mentioned in the remaining 11 included trials, so these trials were judged to be at unclear risk of bias (Barnes 1978; Chin 2009; Fredin 1989; Holford 1976; Hui 1996; Kierkegaard 1993; Mellbring 1986; Ohlund 1983; Scurr 1987; Shirai 1985; Turpie 1989). In Hui 1996, participants were randomised in a ratio of 1:1 in the thigh-length GCS group and 1:4 in the knee-length GCS group. The control group of the thigh-length GCS group was also used as the control for the knee-length GCS group in this trial.

Of note, Chin 2009 was the only included trial published after the publication of the CONSORT statement in 1996 (CONSORT 1996). Despite this, the Chin 2009 trial report did not include a power calculation and did not report the method of randomisation and use of allocation concealment, as advised in the CONSORT statement, suggesting risk of bias.

There was no mention of allocation concealment in 14 of the 20 RCTs judged as at unclear risk of bias. The remaining six studies used sealed envelopes to conceal the allocation of participants to the treatment and control groups and were judged as at low risk of bias (Barnes 1978; Holford 1976; Kalodiki 1996; Mellbring 1986; Turpie 1989; Wille-Jorgensen 1991).

\section{Blinding}

It is inherently difficult to ensure adequate blinding for patients who wear stockings and those who do not. In eight trials, the radiologist reporting the scan results was unaware of whether the participant, or their leg, belonged to the treatment or control group, so these were judged as at low risk of bias (Allan 1983; Bergqvist 1984; Chin 2009; Kalodiki 1996; Turner 1984; Turpie 1989; WilleJorgensen 1985; Wille-Jorgensen 1991). In two trials the results of the studies were analysed without knowledge of the type of prophylaxis, so these were also judged as at low risk of bias (Fredin 1989; Kierkegaard 1993). We judged the remaining 10 studies as at unclear risk of performance and detection bias (Bergqvist 1984; Holford 1976; Hui 1996; Mellbring 1986; Ohlund 1983; Scurr 1977; Scurr 1987; Shirai 1985; Torngren 1980; Tsapogas 1971).

\section{Incomplete outcome data}

In seven trials, results for all included participants were analysed (Barnes 1978; Chin 2009; Kierkegaard 1993; Scurr 1987; Tsapogas 1971; Turner 1984; Turpie 1989). In the remaining trials, participants lost to follow-up were accounted for, with some participants excluded postrandomisation due to failure to comply with wearing the GCS because they found them uncomfortable. One trial did not report participant attrition during the study period (Shirai 1985), but this report could not be accurately appraised as it was published in Japanese and was therefore found to be at unclear risk of bias. We judged the remainder of the studies as at low risk of bias.

\section{Selective reporting}

All included studies reported the incidence of DVTs as stated in their aims. Visual inspection of the funnel plot showed that all included trials came within the expected confidence intervals, though there was a suggestion of minimal publication bias (Figure 4). We found one study to be at unclear risk of bias as it was published in 
(Shirai 1985). The remainder of the studies were judged as at low risk of bias.

Figure 4. Funnel plot of comparison: Incidence of DVT with stockings and without stockings (all specialties).

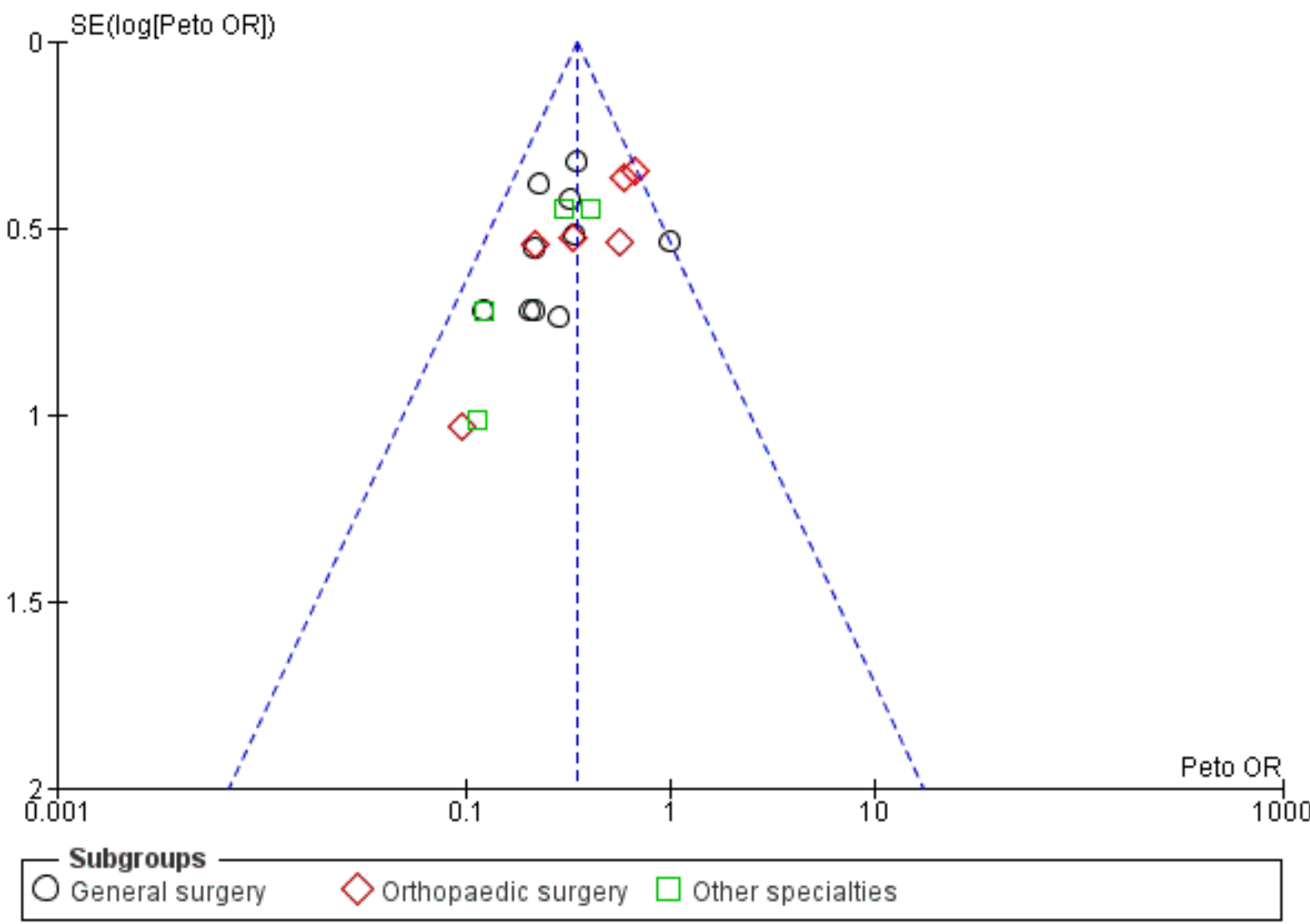

\section{Other potential sources of bias}

None of the trials stratified participants according to DVT risk level. However, our own analysis of the papers indicated that all participants were in either moderate- or high-risk groups.

Six trials obtained funding or support from pharmaceutical companies or manufacturers of GCS, and we were unclear if this could have influenced the studies. These companies included The Kendall Company (Barnes 1978; Scurr 1987; Wille-Jorgensen 1991), Beiersdorf AB (Bergqvist 1984), Brevet Hospital Products (Hui 1996), and Rhone-Poulenc Rorer (Kalodiki 1996).

In addition, Barnes 1978 was terminated early as it was deemed unjustifiable to continue after revealing a major incidence of DVT amongst participants who did not wear stockings; we assessed this study as being at high risk of bias.

In one trial (Tsapogas 1971), participants in the treatment group were given an additional recommendation regarding exercise that was not given to the control group. It is possible this influenced the risk of thrombosis, therefore we judged this study as at unclear risk of bias.
One trial was published in Japanese (Shirai 1985), which made it difficult to accurately appraise the study design.

\section{Effects of interventions}

See: Summary of findings for the main comparison Graduated compression stockings for prevention of deep vein thrombosis - all patients; Summary of findings 2 Graduated compression stockings for prevention of deep vein thrombosis in surgical patients; Summary of findings 3 Graduated compression stockings for prevention of deep vein thrombosis in medical patients

The results of the review should be interpreted with caution, paying particular attention to the detailed notes in the Description of studies section, as these may have influenced the analysis due to variations within the included trials, for example the use of the opposite limb as the control, differing background prophylactic methods used, and the age difference in some of the trials. However, in the majority of the included trials a statistically significant difference between the treated participants (those that used GCS) and the control group (those that did not use GCS) was demonstrated in the incidence of DVT (primary outcome). 


\section{Incidence of DVT}

In the 2014 update, we merged trials assessing the effectiveness of GCS as the sole method of prophylaxis together with trials using a background method of thromboprophylaxis for all participants in addition to the use of GCS in the treatment group. This resulted in a total of 2853 analytic units (1681 individual participants and 1172 individual legs) in the meta-analysis (Analysis 1.1). In the treatment group (GCS), 134 of the 1445 units developed DVT in comparison to 290 of the 1408 units in the control group (no GCS): Peto's odds ratio (OR) of 0.35 ( $95 \%$ confidence interval (Cl) 0.28 to $0.43 ; 2853$ units; 20 studies; $\mathrm{P}<0.001$; high-quality evidence). This amounted to a $9 \%$ incidence of DVT in the treatment group in comparison to a $21 \%$ incidence in the control group.
The $1^{2}$ statistic for this analysis suggested $10 \%$ heterogeneity, with $\mathrm{P}=0.33$ (Analysis 1.1). This was supported by the corresponding forest plot (Figure 4), using Peto's ORs, which showed that results for all studies were within or on the $95 \% \mathrm{Cl}$, suggesting minimal publication bias.

\section{Subgroup analysis by specialty}

We performed subgroup analysis based upon the specialty under which the participants were managed (Figure 5). There was no significant difference between specialty subgroups regarding the effectiveness of stockings in reducing the incidence of DVT ( $P=$ 0.15).

Figure 5. Number of analytic units from each specialty included in the meta-analysis.

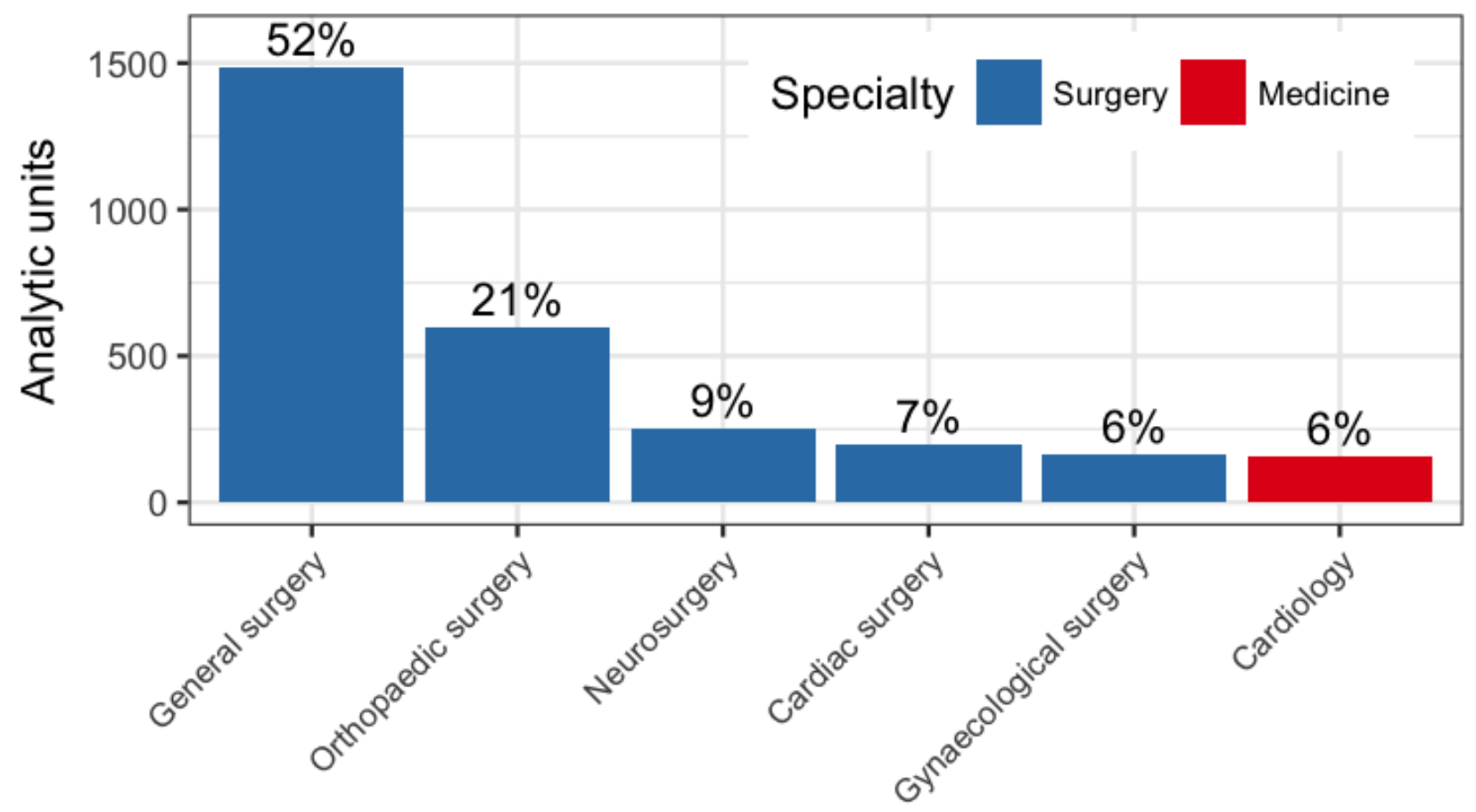

The majority of participants were general surgical patients, accounting for 1486 of 2853 units (52\%). Amongst this cohort, the incidence of DVT was 52 of $741(7 \%)$ in the treatment group and 148 of $745(20 \%)$ in the control group (Peto OR $0.30,95 \% \mathrm{Cl} 0.22$ to $0.41 ; 1486$ units; 10 studies; high-quality evidence) (Allan 1983; Bergqvist 1984; Holford 1976; Mellbring 1986; Scurr 1977; Scurr 1987; Torngren 1980; Tsapogas 1971; Wille-Jorgensen 1985; WilleJorgensen 1991).

Participants undergoing orthopaedic surgery accounted for 598 of 2853 units (21\%) (Barnes 1978; Chin 2009; Fredin 1989; Hui 1996; Kalodiki 1996; Ohlund 1983). Amongst participants undergoing orthopaedic surgery, 70 of 314 units (22\%) in the treatment group and 97 of 284 units (34\%) in the control group developed DVT (Peto OR $0.47,95 \% \mathrm{Cl} 0.32$ to 0.68 ; 598 units; 6 studies; high-quality evidence) (Analysis 1.1).
The four remaining trials on participants from other specialties provided small sample sizes for each of the specialities (Kierkegaard 1993; Shirai 1985; Turner 1984; Turpie 1989). Combining the results favoured the use of stockings (Peto OR 0.28 , $95 \% \mathrm{Cl} 0.16$ to $0.48 ; 769$ participants; 4 studies; moderate-quality evidence). Of note, only one trial considered medical patients (Kierkegaard 1993), making it difficult to confidently judge the effect of stockings in these participants (Analysis 1.1).

Subgroup analysis to compare all surgery versus medical did not reveal any differences in DVT incidence $(P=0.15)$. Combining results from 19 trials focusing on surgical patients, 134 of 1365 units $(9.8 \%)$ developed DVT in the GCS group compared to 282 of 1328 units $(21.2 \%)$ in the control group. The Peto OR was $0.35(95 \% \mathrm{Cl} 0.28$ to $0.44 ; \mathrm{P}<0.001$; high-quality evidence), with an overall effect favouring treatment with GCS (Analysis 1.2). 
Based on the results from one trial focusing on medical patients admitted following acute myocardial infarction (Kierkegaard 1993), 0 of 80 legs (0\%) developed DVT in the GCS group compared to 8 of 80 legs $(10 \%)$ in the control group. The Peto OR was $0.12(95 \% \mathrm{Cl}$ 0.03 to $0.51 ; P=0.004$; low-quality evidence), with an overall effect favouring treatment with GCS (Analysis 1.2).

\section{Incidence of proximal DVT}

Proximal DVTs, which occur in the popliteal, femoral, and iliac veins, are considered to be of greatest clinical significance as they are more likely to embolise to the pulmonary veins and can thereby potentially result in fatal $\mathrm{PE}$. We therefore assessed the incidence of proximal DVT in the two experimental arms of the included trials. Eight trials provided data for the incidence of proximal DVT amongst 1035 included units (Barnes 1978; Bergqvist 1984; Chin 2009; Fredin 1989; Kalodiki 1996; Kierkegaard 1993; Scurr 1987; Turpie 1989). The incidence of proximal DVT was 7 of 517 units (1\%) in the treatment group and 28 of 518 units $(5 \%)$ in the control group (Peto OR 0.26, 95\% Cl 0.13 to 0.53; 1035 units; 8 studies; $\mathrm{P}<0.001$; moderate-quality evidence). There was no significant difference between surgical subgroup specialities regarding the effectiveness of stockings in reducing the incidence of proximal DVT $(P=0.79)$ (Analysis 2.1).

We carried out subgroup analysis investigating differences between surgical and medical patients. Results from seven included studies evaluating surgical patients showed the incidence of proximal DVT as 7 of 437 units (1.6\%) in the GCS group and 28 of 438 units (6.4\%) in the control group (Barnes 1978; Bergqvist 1984; Chin 2009; Fredin 1989; Kalodiki 1996; Scurr 1987; Turpie 1989). The Peto OR was 0.26 ( $95 \% \mathrm{Cl} 0.13$ to 0.53 ; 875 units; $\mathrm{P}<0.001$; moderate-quality evidence), with an overall effect favouring treatment with GCS. We downgraded the evidence for proximal DVT due to low event rate (imprecision). No events of proximal DVT were recorded in the one study involving medical patients (Analysis 2.2) (Kierkegaard 1993).

\section{Incidence of PE}

Five trials, all based on surgical patients, provided data for the incidence of PE amongst 569 included participants (Barnes 1978; Chin 2009; Holford 1976; Kalodiki 1996; Wille-Jorgensen 1985). Routine screening for PE was only conducted in two of these studies using perfusion-ventilation scintigraphy (Holford 1976; Kalodiki 1996). This method was used to confirm clinically apparent PE in the remaining studies, except in one trial where PE was diagnosed at autopsy (Turpie 1989). The incidence of PE was 5 of 283 participants $(2 \%)$ in the treatment group and 14 of 286 participants (5\%) in the control group (Peto OR $0.38,95 \% \mathrm{Cl} 0.15$ to $0.96 ; 569$ participants; 5 studies; $P=0.04$; low-quality evidence). These results should be interpreted with caution in light of the aforementioned limitations in reporting of the incidence of PE in the included trials. (Analysis 3.1).

One further trial reported that one participant was diagnosed with PE at autopsy but did not state to which group this participant belonged (Turpie 1989). However, the cause of death of this participant was found to be cerebral oedema. Two further trials reported a cumulative incidence of three cases of PE but did not specify to which group these participants belonged (Bergqvist 1984; Fredin 1989). Torngren 1980 reported that no participants suffered fatal PE. There was no significant difference between subgroups regarding the effectiveness of stockings in reducing the incidence of PE $(P=0.76)$. (Analysis 3.1).

\section{Adverse effects and complications from GCS}

Seven of 20 trials mentioned the incidence of adverse effects, but none of the trials stated to which groups the participants belonged (Bergqvist 1984; Chin 2009; Fredin 1989; Kalodiki 1996; Kierkegaard 1993; Torngren 1980; Wille-Jorgensen 1991).

Kierkegaard 1993 reported that some participants experienced postphlebitic changes. Four trials mentioned the incidence of bleeding associated with the background antithrombotic measure used (Bergqvist 1984; Fredin 1989; Kalodiki 1996; Wille-Jorgensen 1991). Kalodiki 1996 reported no difference in haemorrhagic complications between the treatment and control groups. One trial reported that none of the participants showed any signs of postoperative haemorrhage or side effects (Torngren 1980). Similarly, one further trial reported no adverse events related to the use of GCS (Chin 2009).

Two further trials reported participants' complaints (Hui 1996; Turpie 1989). In one trial, $23 \%$ of participants wearing aboveknee stockings and $16 \%$ of participants wearing below-knee stockings found the stockings too uncomfortable and requested their removal (Hui 1996). Ambulant patients in another trial reported disturbance as the stockings fell down easily, which was likely to be due to improper fitting (Turpie 1989).

\section{DISCUSSION}

\section{Summary of main results}

Meta-analysis of the 20 included RCTs showed high-quality evidence that application of GCS decreased the occurrence of DVT in hospitalised patients (Analysis 1.1).

Eight trials reported the incidence of proximal DVT (Barnes 1978; Bergqvist 1984; Chin 2009; Fredin 1989; Kalodiki 1996; Kierkegaard 1993; Scurr 1987; Turpie 1989), and five trials reported the incidence of PE (Barnes 1978; Chin 2009; Holford 1976; Kalodiki 1996; WilleJorgensen 1985). A lower incidence of proximal DVT (moderatequality evidence) and PE (low-quality evidence) was noted amongst participants fitted with GCS (Analysis 2.1; Analysis 3.1), however the low incidence rate coupled with a relatively small sample size limits the power of these meta-analyses, thereby making it difficult to confidently infer the effectiveness of GCS in preventing these outcomes.

Few adverse events were reported. In one trial some participants removed their stockings earlier than they should have done, presumably due to discomfort (Hui 1996). No other trials reported complications associated with wearing stockings. In one trial some participants developed postphlebitic changes (Kierkegaard 1993). In contrast, four studies mentioned bleeding complications related to the associated use of heparin, dextran, or aspirin, but the numbers were too small and not uniform enough to make any definitive judgement (Bergqvist 1984; Fredin 1989; Kalodiki 1996; Mellbring 1986; Wille-Jorgensen 1991).

\section{Overall completeness and applicability of evidence}

This review included predominantly patients undergoing general surgical and orthopaedic surgical procedures (Figure 5), and thus provides good evidence for the use of GCS amongst these patient groups. However, only one RCT included hospitalised medical patients, and no trial included participants deemed to have low risk 
of developing DVT (Kierkegaard 1993), hence we cannot comment on the benefits of using GCS in these patient groups.

The available evidence was based predominantly on the use of above-knee stockings. Only Hui 1996 looked at the difference between thigh-length GCS versus no stockings and knee-length GCS versus no stockings. In six trials, the length of the GCS used was not made explicit (Allan 1983; Chin 2009; Kierkegaard 1993; Ohlund 1983; Turner 1984; Wille-Jorgensen 1991). The numbers were too small to draw any conclusions as to the efficacy of DVT prevention based on the length of the stockings used. This is not the remit of this review but is the subject of another Cochrane Review, which reported insufficient high-quality evidence to determine whether knee-length and thigh-length stockings differ in their effectiveness in reducing the incidence of DVT in hospitalised patients (Sajid 2012).

Duration of routine follow-up was 7 to 14 days, or until discharge, with a single study routinely screening for symptomatic DVT at 30-day follow-up (Chin 2009). This contrasts with epidemiological data, which demonstrates the greatest risk of postoperative DVT at four to six weeks after surgery (Sweetland 2009). The lower duration routine follow-up in the included studies does not cover this period of increased DVT risk and thus fails to accurately estimate the true magnitude of the effect of GCS in preventing DVT following discharge into the community.

None of the RCTs were uniform in detailing or recommending the duration of time that GCS should be worn postoperatively, that is until discharge, mobilisation, or the next clinic visit. This aspect is important because we know from clinical experience that DVT can still occur at home after discharge, and there have been a number of incidences of death after discharge that were due to DVT and $\mathrm{PE}$. This is further supported by the results from the Million Women Study (Sweetland 2009).

Some of these areas of uncertainty have been addressed in the published protocol of an ongoing study (GAPS), where hospitalised surgical patients will receive thromboprophylaxis (low molecular weight heparin (LMWH) only versus LMWH and GCS), with the primary outcome as incidence of DVT at 90-day follow-up. In light of the increased use of chemoprophylaxis for DVT, this trial aims to specifically evaluate the additional benefit of GCS over LMWH as thromboprophylaxis. We will evaluate the final report of this study for inclusion in this review when it is available.

\section{Quality of the evidence}

We have included 20 RCTs of good methodological quality providing 2853 analytic units in this meta-analysis to determine the effectiveness of the use of GCS in hospitalised patients (Analysis 1.1). This sample size provides high-quality evidence to support the use of GCS to prevent DVT in the clinical setting, especially amongst surgical patients, since most included participants underwent either general surgical or orthopaedic surgical procedures (Figure 5). Moderate-quality evidence suggests that GCS may prevent proximal DVT; we downgraded the quality of the evidence due to imprecision. We found low-quality evidence for GCS in preventing $\mathrm{PE}$, downgrading the evidence as routine screening for $\mathrm{PE}$ was done in only two of the five RCTs reporting on this outcome, and results were inconsistent. Only one included trial considered hospitalised medical patients, making it difficult to form a judgement regarding this subgroup of patients (Kierkegaard 1993).
Furthermore, small sample sizes limited subgroup analysis based on type of procedure, length of stockings used, or type of background prophylaxis. We were unable to confidently assess the variation in effectiveness of GCS over these parameters.

\section{Potential biases in the review process}

Interestingly, all but one of the 20 included trials were conducted before the CONSORT guidelines for reporting RCTs were published (CONSORT 1996). Most importantly, 11 of 20 trials either did not report sufficiently or used an inappropriate method of randomisation (see the Risk of bias in included studies section). We therefore performed a sensitivity analysis to assess the associated potential risk of bias, which found no significant difference in the effectiveness of stockings in reducing the incidence of DVT amongst trials that reported an appropriate method of randomisation and those that did not $(P=0.78$, Analysis 4.1).

Seven of the 20 included RCTs involved the use of the other leg as the control (Bergqvist 1984; Kierkegaard 1993; Mellbring 1986; Scurr 1977; Scurr 1987; Shirai 1985; Torngren 1980). It is possible that GCS applied to one leg could have an effect on the other leg of the same patient (Spiro 1970), although there is no clear evidence for this. If this is true, it may bias the results of these studies. None of the included studies randomising individual legs reported the use of a matched or paired analysis to address statistical bias due to ignoring the pairing. This could result in these studies receiving too little weight in the meta-analysis due to wider confidence intervals, and thereby possibly disguising clinically important heterogeneity (Higgins 2011). However, since the studies are underweighted rather than overweighted, the analysis is conservative. Despite such concerns, all these trials have demonstrated that GCS reduced the risk of DVT compared to when GCS were not applied. A sensitivity analysis performed to assess this further found stockings to be effective in reducing the incidence of DVT irrespective of whether the unit of randomisation was individual legs or individual participants (Analysis 4.2). In other words, there was no difference in the effectiveness of stockings in reducing the incidence of DVT irrespective of the unit of randomisation $(P=0.24)$.

As part of a previous update, we merged trials using stockings as the sole method of thromboprophylaxis and those using stockings over a background method of thromboprophylaxis, thereby introducing a potential bias. However, both these groups of trials demonstrated a reduced incidence of DVT, with or without a background method of thromboprophylaxis (Analysis 4.3), with no clear difference in the magnitude of effect $(P=0.25)$. It must be stressed that results for the use of GCS over a background method of thromboprophylaxis should be interpreted with some caution, as this group of trials was heterogeneous. Background prophylaxis varied between dextran 70, heparin, aspirin, and sequential compression. We could not assess the extent of influence of individual background prophylaxis since further grouping would have reduced the number of participants so much that the data would not be valid.

Flordal 1995 and Lensing 1993 have previously highlighted poor efficacy of using radioactive 1125 fibrinogen uptake test (FUT) as the only diagnostic modality for DVT. In this review, eight of the 20 included trials relied solely on FUT to diagnose DVT. We therefore performed a sensitivity analysis to assess the associated potential risk of bias by the inclusion of these studies (Analysis 4.4), which found that results of trials using phlebography to confirm the diagnosis of DVT following a positive FUT and those using 
other modalities for the diagnosis of DVT (ultrasonography, or phlebography alone) also strongly favoured the use of stockings in diminishing the risk of DVT. There was no significant difference in the effectiveness of stockings in reducing the incidence of DVT between subgroups of diagnostic modalities $(P=0.29)$.

After excluding stroke patients, we identified only one RCT that involved a medical specialty, which was in patients following a myocardial infarction (Kierkegaard 1993). It was thus difficult to confidently judge the effectiveness of GCS in preventing DVT in medical patients, and further trials are required in this cohort of patients.

It is important to note that visual interpretation of the funnel plot demonstrated a borderline risk of publication bias in assessing the effectiveness of stockings in preventing DVT (Figure 4; Analysis 1.1). However, we noted no clear evidence of publication bias in metaanalyses of the incidence of proximal DVT and PE (Figure 6; Figure 7).

Figure 6. Funnel plot of comparison: Incidence of proximal DVT with stockings and without stockings (all specialties).

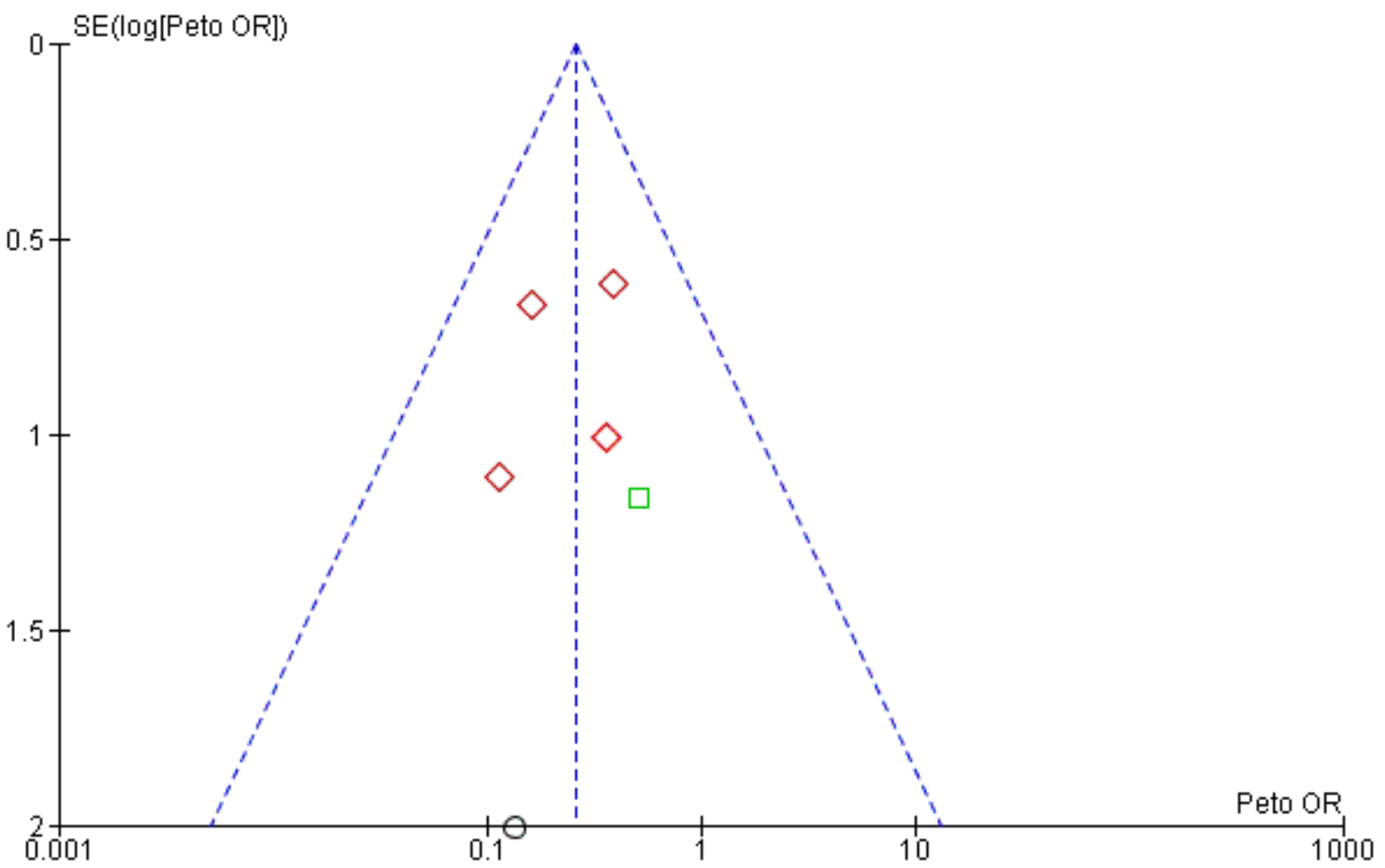

Subgroups

General surgery $\diamond$ Orthopaedic surgery $\square$ Other specialties 
Figure 7. Funnel plot of comparison: Incidence of PE with stockings and without stockings (all specialties).

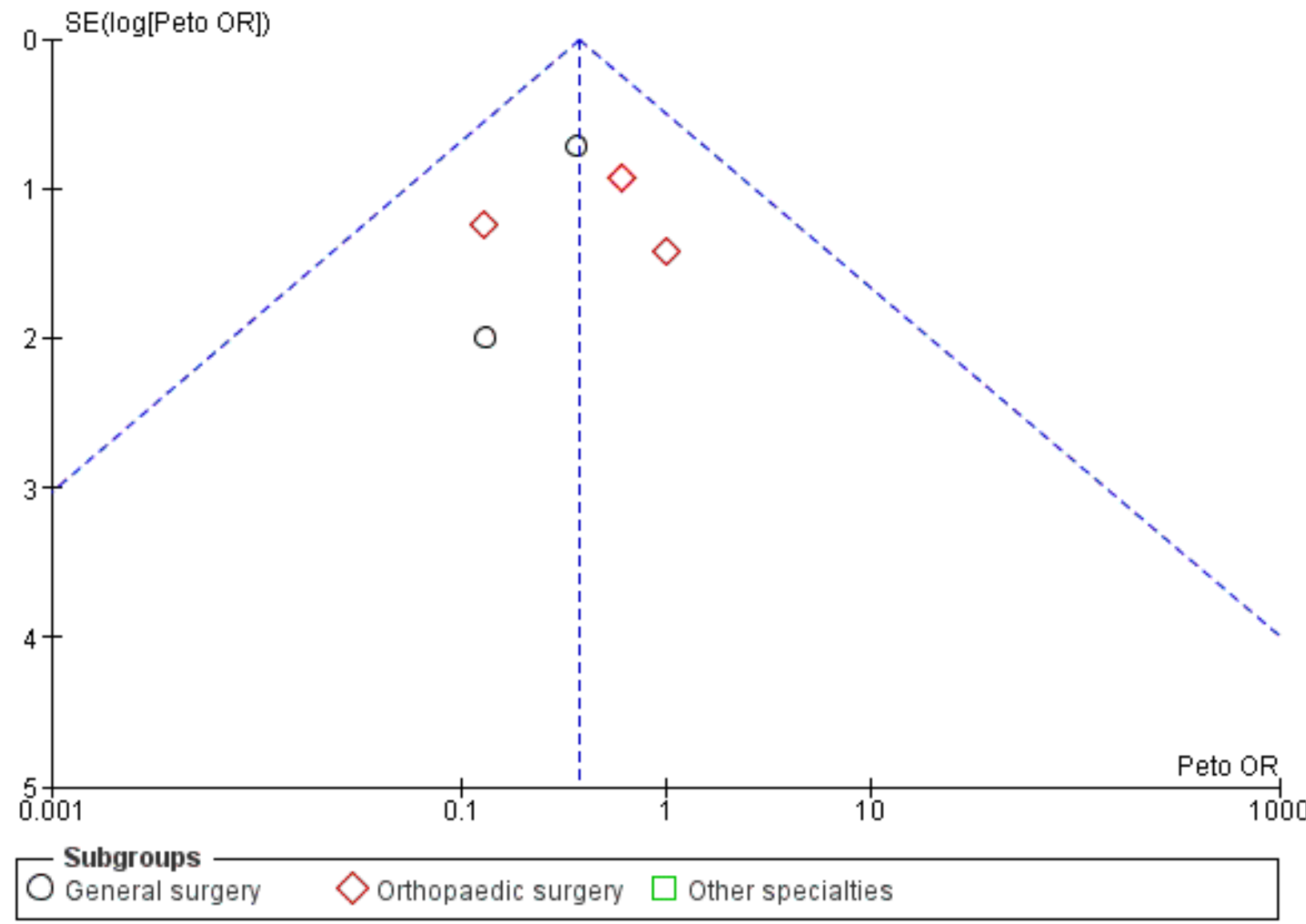

\section{Agreements and disagreements with other studies or reviews}

Results from this review are comparable to those of a previous health technology assessment (Roderick 2005), which found a 66\% risk reduction with the application of GCS and a $60 \%$ risk reduction when GCS were used on a background of another prophylactic method. The variation in the degree of risk reduction reported by that review, as compared to our results, may be because their analyses were based upon the number of participants originally randomised in the included trials and included participants who were later excluded (i.e. an intention-to-treat analysis). Furthermore, a number of trials included in Roderick 2005 did not meet our inclusion criteria.

The National Institute for Health and Care Excellence (NICE) has published guidance for reducing the risk of venous thromboembolism amongst hospitalised patients (NICE 2010). Their recommendations are consistent with our finding that GCS are more effective than no prophylaxis. However, NICE recommends that GCS should not be prescribed to patients admitted for stroke; this was based primarily on the CLOTS 2009 trial in which large proportions of patients were prescribed aspirin, which may have influenced the results. It also raises the issue of lack of evidence concerning the use of mechanical prophylaxis in medical patients.

\section{AUTHORS' CONCLUSIONS \\ Implications for practice}

We found high-quality evidence that graduated compression stockings (GCS) are effective in reducing the risk of deep vein thrombosis (DVT) in hospitalised patients who have undergone general and orthopaedic surgery, with or without other methods of background thromboprophylaxis, where clinically appropriate. We found moderate-quality evidence that GCS probably reduce the risk of proximal DVT and low-quality evidence that GCS may reduce the risk of pulmonary embolism. There remains a paucity of evidence to assess the effectiveness of GCS in diminishing risk of DVT in medical patients.

\section{Implications for research}

There is scope for further research in this field:

- studies are needed to evaluate whether specific target groups such as patients with malignancy, a past history of DVT, or hypercoagulable states would benefit from the use of GCS;

- amongst trials included in this review, participants were followed up for a period of 7 to 14 days, or until discharge. However, since the risk of DVT is greatest at four to six weeks postoperatively, studies are needed to investigate the duration of DVT prophylaxis required to prevent DVT episodes at home after discharge from hospital; 
- none of the included randomised controlled trials specifically addressed complications associated with the use of GCS. This needs to be examined further, particularly in specific groups such as orthopaedic patients, because concerns have been raised that consequent complications may outweigh the benefits of GCS if they are worn improperly;

- randomised controlled trials are needed:

o in patients with medical illness as opposed to surgical illness;

- to compare above-knee with below-knee GCS;

- to compare GCS against other methods of prophylaxis;
- to evaluate effectiveness of GCS in preventing venous thromboembolism-associated mortality.

- finally, the cost implications for any health service providers, and comparison with other methods, need to be assessed.

\section{ACKNOWLEDGEMENTS}

The review authors would like to thank Dr Karen Welch and $\mathrm{Dr}$ Cathryn Broderick for their support in updating this review. We thank Dr Sachiendra V Amaragiri for his input in previous versions of this review. 
REFE RE N CES

\section{References to studies included in this review}

\section{Allan 1983 \{published data only\}}

Allan A, Williams JT, Bolton JP, Le Quesne LP. The use of graduated compression stockings in the prevention of postoperative deep vein thrombosis. British Journal of Surgery 1983;70(3):172-4.

\section{Barnes 1978 \{published data only\}}

Barnes RW, Brand RA, Clarke W, Hartley N, Hoak JC. Efficacy of graded-compression antiembolism stockings in patients undergoing total hip arthroplasty. Clinical Orthopaedics and Related Research 1978;132:61-7.

\section{Bergqvist 1984 \{published data only\}}

Bergqvist D, Lindblad B. The thromboprophylactic effect of graded elastic compression stockings in combination with dextran 70. Archives of Surgery 1984;119(11):1329-31.

\section{Chin 2009 \{published data only\}}

Chin PL, Amin MS, Yang KY, Yeo SJ, Lo NN. Thromboembolic prophylaxis for total knee arthroplasty in Asian patients: a randomised controlled trial. Journal of Orthopaedic Surgery 2009;17(1):1-5

\section{Fredin 1989 \{published data only\}}

Fredin H, Bergqvist D, Cederholm C, Lindblad B, Nyman U. Thromboprophylaxis in hip arthroplasty. Dextran with graded compression or preoperative dextran compared in 150 patients. Acta Orthopaedica Scandinavica 1989;60(6):678-81.

\section{Holford 1976 \{published data only\}}

Holford CP. Graded compression for preventing deep vein thrombosis. British Medical Journal 1976:2(6042):969-70.

\section{Hui 1996 \{published data only\}}

Hui AC, Heras-Palou C, Dunn I, Triffitt PD, Crozier A, Imeson J, et al. Graded compression stockings for prevention of deep-vein thrombosis after hip and knee replacement. Journal of Bone and Joint Surgery. British Volume 1996;78(4):550-4.

\section{Kalodiki 1996 \{published data only\}}

Kalodiki E, Gill K, Al-Kutobi, Birch R, Harris N, Hunt D, et al. Low molecular weight heparin with or without graduated elastic compression in deep vein prophylaxis after elective hip replacement. British Journal of Surgery 1992; Vol. 79, issue 11:1223.

Kalodiki E, Nicolaides A, Al-Kutoubi A, Birch B, Harris N, Hunt D, et al. Low molecular weight heparin (LMWH) and LMWH plus graduated elastic compression for deep venous thrombosis (DVT) prophylaxis in total hip replacement. Thrombosis and Haemostasis 1993; Vol. 69, issue 6:650; Abstract No 387.

Kalodiki E, Nicolaides AN, Al-Kutoubi A, Birch R, Harris N, Hunt D, et al. LMWH and LMWH plus graduated elastic compression for DVT prophylaxis in total hip replacement. Thrombosis and Haemostasis 1993; Vol. 69, issue 6:619; Abstract No 270.
* Kalodiki EP, Hoppensteadt DA, Nicolaides AN, Fareed J, Gill K, Regan F, et al. Deep venous thrombosis prophylaxis with low molecular weight heparin and elastic compression in patients having total hip replacement. A randomised controlled trial. International Angiology 1996;15(2):162-8.

\section{Kierkegaard 1993 \{published data only\}}

Kierkegaard A, Norgren L. Graduated compression stockings in the prevention of deep vein thrombosis in patients with acute myocardial infarction. European Heart Journal 1993;14(10):1365-8.

\section{Mellbring 1986 \{published data only\}}

Mellbring G, Palmer K. Prophylaxis of deep vein thrombosis after major abdominal surgery. Comparison between dihydroergotamine-heparin and intermittent pneumatic calf compression and evaluation of added graduated static compression. Acta Chirurgica Scandinavica 1986;152:597-600.

Ohlund 1983 \{published data only\}

Ohlund C, Fransson SG, Starck SA. Calf compression for prevention of thromboembolism following hip surgery. Acta Orthopaedica Scandinavica 1983;54(6):896-9.

Scurr 1977 \{published data only\}

Scurr JH, Ibrahim SZ, Faber RG, Le Quesne LP. The efficacy of graduated compression stockings in the prevention of deep vein thrombosis. British Journal of Surgery 1977;64(5):371-3.

\section{Scurr 1987 \{published data only\}}

Scurr JH, Coleridge-Smith PD, Hasty JH. Regimen for improved effectiveness of intermittent pneumatic compression in deep venous thrombosis prophylaxis. Surgery 1987;102(5):816-20.

Shirai 1985 \{published data only\}

Shirai N. Study on prophylaxis of postoperative deep vein thrombosis. Acta Scholae Medicinalis Universitatis in Gifu 1985;33(6):1173-83.

\section{Torngren 1980 \{published data only\}}

Torngren S. Low dose heparin and compression stockings in the prevention of postoperative deep venous thrombosis. British Journal of Surgery 1980;67(7):482-4.

Tsapogas 1971 \{published data only\}

Tsapogas MJ, Goussous H, Peabody RA, Karmody AM, Eckert C. Postoperative venous thrombosis and the effectiveness of prophylactic measures. Archives of Surgery 1971;103(5):561-7.

Turner 1984 \{published data only\}

Turner GM, Cole SE, Brooks JH. The efficacy of graduated compression stockings in the prevention of deep vein thrombosis after major gynaecological surgery. British Journal of Obstetrics and Gynaecology 1984;91(6):588-91.

Turpie 1989 \{published data only\}

Turpie AG, Hirsh J, Gent M, Julian DH, Johnson JA. A randomized trial comparing graduated compression stockings alone or graduated compression stockings plus intermittent 
pneumatic compression with control in the prevention of deep vein thrombosis in neurosurgical patients. Arteriosclerosis 1988; Vol. 8, issue 5:675A.

* Turpie AGG, Hirsh J, Gent M, Julian D, Johnson J. Prevention of deep vein thrombosis in potential neurosurgical patients. A randomized trial comparing graduated compression stockings alone or graduated compression stockings plus intermittent pneumatic compression with control. Archives of Internal Medicine 1989;149(3):679-81.

\section{Wille-Jorgensen 1985 \{published data only\}}

Wille-Jorgensen P, Thorup J, Fischer A, Holst-Christensen J, Flamsholt R. Heparin with and without graded compression stockings in the prevention of thromboembolic complications of major abdominal surgery: a randomised trial. British Journal of Surgery 1985;72(7):579-81.

\section{Wille-Jorgensen 1991 \{published data only\}}

Wille-Jorgensen P, Hauch O, Dimo B, Christensen SW, Jensen R, Hansen B. Prophylaxis of deep venous thrombosis after acute abdominal operation. Surgery, Gynecology \& Obstetrics 1991;172(1):44-8.

\section{References to studies excluded from this review}

\section{Ayhan 2013 \{published data only\}}

Ayhan H, Iyigun E, Ince S, Can MF, Hatipoglu S, Saglam M. A randomised clinical trial comparing the patient comfort and efficacy of three different graduated compression stockings in the prevention of postoperative deep vein thrombosis. Journal of Clinical Nursing 2015;24(15-16):2247-57.

* Ayhan H, Iyigun E, Ince S, Can MF, Hatipoglu S, Saglam M. Comparison of three different protocols in the prevention of postoperative deep vein thrombosis in patients at highrisk: randomized clinical study. European Surgical Research 2013;50(Suppl 1):64-5.

\section{Barinov 2014 \{published data only\}}

Barinov VE, Lobastov KV, Tsaplin SN, Schastlivtsev IV, Boiarintsev VV, Laberko LA, et al. Role of compression bandage with elevated level of pressure in decreasing incidence of venous thrombosis in high-risk patients. Angiologiia i Sosudistaia Khirurgiia [Angiology \& Vascular Surgery] 2014;20(2):98-104.

\section{Belcaro 1993 \{published data only\}}

Belcaro G, Laurora G, Cesarone MR, De Sanctis MT. Prophylaxis of recurrent deep vein thrombosis. A randomized, prospective study using indobufen and graduated elastic compression stockings. Angiology 1993;44(9):695-9.

\section{Bolton 1978 \{published data only\}}

Bolton J. The prevention of post-operative deep vein thrombosis by graduated compression stocking. Scottish Medical Journal 1978;23(4):333-4.

\section{Brunkwall 1991 \{published data only\}}

Brunkwall J, Bergqvist D, Takolander R. Deep vein thrombosis after renal transplantation is not reduced by graded compression stockings. Thrombosis and Haemostasis 1991; Vol. 65, issue 6:1132; Abstract No 1572

Caprini 1983 \{published data only\}

Caprini JA, Chucker JL, Zuckerman L, Vagher JP, Franck CA, Cullen JE. Thrombosis prophylaxis using external compression. Surgery, Gynecology and Obstetrics 1983;156(5):599-604.

\section{Chandhoke 1991 \{published data only\}}

Chandhoke PS, Gretchen AW, Gooding GAW, Narayanan P. Prospective randomized trial of Coumadin vs sequential compression stockings as prophylaxis for postoperative deep venous thrombosis in major urologic surgery. Journal of Urology 1991; Vol. 145 Suppl 4:371A; Abstract No 636.

\section{CLOTS 2009 \{published data only\}}

Dennis M, Mordi N, Graham C, Sandercock P, CLOTS Trials Collaboration. The timing, extent, progression and regression of deep vein thrombosis in immobile stroke patients: observational data from the CLOTS multicenter randomized trials. Journal of Thrombosis and Haemostasis 2011;9(11):2193-200.

* Dennis M, Sandercock PA, Reid J, Graham C, Murray G, Venables $\mathrm{G}$, et al. Effectiveness of thigh-length graduated compression stockings to reduce the risk of deep vein thrombosis after stroke (CLOTS Trial 1): a multicentre, randomised controlled trial. Lancet 2009;373(9679):1958-65.

\section{Cohen 2007 \{published data only\}}

Cohen AT, Skinner JA, Warwick D, Brenkel I. The use of graduated compression stockings in association with fondaparinux in surgery of the hip. A multicentre, multinational, randomised, open-label, parallel-group comparative study. Journal of Bone and Joint Surgery. British Volume 2007;89(7):887-92.

\section{Fasting 1985 \{published data only\}}

Fasting $\mathrm{H}$, Andersen $\mathrm{K}$, Kraemmer Nielsen $\mathrm{H}$, Husted SE, Koopmann HD, Simonsen O, et al. Prevention of postoperative deep venous thrombosis. Low-dose heparin versus graded compression stockings. Acta Chirurgica Scandinavica 1985;151(3):245-8.

\section{Flanc 1969 \{published data only\}}

Flanc C, Kakkar VV, Clarke MB. Postoperative deepvein thrombosis. Effect of intensive prophylaxis. Lancet 1969;1(7593):477-8.

\section{Gao 2012 \{published data only\}}

Gao J, Zhang ZY, Li Z, Liu CD, Zhan YX, Qiao BL, et al. Two mechanical methods for thromboembolism prophylaxis after gynaecological pelvic surgery: a prospective, randomised study. Chinese Medical Journal 2012;125:4259-63.

\section{Hansberry 1991 \{published data only\}}

Hansberry KL, Thompson IM Jr, Bauman J, Deppe S, Rodriguez FR. A prospective comparison of thromboembolic stockings, external sequential pneumatic compression stockings and heparin sodium/dihydroergotamine mesylate for 
the prevention of thromboembolic complications in urological surgery. Journal of Urology 1991;145(6):1205-8.

\section{Ibegbuna 1997 \{published data only\}}

Ibegbuna V, Delis K, Nicolaides AN. Effect of lightweight compression stockings on venous haemodynamics. International Angiology 1997;16(3):185-8.

Ido 1995 \{published data only\}

Ido K, Suzuki T, Taniguchi Y, Kawamoto C, Isoda N, Nagamine N, et al. Femoral vein stasis during laparoscopic cholecystectomy: effects of graded elastic compression leg bandages in preventing thrombus formation. Gastrointestinal Endoscopy 1995;42:151-5.

\section{KANT study \{published data only\}}

Camporese G, Bernardi E, N'Tita K, Verlato F, Salmistraro G, Cordova R, et al. Different thromboprophylaxis approaches in patients undergoing knee arthroscopy (KANT study): a prospective randomized study. Journal of Thrombosis and Haemostasis 2005; Vol. 3, issue s1:Abstract No P1618.

* Camporese G, Bernardi E, Prandoni P, Noventa F, Verlato F, Simioni $P$, et al. Low-molecular-weight heparin versus compression stockings for thromboprophylaxis after knee arthroscopy: a randomized trial. Annals of Internal Medicine 2008;149(2):73-82.

Camporese G, N'Tita K, Rossi F, Bernardi E, Verlato F, Salmistraro G, et al. Different thromboprophylaxis approaches in patients undergoing knee arthroscopy (KANT study): interim report of prospective randomized study. Journal of Thrombosis and Haemostasis 2003; Vol. 1, issue s1:Abstract No P1888.

\section{Koopmann 1985 \{published data only\}}

Koopmann HD, Andersen K, Husted SE, Nielsen HK, Fasting H, Simonsen $\mathrm{O}$, et al. Prevention of postoperative venous thrombosis. A comparison between low-dose heparin and graduated compression stockings. Ugeskrift for Laeger 1985;147(29):2296-8.

\section{Lacut 2005 \{published data only\}}

Lacut K, Bressollette L, Le Gal G, Etienne E, De Tinteniac A, Renault, et al. Prevention of venous thrombosis in patients with acute intracerebral hemorrhage. Neurology 2005;65(6):865-9.

\section{Lee 1989 \{published data only\}}

Lee RE, Ho KN, Karran SJ, Taylor I. Haemorrhagic effects of sodium heparin and calcium heparin prophylaxis in patients undergoing mastectomy. Journal of the Royal College of Surgeons of Edinburgh 1989;34:149-51.

\section{Lobastov 2013 \{published data only\}}

Lobastov K, Barinov V, Obolensky V, Laberko L, Rodoman G. Electrical calf muscle stimulation combined with low dose unfractionated heparin (LDUH) and elastic compression (EC) versus $\mathrm{LDUH}$ with $\mathrm{EC}$ alone in the prevention of postoperative DVT. Scientific Programme and Book of Abstracts. 14th Meeting of the European Venous Forum; 2013 June 27-30; Belgrade, Serbia. 2013:5.
Maksimovic 1996 \{published data only\}

Maksimovic ZV, Lausevic Z, Kostic R, Kolic Z, Petrovic G, Sego D. Medicamentous prophylaxis of deep vein thrombosis in emergency surgical patients. International Angiology 1996; Vol. 15 Suppl 1, issue 2:31.

Manella 1981 \{published data only\}

Manella KJ. Comparing the effectiveness of elastic bandages and shrinker socks for lower extremity amputees. Physical Therapy 1981;61(3):334-7.

\section{Marston 1995 \{published data only\}}

Marston RA, Farrah J, Sommerville MA, Coleridge-Smith EP. What is the true incidence of deep vein thrombosis after major joint replacement surgery? [abstract]. Journal of Bone and Joint Surgery. British Volume 1995;77-B Suppl 1:11.

\section{Maxwell 2000 \{published data only\}}

Maxwell GL. A prospective randomized trial comparing external pneumatic compression stockings (EPC) to the low molecular weight heparin (LMWH) dalteparin in the prevention of thromboembolic events (TE) among gynaecologic oncology patients. Proceedings of the American Society of Clinical Oncology 2000;19:388a.

\section{Muir 2000 \{published data only\}}

Muir KW, Watt A, Baxter G, Grosset DG, Lees KR. Randomised trial of graded compression stockings for prevention of deepvein thrombosis after acute stroke. QJM - Monthly Journal of the Association of Physicians 2000;93(6):359-64.

\section{NCT00333021 \{published data only\}}

NCT00333021. Abdominal surgery study of GSK576428 (fondaparinux sodium) in Japanese patients. clinicaltrials.gov/ ct2/show/NCT00333021 (first received 2 June 2006).

\section{NCT01234064 \{published data only\}}

NCT01234064. Graduated compression stockings (GCS) pilot substudy. clinicaltrials.gov/ct2/show/NCT01234064 (first received 4 November 2010).

\section{NCT01935414 \{published data only\}}

NCT01935414. Geko neuromuscular stimulator vs thromboembolism deterrent stockings (TEDS): DVT prevention study. clinicaltrials.gov/ct2/show/NCT01935414 (first received 5 September 2015).

\section{Necioglu 2008 \{published data only\}}

Necioglu OD, Kenangil G, Gundogdu L, Ozkurt H, Forta H, Yalcin D. Heparin treatment for the prophylaxis of deep venous thrombosis in primary intracerebral haemorrhages. European Journal of Neurology 2008;15:72.

\section{Norgren 1996 \{published data only\}}

Norgren L, Austrell CH, Brummer R, Swartbol P. Low incidence of deep vein thrombosis after total hip replacement: an interim analysis of patients on low molecular weight heparin vs sequential gradient compression prophylaxis. International Angiology 1996;15(3 Suppl 1):11-4. 
Nurmohamed 1996 \{published data only\}

Nurmohamed MT, Van Riel AM, Henkens CMA, Koopman MMW, Que GTH, D'Azemar P, et al. Low molecular weight heparin and compression stockings in the prevention of venous thromboembolism in neurosurgery. Thrombosis and Haemostasis 1996;75(2):233-8.

\section{Orken 2009 \{published data only\}}

Orken DN, Kenangil G, Ozkurt H, Guner C, Gundogdu L, Basak M, et al. Prevention of deep venous thrombosis and pulmonary embolism in patients with acute intracerebral hemorrhage. Neurologist 2009;15:329-31.

\section{Patel 1988 \{published data only\}}

Patel A, Couband D, Feron JM, Signoret F. Prevention of deep venous thrombosis in arthroplastic surgery of the hip by the combination of heparinotherapy and the antithrombosis stocking. Presse Medicale 1988;17(23):1201-3.

\section{Perkins 1999 \{published data only\}}

Perkins J, Beech A, Hands L. Randomized controlled trial of heparin plus graduated compression stocking for the prophylaxis of deep venous thrombosis in general surgical patients. British Journal of Surgery 1999; Vol. 86:701.

\section{Porteous 1989 \{published data only\}}

Porteous MJ, Nicholson EA, Morris LT, James R, Negus D. Thigh length versus knee length stockings in the prevention of deep vein thrombosis. British Journal of Surgery 1989;76(3):296-7.

\section{Rabe 2013 \{published data only\}}

Rabe E. Thigh-length versus lower leg compression stockings for the prevention of postthrombotic syndrome in patients with proximal deep leg vein thrombosis: a randomized study. Vasomed 2013;1:57.

\section{Ramos 1996 \{published data only\}}

Ramos R, Salem BI, De Pawlikowski MP, Coordes C, Eisenberg S, Leidenfrost $R$. The efficacy of pneumatic compression stockings in the prevention of pulmonary embolism after cardiac surgery. Chest 1996;109(1):82-5.

\section{Rasmussen 1988 \{published data only\}}

Rasmussen A, Hansen PT, Lindholt J, Poulsen TD, Toftdahl DB, Gram J, et al. Venous thrombosis after abdominal surgery. A comparison between subcutaneous heparin and antithrombotic stockings or both. Journal of Medicine 1988;19(3-4):193-201.

\section{Rocca 2012 \{published data only\}}

Rocca A, Compagna R, de Vito D, Della Corte GA, Bianco T, Amato B. Compression therapy in chronic venous disease. European Surgical Research 2012;49:140.

\section{Rosengarten 1970 \{published data only\}}

Rosengarten DS, Laird J, Jeyasingh K, Martin P. The failure of compression stockings (Tubigrip) to prevent deep venous thrombosis after operation. British Journal of Surgery 1970;57(4):296-9.

\section{Ryan 2002 \{published data only\}}

Ryan MG, Westrich GH, Potter HG, Sharrock N, Maun LM, Macaulay W, et al. Effect of mechanical compression on the prevalence of proximal deep venous thrombosis as assessed by magnetic resonance venography. Journal of Bone and Joint Surgery. American Volume 2002;84-A(11):1998-2004.

\section{Sakon 2012 \{published data only\}}

Sakon M, Nakamura M. Darexaban (YM150) prevents venous thromboembolism in Japanese patients undergoing major abdominal surgery: phase III randomized, mechanical prophylaxis-controlled, open-label study. Thrombosis Research 2012;130(3):e52-9.

\section{Serin 2010 \{published data only\}}

Serin K, Yanar H, Ozdenkaya Y, Tugrul S, Kurtoglu M, Serin K, et al. Venous thromboembolism prophylaxis methods in trauma and emergency surgery intensive care unit patients: low molecular weight heparin versus elastic stockings and intermittent pneumatic compression. Ulusal Travma ve Acil Cerrahi Dergisi [Turkish Journal of Trauma and Emergency Surgery] 2010;16:130-4.

\section{Shilpa 2013 \{published data only\}}

Shilpa NV, Puttanna, Shivaprasad, Verghese J, Rajagopalan N. Study comparing different methods of thromboprophylaxes pharma-coprophylaxis vs mechanoprophylaxis (TED stockings vs crepe bandage). Indian Journal of Critical Care Medicine 2013;17:35

\section{Silbersack 2004 \{published data only\}}

Silbersack Y, Taute BM, Hein W, Podhaisky H. Prevention of deep-vein thrombosis after total hip and knee replacement. Low-molecular-weight heparin in combination with intermittent pneumatic compression. Journal of Bone and Joint Surgery. British Volume 2004;86(6):809-12.

\section{Sobieraj-Teague 2012 \{published data only\}}

Sobieraj-Teague M, Hirsh J, Yip G, Gastaldo F, Stokes T, Sloane D, et al. Randomized controlled trial of a new portable calf compression device (Venowave) for prevention of venous thrombosis in high-risk neurosurgical patients. Journal of Thrombosis and Haemostasis 2012;10:229-35.

\section{Sultan 2011 \{published and unpublished data\}}

Sultan MJ, Zheng TT, Kurdy N, McCollum CN. Role of engineered compression stockings in preventing deep vein thrombosis following ankle fractures. Phlebology 2011;26(3):267.

\section{Sultan 2014 \{published data only\}}

Sultan MJ, Zhing T, Morris J, Kurdy N, McCollum CN. Compression stockings in the management of fractures of the ankle: a randomised controlled trial. Bone and Joint Journal 2014;96-B(2049-4408 (Electronic), 8):1062-9.

\section{Vignon 2013 \{published data only\}}

Vignon P, Dequin PF, Renault A, Mathonnet A, Paleiron N, Imbert A, et al. Clinical Research in Intensive Care and Sepsis Group (CRICS Group). Intermittent pneumatic compression to prevent venous thromboembolism in patients with high risk 
of bleeding hospitalized in intensive care units: the CIREA1 randomized trial. Intensive Care Medicine 2013;39(5):872-80.

\section{Westrich 1996 \{published data only\}}

Westrich GH, Sculco TP. Pneumatic plantar compression compared with aspirin for deep venous thrombosis prophylaxis after total knee arthroplasty [abstract]. Orthopaedic Transactions 1996; Vol. 20:398.

\section{Wilkins 1952 \{published data only\}}

Wilkins RW, Mixter G Jr, Stanton JR, Litter J. Elastic stockings in the prevention of pulmonary embolism: a preliminary report. New England Journal of Medicine 1952;246(10):360-4.

\section{Wille-Jorgensen 1986 \{published data only\}}

Wille-Jorgensen P. Low-dosage heparin combined with either dihydroergotamine or graduated supportive stockings. Combined prevention of thrombosis in colonic surgery. Ugeskrift for Laeger 1986;148(9):501-3.

Wilson 1994 \{published data only\}

Wilson YG, Allen PE, Skidmore R, Baker AR. Influence of compression stockings on lower-limb venous haemodynamics during laparoscopic cholecystectomy. British Journal of Surgery 1994;81(6):841-4.

\section{Yang 2009 \{published data only\}}

Yang BL, Zhang ZY, Guo SL. Clinical significance of preventive treatment of thrombosis for patients undergoing gynaecological surgery with high risk factors. Chung-Hua Fu Chan Ko Tsa Chih [Chinese Journal of Obstetrics \& Gynecology] 2009;44(8):570-3.

\section{Zhang 2011 \{published data only\}}

Zhang C, Zeng W, Zhou H, Zheng BX, Cheng JC, Li XY, et al. The efficacy of intermittent pneumatic compression in the prevention of venous thromboembolism in medical critically ill patients. Chinese Critical Care Medicine 2011;23(9):563-5.

\section{Zheng 2014 \{published data only\}}

Zheng H, Gao Y, Yan X, Gao M, Gao W. Prophylactic use of low molecular weight heparin in combination with graduated compression stockings in post-operative patients with gynecologic cancer. Zhonghua zhong liu za zhi [Chinese Journal of Oncology] 2014;36(1):39-42.

\section{References to studies awaiting assessment}

Celebi 2001 \{published data only\}

Celebi F, Balik AA, Yildirgan MI, Basoglu M, Adiguzel H, Oren D. Thromboembolic prophylaxis after major abdominal surgery. Turkish Journal of Trauma and Emergency Surgery 2001;7(1):44-8

\section{References to ongoing studies}

\section{ChiCTR1800014257 \{published data only\}}

ChiCTR1800014257. The strategies of risk-stratified prophylaxis of deep venous thrombosis after gynecologic pelvic surgery in patients at different levels of risk: a prospective multicenter randomized controlled trial. www.chictr.org.cn/ hvshowproject.aspx?id=12675 (first received 2 January 2018).

GAPS \{published data only\}

GAPS Trial Investigators. Examining the benefit of graduated compression stockings as an adjunct to low dose low molecular weight heparin in the prevention of venous thromboembolism in elective surgical inpatients identified as moderate or high risk for venous thromboembolism: a multi-centre randomised controlled trial. www.isrctn.com/ISRCTN13911492 (first received 27 January 2016). [DOI: 10.1186/ISRCTN13911492]

Lawton R. Graduated compression as an adjunct to pharmacoprophylaxis in surgery (GAPS): the issues of recruiting to a multicenter trial in venous thromboembolism prevention. Journal of Vascular Surgery: Venous and Lymphatic Disorders 2017;5:165.

* Shalhoub J, Norrie J, Baker C, Bradbury AW, Dhillon K, Everington T, et al. GAPS Trial Investigators. Graduated compression stockings as an adjunct to low dose low molecular weight heparin in venous thromboembolism prevention in surgery: a multicentre randomised controlled trial. European Journal of Vascular and Endovascular Surgery 2016;53(6):880-5. [DOI: 10.1016/j.ejvs.2017.02.013; PUBMED: 28396238]

IRCT2017080935594N1 \{published data only\}

* IRCT2017080935594N1. Comparison of efficacy compressive stocking with heparin and enoxaparin in prevention of deep vein thrombosis of lower extremities in hysterectomized patients. en.irct.ir/trial/26850?revision=26850 (first received 28 September 2017).

\section{Additional references}

\section{Atkins 2004}

Atkins D, Best D, Briss PA, Eccles M, Falck-Ytter Y, Flottorp S, et al. Grading quality of evidence and strength of recommendations. BMJ 2004;328(7454):1490. [DOI: 10.1136/bmj.328.7454.1490]

\section{Benko 2001}

Benko T, Cooke EA, McNally MA, Mollan RAB. Graduated compression stockings: knee length or thigh length. Clinical Orthopaedics and Related Research 2001;383:197-203.

\section{CONSORT 1996}

Begg C, Cho M, Eastwood S, Horton R, Moher D, Olkin I, et al. Improving the quality of reporting of randomized controlled trials: the CONSORT statement. JAMA 1996;276(8):637-9.

\section{Deeks 2001}

Deeks JJ, Altman DG, Bradburn MJ. Statistical methods for examining heterogeneity and combining results from several studies in meta-analysis. In: Egger M, Davey Smith G, Altman DG editor(s). Systematic Reviews in Health Care: Meta-analysis in Context. 2nd Edition. London (UK): BMJ Publication Group, 2001.

Flordal 1995

Flordal PA, Bergqvist D, Ljungström KG, Törngren S. Clinical relevance of the fibrinogen uptake test in patients undergoing 
elective general abdominal surgery - relation to major thromboembolism and mortality. Fragmin Multicentre Study Group. Thrombosis Research 1995;80(6):491-7.

\section{GRADEpro GDT 2015 [Computer program]}

McMaster University (developed by Evidence Prime). GRADEpro GDT. Version accessed 23 January 2018. Hamilton (ON): McMaster University (developed by Evidence Prime), 2015.

\section{Higgins 2011}

Higgins JP, Green S, editor(s). Cochrane Handbook for Systematic Reviews of Interventions Version 5.1.0 (updated March 2011). The Cochrane Collaboration, 2011. Available from handbook.cochrane.org.

\section{ICS 2013}

Nicolaides AN, Fareed J, Kakkar AK, Comerota AJ, Goldhaber SZ, Hull R, et al. Prevention and treatment of venous thromboembolism. International Consensus Statement (Guidelines according to scientific evidence). International Angiology 2013;32(2):111-260.

\section{Kahn 2008}

Kahn SR, Shrier I, Julian JA. Determinants and time course of the postthrombotic syndrome after acute deep venous thrombosis. Annals of Internal Medicine 2008;149:698-707.

\section{Lensing 1993}

Lensing AW, Hirsh J. 125I-fibrinogen leg scanning: reassessment of its role for the diagnosis of venous thrombosis in postoperative patients. Thrombosis and Haemostasis 1993;69(1):2-7.

\section{Naccarato 2010}

Naccarato M, Chiodo Grandi F, Dennis M, Sandercock PA. Physical methods for preventing deep vein thrombosis in stroke. Cochrane Database of Systematic Reviews 2010, Issue 8. [DOI: 10.1002/14651858.CD001922.pub3]

\section{NICE 2010}

National Clinical Guidelines Centre - Acute and Chronic Conditions. Venous thromboembolism: reducing the risk of venous thromboembolism (deep vein thrombosis and pulmonary embolism) in patients admitted to hospital. www.nice.org.uk/guidance/cg92 2010 (accessed 22 March 2011).

\section{RevMan 2012 [Computer program]}

The Nordic Cochrane Centre, The Cochrane Collaboration. Review Manager (RevMan). Version 5.2. Copenhagen: The Nordic Cochrane Centre, The Cochrane Collaboration, 2012.

\section{Roderick 2005}

Roderick P, Ferris G, Wilson K, Halls H, Jackson D, Collins R, et al. Towards evidence-based guidelines for the prevention of venous thromboembolism: systematic reviews of mechanical methods, oral anticoagulation, dextran and regional anaesthesia as thromboprophylaxis. Health Technology Assessment 2005; Vol. 9:49.

\section{Ryan 2016}

Ryan R, Hill S. How to GRADE the quality of the evidence. Cochrane Consumers and Communication Group. cccrg.cochrane.org/author-resources (accessed prior to 31 December 2016)

\section{Sajid 2012}

Sajid M, Desai M, Morris RW, Hamilton G. Knee length versus thigh length graduated compression stockings for prevention of deep vein thrombosis in postoperative surgical patients. Cochrane Database of Systematic Reviews 2012, Issue 5. [DOI: 10.1002/14651858.CD007162.pub2]

\section{Seinturier 2005}

Seinturier C, Bosson JL, Colonna M, Imbert B, Carpentier PH. Site and clinical outcome of deep vein thrombosis of the lower limbs: an epidemiological study. Journal of Thrombosis and Haemostasis 2005;3(7):1362-7.

\section{SIGN 2010}

Scottish Intercollegiate Guidelines Network (SIGN). SIGN 122 Prevention and management of venous thromboembolism. www.sign.ac.uk/pdf/qrg122.pdf 2010 (accessed 24 March 2011).

\section{Spiro 1970}

Spiro M, Roberts VC, Richards JB. Effect of externally applied pressure on femoral vein blood flow. British Medical Journal 1970;1(698):719-23.

\section{Sweetland 2009}

Sweetland S, Green J, Liu B, Berrington de González A, Canonico M, Reeves G, et al. Million Women Study collaborators. Duration and magnitude of the postoperative risk of venous thromboembolism in middle aged women: prospective cohort study. BMJ 2009;340:b4583.

\section{Søgaard 2014}

Søgaard KK, Schmidt M, Pederson L, Horváth-

Puhó E, Sørensen HT. 30-year mortality after venous thromboembolism: a population-based cohort study. Circulation 2014;130(10):829-36.

\section{THRIFT 1992}

Risk of and prophylaxis for venous thromboembolism in hospital patients. Thromboembolic Risk Factors (THRIFT) Consensus Group. BMJ 1992;305(6853):567-74.

\section{Virchow 1858}

Virchow R. Die Cellularpathologie in ihrer Begrundung auf physiologische und pathologische Gewebsleher. Berlin: Hirschwald A, 1858.

\section{White 2003}

White $\mathrm{RH}$. The epidemiology of venous thromboembolism. Circulation 2003;107(23 Suppl 1):14-8. 


\section{References to other published versions of this review}

\section{Amaragiri $\mathbf{2 0 0 0}$}

Amaragiri SV, Lees T. Elastic compression stockings for prevention of deep vein thrombosis. Cochrane Database of Systematic Reviews 2000, Issue 1. [DOI: 10.1002/14651858.CD001484]

\section{Sachdeva 2010}

Sachdeva A, Dalton M, Amaragiri SV, Lees T. Elastic compression stockings for prevention of deep vein thrombosis. Cochrane
Database of Systematic Reviews 2010, Issue 7. [DOI: 10.1002/14651858.CD001484.pub2]

\section{Sachdeva 2014}

Sachdeva A, Dalton M, Amaragiri SV, Lees T. Graduated compression stockings for prevention of deep vein thrombosis. Cochrane Database of Systematic Reviews 2014, Issue 12. [DOI: 10.1002/14651858.CD001484.pub3]

* Indicates the major publication for the study

\section{CHARACTERISTICS OF STUDIES}

Characteristics of included studies [ordered by study ID]

\section{Allan 1983}

\begin{tabular}{ll}
\hline Methods & Study: RCT \\
& Exclusions postrandomisation: 11 \\
& Losses to follow-up: 0 \\
& DVT diagnosis: FUT. Scanned on first, second, third, fifth, and seventh day after operation. In partici- \\
pants with evidence of DVT, scanning was continued until the participant left the hospital. Phlebogram \\
performed if evidence of DVT to assess proximal involvement. \\
Follow-up: 7 days \\
Statistical analysis: Chi2 test \\
Country: UK \\
Total number of participants: 211 \\
Total available for analysis: 200 \\
Age: $>40$ years \\
Sex: male and female \\
Inclusion criteria: abdominal surgery greater than 30 minutes duration \\
Exclusion criteria: past DVT, PE, varicose veins, steroid or anticoagulant therapy
\end{tabular}

Interventions

Type of treatment: GCS length not stated

Control: 103

Treatment: 97

Duration: GCS fitted on the evening before the operation and continued until 7 days thereafter.

\begin{tabular}{ll}
\hline DVT & Control: 37 \\
& Treatment: 15 \\
& P $<0.025$ \\
& PE: not mentioned \\
& Benign and malignant patients were differentiated as follows. \\
& Benign \\
Control: 51, DVT: 16 \\
Treatment: 49, DVT: 5 \\
P $<0.058$ \\
Malignant \\
Control: 52, DVT: 21 \\
Treatment: 48, DVT: 10 \\
P $<0.05$ \\
Incidence of proximal DVT not reported.
\end{tabular}


Allan 1983 (Continued)

No adverse events were reported.

The Kendall Company supplied the stockings and fibrinogen in the study.

\section{Risk of bias}

\begin{tabular}{|c|c|c|}
\hline Bias & Authors' judgement & Support for judgement \\
\hline $\begin{array}{l}\text { Random sequence genera- } \\
\text { tion (selection bias) }\end{array}$ & Low risk & Participants were allocated using random number series. \\
\hline $\begin{array}{l}\text { Allocation concealment } \\
\text { (selection bias) }\end{array}$ & Unclear risk & Method of concealment not described. \\
\hline $\begin{array}{l}\text { Blinding (performance } \\
\text { bias and detection bias) } \\
\text { All outcomes }\end{array}$ & Low risk & $\begin{array}{l}\text { "The scans were assessed without reference to patient or group." } \\
\text { Comment: probably done }\end{array}$ \\
\hline $\begin{array}{l}\text { Incomplete outcome data } \\
\text { (attrition bias) } \\
\text { All outcomes }\end{array}$ & Low risk & $11 / 211$ participants were not analysed, but were accounted for. \\
\hline $\begin{array}{l}\text { Selective reporting (re- } \\
\text { porting bias) }\end{array}$ & Low risk & Results of all outcomes were reported. \\
\hline Other bias & Low risk & No other source of bias identified. \\
\hline
\end{tabular}

\section{Barnes 1978}

Study: RCT
Exclusions postrandomisation: 0
Losses to follow-up: 0
DVT diagnosis: Doppler ultrasound on alternate days until discharge. Venography if positive and lung
perfusion scan if venography substantiates or on clinical manifestation of chest pain
PE diagnosis: only participants with clinical manifestations of PE were evaluated with chest X-rays, ar-
terial blood gases, and perfusion lung scanning.
Statistical analysis: Fisher exact probability
Follow-up: "until discharge"

\section{Participants}

\section{Country: USA}

Total number of participants: 18

Total available for analysis: 18

Age: $>50$ years

Sex: male and female

Inclusion criteria: all patients admitted for hip operation

Exclusion criteria: none

\begin{tabular}{ll}
\hline Interventions & Type of treatment: GCS thigh length \\
& Additional background thromboprophylaxis: aspirin \\
& Control: 10 \\
& Treatment: 8 \\
& Duration: GCS fitted on the day of surgery until discharge.
\end{tabular}

Outcomes

DVT (all)

Control: 5 
Barnes 1978 (Continued)

Treatment: 0

$\mathrm{P}=0.029$

Proximal DVT

Control: 4

Treatment: 0

$P$ not reported

\section{Symptomatic PE (confirmed by lung perfusion scan)*}

Control: 3

Treatment: 0

*Evaluation of PE using lung perfusion scans was only performed in participants with clinical manifestations of PE.

\begin{tabular}{|c|c|}
\hline Notes & $\begin{array}{l}\text { Some participants had: } \\
\text { - aspirin during the study; } \\
\text { - previous DVT; } \\
\text { - previous leg injuries; } \\
\text { - varicose veins; } \\
\text { - venous skin changes. }\end{array}$ \\
\hline
\end{tabular}

Study was stopped due to an increased incidence of DVT in the control group.

All 3 participants with radiographically confirmed PEs were also noted as having DVTs. Incidence of adverse events not mentioned.

\section{Risk of bias}

\begin{tabular}{|c|c|c|}
\hline Bias & Authors' judgement & Support for judgement \\
\hline $\begin{array}{l}\text { Random sequence genera- } \\
\text { tion (selection bias) }\end{array}$ & Unclear risk & Method of randomisation not mentioned. \\
\hline $\begin{array}{l}\text { Allocation concealment } \\
\text { (selection bias) }\end{array}$ & Low risk & Sealed envelopes were used. \\
\hline $\begin{array}{l}\text { Blinding (performance } \\
\text { bias and detection bias) } \\
\text { All outcomes }\end{array}$ & Unclear risk & Not mentioned \\
\hline $\begin{array}{l}\text { Incomplete outcome data } \\
\text { (attrition bias) } \\
\text { All outcomes }\end{array}$ & Low risk & All 18 participants were accounted for and included in the analysis. \\
\hline $\begin{array}{l}\text { Selective reporting (re- } \\
\text { porting bias) }\end{array}$ & Low risk & Results of all outcome measures were reported. \\
\hline Other bias & High risk & $\begin{array}{l}\text { This study was terminated early. "It was considered medically unjustifiable to } \\
\text { continue this study when a significantly greater incidence of major deep vein } \\
\text { thrombosis developed in the patients not wearing stockings." }\end{array}$ \\
\hline & & $\begin{array}{l}\text { Also, authors of this study were awarded a grant from the Kendall Research } \\
\text { Center, who manufacture stockings. }\end{array}$ \\
\hline
\end{tabular}

\section{Bergqvist 1984}

Methods Study: RCT


Bergqvist 1984 (Continued)

Exclusions postrandomisation: 8

Losses to follow-up: 0

DVT diagnosis: FUT. Scanned first and subsequently every second day

Follow-up: 7 days for DVT, 30 days for fatal PE or postoperative complications

Statistical analysis: exact binomial test

\begin{tabular}{|c|c|}
\hline Participants & $\begin{array}{l}\text { Country: Sweden } \\
\text { Total number of participants: } 88 \\
\text { Total available for analysis: } 80 \\
\text { Age: } 50 \text { years } \\
\text { Sex: male and female } \\
\text { Inclusion criteria: all abdominal operations } \\
\text { Exclusion criteria: }<50 \text { years of age }\end{array}$ \\
\hline Interventions & $\begin{array}{l}\text { Type of treatment: GCS thigh length } \\
\text { Additional background thromboprophylaxis: dextran } 70 \\
\text { Control: } 80 \text { ( } 39 \text { right leg and } 41 \text { left leg) } \\
\text { Treatment: } 80 \text { ( } 41 \text { right leg and } 39 \text { right leg) } \\
\text { Duration: evening before the operation until the seventh postoperative day }\end{array}$ \\
\hline Outcomes & $\begin{array}{l}\text { DVT (all) } \\
\text { Control: } 8 \\
\text { Treatment: } 0 \\
\text { P<0.01 } \\
\text { Proximal DVT } \\
\text { Control: } 1 \\
\text { Treatment: } 0 \\
\text { P not reported }\end{array}$ \\
\hline Notes & $\begin{array}{l}\text { This study included the infusion of dextran } 70 \text { as prophylactic measure in addition to stockings in both } \\
\text { groups; non-stockinged legs acted as control. } \\
1 \text { participant had symptoms of PE. } \\
\text { Adverse events: bleeding complications reported in } 4 \text { participants, but no adverse events associated } \\
\text { with GCS were reported. }\end{array}$ \\
\hline
\end{tabular}

\section{Risk of bias}

\begin{tabular}{lll}
\hline Bias & Authors' judgement & Support for judgement \\
\hline $\begin{array}{l}\text { Random sequence genera- } \\
\text { tion (selection bias) }\end{array}$ & Low risk & "using a random number table" \\
\hline $\begin{array}{l}\text { Allocation concealment } \\
\text { (selection bias) }\end{array}$ & Unclear risk & Not mentioned \\
\hline $\begin{array}{l}\text { Blinding (performance } \\
\text { bias and detection bias) } \\
\text { All outcomes }\end{array}$ & Low risk & "When analysing the data from the fibrinogen test, it was not clear which leg \\
\hline $\begin{array}{l}\text { Incomplete outcome data } \\
\text { (attrition bias) } \\
\text { All outcomes }\end{array}$ & Low risk & was stockinged." \\
\hline $\begin{array}{l}\text { Selective reporting (re- } \\
\text { porting bias) }\end{array}$ & Low risk & $8 / 80$ participants were not analysed, but were accounted for. \\
\hline
\end{tabular}


Bergqvist 1984 (Continued)

Other bias
Unclear risk
The study was partly funded by a grant from Beiersdorf $A B$, who also supplied the compression stockings.

Chin 2009

Study: RCT
Exclusions postrandomisation: 0
Losses to follow-up: 0
DVT diagnosis: bilateral duplex ultrasonography (frequency of investigation unspecified)
PE diagnosis: ventilation-perfusion scanning or spiral computed tomography of the chest, or both
Follow-up: 1 month
Statistical analysis: Chi2 test
Country: Singapore
Total number of participants: 440
Total available for analysis: 440 . Of these, 220 participants from 2 experimental groups (no prophylaxis
and GCS only) were eligible for inclusion in our review.
Age: 47 to 85 years
Sex: male and female
Inclusion criteria: low-risk patients undergoing elective total knee arthroplasty with no known predis-
position to thromboembolism
Exclusion criteria: use of anticoagulants or aspirin, history of PE or DVT in the previous year, BMI $>30$
kg/m², preoperative prolonged immobilisation or being wheelchair bound, bleeding tendency or a
history of GI bleeding, surgery in the previous 6 months, cerebrovascular accident in the previous 3
months, uncontrolled hypertension, congestive cardiac failure, renal or liver impairment, allergy to
heparin or heparin-induced thrombocytopenia, varicose veins or CVI, PVD, skin ulcers, dermatitis, or
wounds, and malignancy

Interventions

Type of treatment: GCS applied to legs (length unspecified)

Control: 110 (group 1)

Treatment: 110 (group 2)

Duration: applied until day 5 to 7 or stopped earlier if participants were suspected as having DVT or PE based on bilateral duplex ultrasonography

$\begin{array}{ll}\text { DVT (all) } & \text { Control: } 24 \text { (3 proximal, } 21 \text { distal) } \\ \text { Treatment: } 14 \text { (1 proximal, 13 distal) } \\ \text { P }=0.119 \\ \text { Proximal DVT } \\ \text { Control: } 3 \\ \text { Treatment: } 1 \\ \text { Symptomatic PE } \\ \text { Control: } 1 \\ \text { Treatment: } 1 \\ \text { Participants were divided into } 4 \text { experimental groups consisting of } 110 \text { participants each: no prophylax- } \\ \text { is, GCS only, IPC only, and LMWH only. Only patients at low risk of developing VTE were included. } \\ \text { Standardised rehabilitation protocols were used, with continuous passive movements initiated on day } \\ \text { 2 and ambulation on day } 3 \text { postoperatively. }\end{array}$


Chin 2009 (Continued)

Adverse events: no adverse effects such as skin rash, swelling above the appliance, pressure necrosis of the skin, or peroneal nerve palsy related to the use of GCS and IPC. At 1-month follow-up, 2 participants each in the control and GCS group were readmitted due to superficial wound infections.

Funding source was not disclosed.

\section{Risk of bias}

\begin{tabular}{|c|c|c|}
\hline Bias & Authors' judgement & Support for judgement \\
\hline $\begin{array}{l}\text { Random sequence genera- } \\
\text { tion (selection bias) }\end{array}$ & Unclear risk & Not mentioned \\
\hline $\begin{array}{l}\text { Allocation concealment } \\
\text { (selection bias) }\end{array}$ & Unclear risk & Not mentioned \\
\hline $\begin{array}{l}\text { Blinding (performance } \\
\text { bias and detection bias) } \\
\text { All outcomes }\end{array}$ & Low risk & $\begin{array}{l}\text { Single-blinded. "Bilateral duplex ultrasonography (carried out by one of } 3 \text { ded- } \\
\text { icated ultrasonographers blinded to the prophylactic method used)." }\end{array}$ \\
\hline $\begin{array}{l}\text { Incomplete outcome data } \\
\text { (attrition bias) } \\
\text { All outcomes }\end{array}$ & Low risk & All 440 participants were accounted for and analysed. \\
\hline $\begin{array}{l}\text { Selective reporting (re- } \\
\text { porting bias) }\end{array}$ & Low risk & Results of all outcome measures were reported. \\
\hline Other bias & Low risk & No other sources of bias identified. \\
\hline
\end{tabular}

Fredin 1989

\begin{tabular}{ll}
\hline Methods & Study: RCT \\
& Exclusions postrandomisation: 6 \\
& Losses to follow-up: 0 \\
& DVT diagnosis: FUT on first and every alternate day for 10 days \\
& Follow-up: phlebography at 10 days, clinical follow-up regarding fatal PE and postoperative complica- \\
& tions up to 30 days \\
& Statistical analysis: Student's t-test \\
Country: Sweden & Total number of participants: 150 \\
& Total available for analysis: 144 \\
& Age: $>40$ years \\
& Sex: male and female \\
Inclusion criteria: all patients for total hip arthroplasty & Exclusion criteria: swelling of legs, leg ulcers, eczema, malignancy, varicose veins, previous DVT, previ- \\
& ous PE, and cardiovascular diseases \\
& Type of treatment: GCS thigh length \\
& Additional background thromboprophylaxis: dextran 70 \\
Control: 48 \\
Treatment: 49 \\
Duration: applied on the evening before the operation for 14 days
\end{tabular}

\section{Outcomes}

DVT (all, unit of analysis = individual legs) 
Fredin 1989 (Continued)

Control: 13 of 47

Treatment: 3 of 49

$\mathrm{P}<0.01$

Proximal DVT (unit of analysis = individual legs)

Control: 9 of 47

Treatment: 1 of 49

Symptomatic PE (confirmed by scintigraphy)

Control: 2

Treatment: 0

$P$ not reported

Notes

All participants had regular dextran 70 prophylaxis.

Individual participants were randomised to the 3 treatment groups. However, we included only the non-operated leg's values in our analysis because in these orthopaedic patients thrombotic process may have already been initiated during surgery.

Incidence of symptomatic DVT not reported.

Adverse events: 2 participants reported discomfort and discontinued wearing stockings after 2 days. Incidence of bleeding reported, which might have been associated with low-dose heparin: 3 wound haematomas and minor bleeding from gastric drainage in 1 participant. A further 7 participants were withdrawn from the trial due to bleeding, which might also have been due to heparin.

Funded by Swedish Medical Research Council

\section{Risk of bias}

\begin{tabular}{|c|c|c|}
\hline Bias & Authors' judgement & Support for judgement \\
\hline $\begin{array}{l}\text { Random sequence genera- } \\
\text { tion (selection bias) }\end{array}$ & Unclear risk & Not mentioned \\
\hline $\begin{array}{l}\text { Allocation concealment } \\
\text { (selection bias) }\end{array}$ & Unclear risk & Not mentioned \\
\hline $\begin{array}{l}\text { Blinding (performance } \\
\text { bias and detection bias) } \\
\text { All outcomes }\end{array}$ & Low risk & "The data was analysed blindly concerning the type of prophylaxis." \\
\hline $\begin{array}{l}\text { Incomplete outcome data } \\
\text { (attrition bias) } \\
\text { All outcomes }\end{array}$ & Low risk & $6 / 150$ participants were not included in analysis, but were accounted for. \\
\hline $\begin{array}{l}\text { Selective reporting (re- } \\
\text { porting bias) }\end{array}$ & Low risk & Results of all outcome measures were reported. \\
\hline Other bias & Low risk & No other sources of bias identified. \\
\hline
\end{tabular}

\section{Holford 1976}

$\begin{array}{ll}\text { Methods } & \text { Study: RCT } \\ & \text { Exclusions postrandomisation: } 3 \\ & \text { Losses to follow-up: } 0 \\ & \text { DVT diagnosis: FUT on day prior to surgery and every day postoperatively for } 6 \text { to } 7 \text { days } \\ & \text { Follow-up: } 6 \text { to } 7 \text { days }\end{array}$


Holford 1976 (Continued)

Statistical analysis: Chi ${ }^{2}$ test with Yates' correction

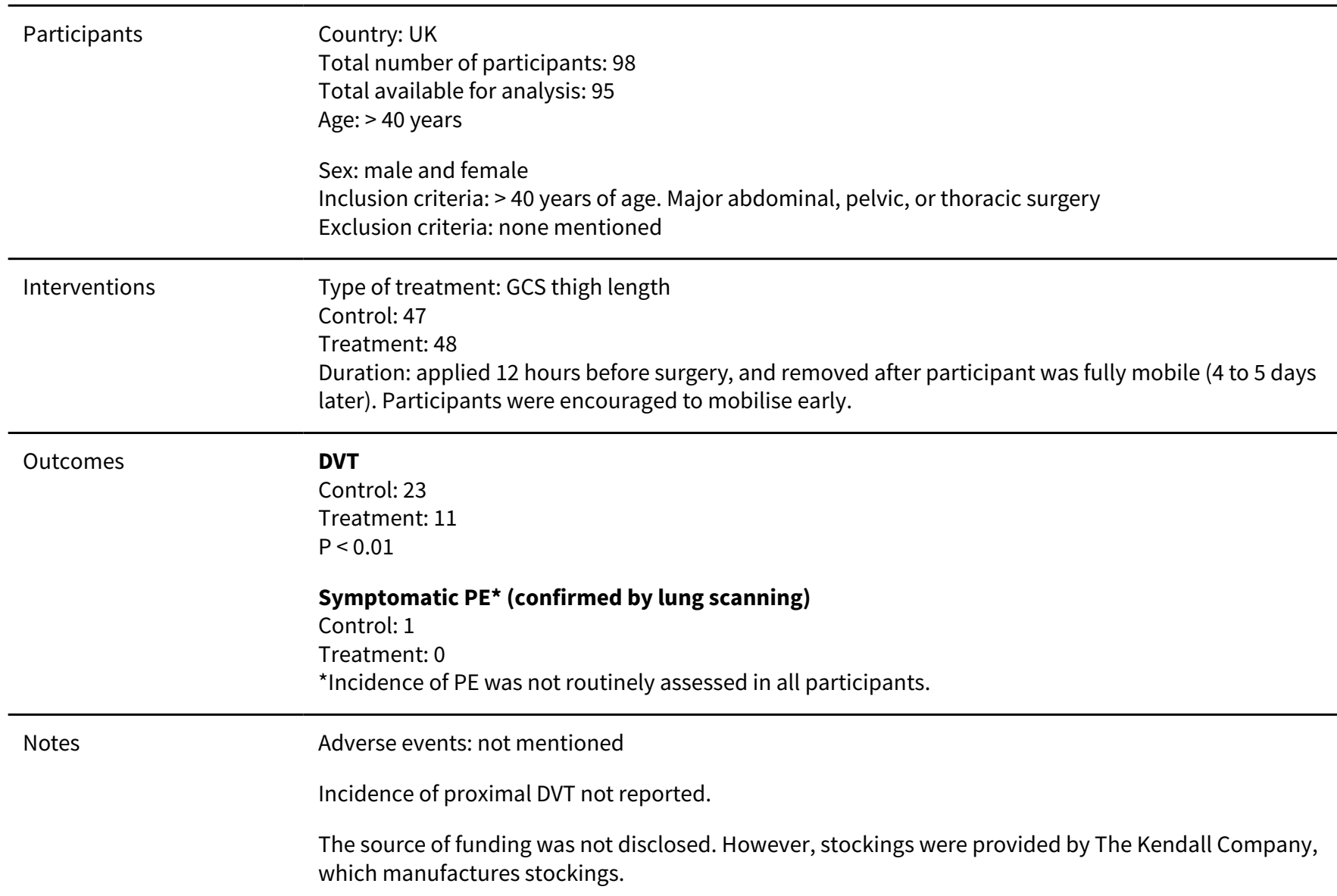

\section{Risk of bias}

\begin{tabular}{|c|c|c|}
\hline Bias & Authors' judgement & Support for judgement \\
\hline \multirow{2}{*}{$\begin{array}{l}\text { Random sequence genera- } \\
\text { tion (selection bias) }\end{array}$} & \multirow[t]{2}{*}{ Unclear risk } & "Patients were allocated randomly" \\
\hline & & Comment: no mention of how this was achieved \\
\hline $\begin{array}{l}\text { Allocation concealment } \\
\text { (selection bias) }\end{array}$ & Low risk & $\begin{array}{l}\text { "Patients were allocated randomly to a stocking group or control group by in- } \\
\text { structions in sealed envelopes." }\end{array}$ \\
\hline $\begin{array}{l}\text { Blinding (performance } \\
\text { bias and detection bias) } \\
\text { All outcomes }\end{array}$ & Unclear risk & No mention of blinding \\
\hline $\begin{array}{l}\text { Incomplete outcome data } \\
\text { (attrition bias) } \\
\text { All outcomes }\end{array}$ & Low risk & $3 / 98$ participants were not included in the analysis, but were accounted for. \\
\hline $\begin{array}{l}\text { Selective reporting (re- } \\
\text { porting bias) }\end{array}$ & Low risk & Results of all outcomes were reported. \\
\hline Other bias & Low risk & No other sources of bias identified. \\
\hline
\end{tabular}


Hui 1996

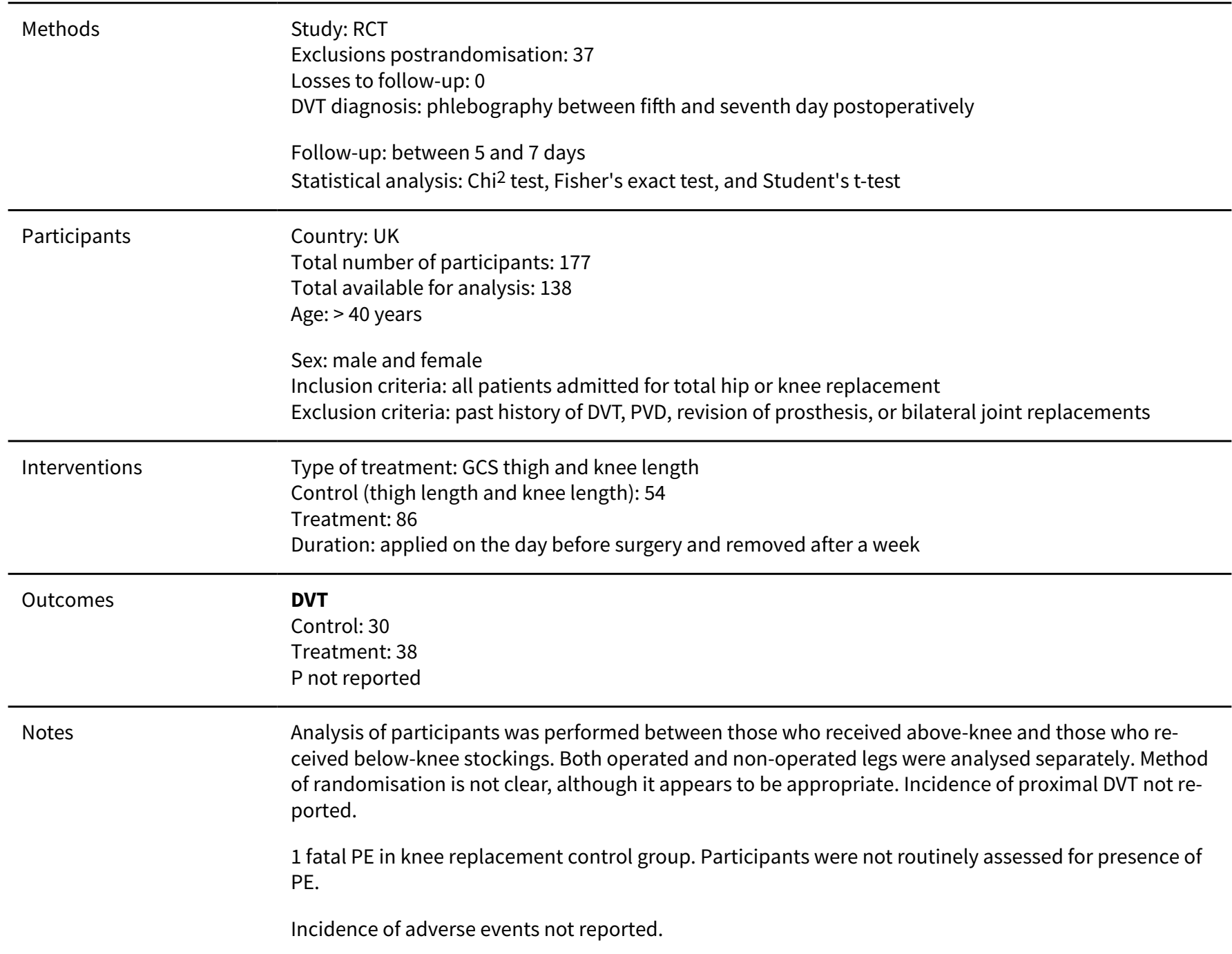

\section{Risk of bias}

\begin{tabular}{|c|c|c|}
\hline Bias & Authors' judgement & Support for judgement \\
\hline $\begin{array}{l}\text { Random sequence genera- } \\
\text { tion (selection bias) }\end{array}$ & Unclear risk & $\begin{array}{l}\text { Method of randomisation not mentioned. Participants were randomised in } \\
\text { a ratio of 1:1 in the thigh-length GCS group and 1:4 in the knee-length GCS } \\
\text { group. }\end{array}$ \\
\hline $\begin{array}{l}\text { Allocation concealment } \\
\text { (selection bias) }\end{array}$ & Unclear risk & Not mentioned \\
\hline $\begin{array}{l}\text { Blinding (performance } \\
\text { bias and detection bias) } \\
\text { All outcomes }\end{array}$ & Unclear risk & Not mentioned \\
\hline
\end{tabular}

Incomplete outcome data Low risk

39/177 participants were not analysed, but were accounted for.

(attrition bias)

All outcomes

Selective reporting (re- Low risk $\quad$ Results of all outcomes were reported.
porting bias) 
Hui 1996 (Continued)

$\begin{array}{ll}\text { Other bias } & \text { Thelear risk } \\ \text { for the knee-length GCS group. Partly funded by Brevet Hospital Products, } \\ \text { which manufactures stockings. }\end{array}$

\section{Kalodiki 1996}

\begin{tabular}{|c|c|}
\hline Methods & $\begin{array}{l}\text { Study: RCT } \\
\text { Exclusion to postrandomisation: } 15 \\
\text { Losses to follow-up: } 0 \\
\text { DVT diagnosis: venography performed on eighth to 12th postoperative day, before discharge. } \\
\text { PE diagnosis: perfusion lung scans performed on the day before surgery and on the eighth to 12th } \\
\text { postoperative day, before discharge. } \\
\text { Follow-up: } 8 \text { to } 10 \text { days for DVT and PE (routinely) } \\
\text { Statistical analysis: Yates' correction }\end{array}$ \\
\hline Participants & $\begin{array}{l}\text { Country: UK } \\
\text { Total number of participants: } 93 \\
\text { Total available for analysis: } 78 \\
\text { Age: > } 40 \text { years } \\
\text { Sex: male and female } \\
\text { Inclusion criteria: patients having unilateral total hip replacement for the first time or without cement } \\
\text { under general anaesthesia } \\
\text { Exclusion criteria: patients with bleeding disorders or bleeding risks, anticoagulant therapy, NSAIDs or } \\
\text { aspirin, cardiovascular disease, renal or hepatic or pancreatic disease, relevant allergies or hypersensi- } \\
\text { tivities }\end{array}$ \\
\hline Interventions & $\begin{array}{l}\text { Type of treatment: GCS thigh length } \\
\text { Additional background thromboprophylaxis: subcutaneous enoxaparin (LMWH) } \\
\text { Control: } 32 \\
\text { Treatment: } 32 \\
\text { Duration: stockings applied on both legs before the operation until discharge. }\end{array}$ \\
\hline Outcomes & $\begin{array}{l}\text { DVT (all) } \\
\text { Control: } 12 \\
\text { Treatment: } 8 \\
\text { P } 0.1 \\
\text { Proximal DVT } \\
\text { Control: } 9 \\
\text { Treatment: } 3^{*} \\
\text { P value: not significant }(0.1>P>0.05) \\
\text { * } 1 \text { additional thrombus in the treatment group was an extension of calf thrombosis. } \\
\text { PE } \\
\text { Control: } 3 / 29 \\
\text { Treatment: } 2 / 31 \\
\text { P value: not significant (value not reported) }\end{array}$ \\
\hline
\end{tabular}

\section{Notes}
All participants in the treatment and control groups had enoxaparin $40 \mathrm{mg} 12$ hours before the opera- tion, and then once daily until discharge.
We excluded an additional group of 14 participants who received no prophylaxis (placebo group) from this review.
Adverse effects: there were no differences in haemorrhagic complications between the 3 groups, and no adverse events were recorded.


Kalodiki 1996 (Continued)

Risk of bias

\begin{tabular}{|c|c|c|}
\hline Bias & Authors' judgement & Support for judgement \\
\hline $\begin{array}{l}\text { Random sequence genera- } \\
\text { tion (selection bias) }\end{array}$ & Low risk & Participants were assigned consecutive numbers. \\
\hline $\begin{array}{l}\text { Allocation concealment } \\
\text { (selection bias) }\end{array}$ & Low risk & Used sealed envelopes \\
\hline $\begin{array}{l}\text { Blinding (performance } \\
\text { bias and detection bias) } \\
\text { All outcomes }\end{array}$ & Low risk & $\begin{array}{l}\text { "Venograms and V/Q scans were reported blindly by an independent panel of } 3 \\
\text { and } 1 \text { radiologist respectively." }\end{array}$ \\
\hline $\begin{array}{l}\text { Incomplete outcome data } \\
\text { (attrition bias) } \\
\text { All outcomes }\end{array}$ & Low risk & $\begin{array}{l}\text { 15/93 participants could not be evaluated because } 10 \text { declined venography } \\
\text { and } 5 \text { did not have it for technical reasons. }\end{array}$ \\
\hline $\begin{array}{l}\text { Selective reporting (re- } \\
\text { porting bias) }\end{array}$ & Low risk & Results of all outcome measures were reported. \\
\hline Other bias & Unclear risk & This study was supported by Rhone-Poulenc Rorer. \\
\hline
\end{tabular}

Kierkegaard 1993

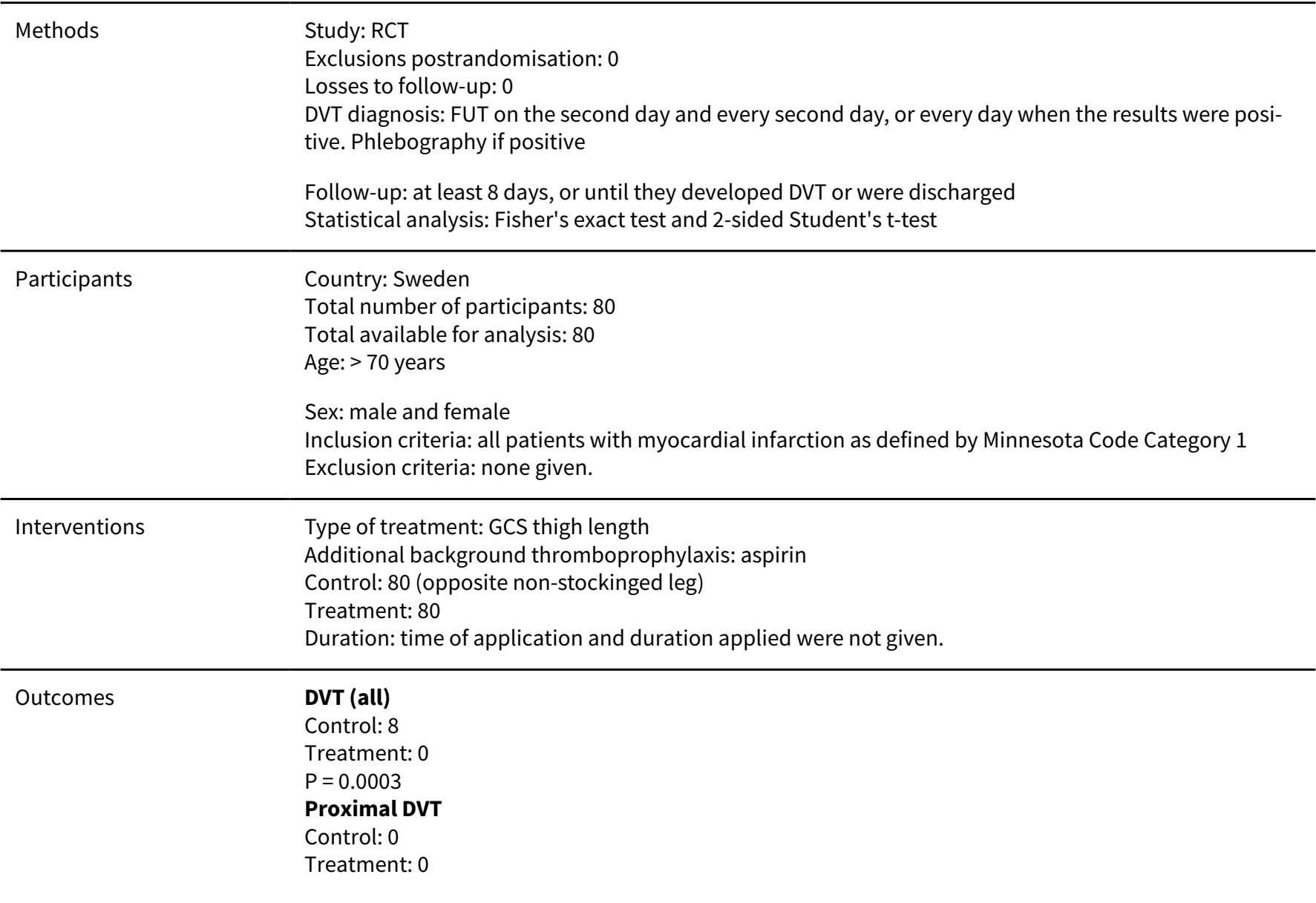


Kierkegaard 1993 (Continued)

\section{Symptomatic DVT}

Control: 0

Treatment: 0

Notes

1 limb was randomised to act as control. Aspirin was used in all participants.

Incidence of PE not mentioned.

Adverse events: postphlebitic changes

Funded by Halmstad Hospital Foundation for Medical Research, the TRYGG-HANSA Foundation for Medical Research, and the Faculty of Medicine, Lund University. Stockings were supplied by The

Kendall Health Products Company, which manufactures stockings.

\section{Risk of bias}

\begin{tabular}{|c|c|c|}
\hline Bias & Authors' judgement & Support for judgement \\
\hline $\begin{array}{l}\text { Random sequence genera- } \\
\text { tion (selection bias) }\end{array}$ & Unclear risk & Method of randomisation not mentioned. \\
\hline $\begin{array}{l}\text { Allocation concealment } \\
\text { (selection bias) }\end{array}$ & Unclear risk & Not mentioned \\
\hline \multirow{2}{*}{$\begin{array}{l}\text { Blinding (performance } \\
\text { bias and detection bias) } \\
\text { All outcomes }\end{array}$} & Low risk & $\begin{array}{l}\text { "Results were calculated without knowledge of which leg had stockings and } \\
\text { which leg developed a positive fibrinogen uptake test." }\end{array}$ \\
\hline & & $\begin{array}{l}\text { Comment: researchers were blinded to the treatment group while calculating } \\
\text { results, however insufficient detail was available to ascertain whether asses- } \\
\text { sors were blinded at the time of FUT or phlebography, or both. }\end{array}$ \\
\hline $\begin{array}{l}\text { Incomplete outcome data } \\
\text { (attrition bias) } \\
\text { All outcomes }\end{array}$ & Low risk & All 80 participants were accounted for and analysed. \\
\hline $\begin{array}{l}\text { Selective reporting (re- } \\
\text { porting bias) }\end{array}$ & Low risk & Results for all outcome measures were reported. \\
\hline Other bias & Low risk & No other sources of bias identified. \\
\hline
\end{tabular}

\section{Mellbring 1986}

$\begin{array}{ll}\text { Methods } & \text { Study: RCT } \\ & \text { Exclusions postrandomisation: } 6 \\ & \text { Losses to follow-up: } \\ & \text { DVT diagnosis: } 125 \text { fibrinogen test preoperatively, then } 1,3,5,7 \text {, and } 9 \text { days } \\ & \text { Follow-up: } 9 \text { days, or until hospitalisation ended } \\ & \text { Statistical analysis: Chi2 test with Yates' correction and Mann-Whitney U test } \\ & \text { Country: Sweden } \\ & \text { Total number of participants: } 114 \text { participants (1 leg from each participant randomised to GCS) } \\ & \text { Total available for analysis: } 108 \text { participants (216 legs) } \\ & \text { Age: }>50 \text { years } \\ \text { Participants } & \text { Sex: male and female } \\ \text { Inclusion criteria: patients }>50 \text { years undergoing surgery for benign or malignant abdominal disease }\end{array}$


Mellbring 1986 (Continued)

Exclusion criteria: patients with iodine hypersensitivity, on anticoagulant therapy, or with signs or symptoms of arterial insufficiency, advanced angina pectoris, or preoperatively immobile

\begin{tabular}{ll}
\hline Interventions & Type of treatment: thigh-length stockings \\
& Additional background thromboprophylaxis: dihydroergotamine + low-dose heparin (DHE-LDH) or in- \\
termittent pneumatic calf compression (IPCC) & Control: 108 \\
Treatment: 108 \\
Duration: applied before surgery and worn until the participant was fully mobilised
\end{tabular}

\begin{tabular}{ll}
\hline Outcomes & DVT (all) \\
Control: 8 & Treatment: 8 \\
P not reported & Proximal DVT \\
Control: unclear & Treatment: unclear \\
& Symptomatic DVT \\
Control: unclear & Treatment: unclear \\
& PE \\
& Control: not assessed \\
& Treatment: not assessed
\end{tabular}

Notes

This study was primarily designed to compare the efficacy of DHE-LDH against IPCC, and participants were therefore randomised to either the DHE-LDH arm or the IPCC arm. Individual legs were randomised to either the GCS or the no-GCS arm, as a secondary study.

\section{Risk of bias}

\begin{tabular}{|c|c|c|}
\hline Bias & Authors' judgement & Support for judgement \\
\hline $\begin{array}{l}\text { Random sequence genera- } \\
\text { tion (selection bias) }\end{array}$ & Unclear risk & Method of randomisation not mentioned. \\
\hline $\begin{array}{l}\text { Allocation concealment } \\
\text { (selection bias) }\end{array}$ & Low risk & Sealed envelope \\
\hline $\begin{array}{l}\text { Blinding (performance } \\
\text { bias and detection bias) } \\
\text { All outcomes }\end{array}$ & Unclear risk & Not reported \\
\hline $\begin{array}{l}\text { Incomplete outcome data } \\
\text { (attrition bias) } \\
\text { All outcomes }\end{array}$ & Low risk & $\begin{array}{l}\text { None. Outcomes for the } 6 \text { participants who were excluded postrandomisation } \\
\text { were reported. } 2 \text { received dextran postoperatively; } 2 \text { did not eventually receive } \\
\text { IPCC; } 1 \text { received heparin postoperatively; and FUT was unsatisfactory in } 1 \text { fur- } \\
\text { ther participant. Outcome data for the remaining } 54 \text { participants (108 legs) } \\
\text { were reported. }\end{array}$ \\
\hline $\begin{array}{l}\text { Selective reporting (re- } \\
\text { porting bias) }\end{array}$ & Low risk & Results for all outcome measures were reported. \\
\hline Other bias & Low risk & No other sources of bias identified. \\
\hline
\end{tabular}


Ohlund 1983

\begin{tabular}{|c|c|}
\hline Methods & $\begin{array}{l}\text { Study: RCT } \\
\text { Exclusion to postrandomisation: } 1 \\
\text { Losses to follow-up: } 0 \\
\text { DVT diagnosis: FUT every day for } 10 \text { days } \\
\text { Follow-up: } 10 \text { days } \\
\text { Statistical analysis: Student's t-test }\end{array}$ \\
\hline Participants & $\begin{array}{l}\text { Country: Sweden } \\
\text { Total number of participants: } 63 \\
\text { Total available for analysis: } 62 \\
\text { Age: > } 50 \text { years } \\
\text { Sex: male and female } \\
\text { Inclusion criteria: all patients admitted for elective hip arthroplasty } \\
\text { Exclusion criteria: none mentioned. }\end{array}$ \\
\hline Interventions & $\begin{array}{l}\text { Type of treatment: GCS length not stated. } \\
\text { Additional background thromboprophylaxis: dextran } 70 \\
\text { Control: } 31 \\
\text { Treatment: } 31 \\
\text { Duration: not mentioned }\end{array}$ \\
\hline Outcomes & $\begin{array}{l}\text { DVT } \\
\text { Control: } 15 \\
\text { Treatment: } 7 \\
\mathrm{P}<0.05\end{array}$ \\
\hline Notes & $\begin{array}{l}\text { All had dextran } 70 \text { infusion at induction of anaesthesia and } 2 \text { days following operation. Dose: } 500 \mathrm{~mL} \\
\text { per day } \\
\text { Incidence of proximal DVT not reported. } \\
\text { Incidence of PE and adverse events not mentioned. } \\
\text { Stockings were supplied by AKLA AB. }\end{array}$ \\
\hline
\end{tabular}

\section{Risk of bias}

\begin{tabular}{lll}
\hline Bias & Authors' judgement & Support for judgement \\
\hline $\begin{array}{l}\text { Random sequence genera- } \\
\text { tion (selection bias) }\end{array}$ & Unclear risk & Method of randomisation not mentioned. \\
\hline $\begin{array}{l}\text { Allocation concealment } \\
\text { (selection bias) }\end{array}$ & Unclear risk & Not mentioned \\
\hline $\begin{array}{l}\text { Blinding (performance } \\
\text { bias and detection bias) } \\
\text { All outcomes }\end{array}$ & Unclear risk & Not mentioned \\
\hline
\end{tabular}

Incomplete outcome data Low risk $\quad$ 1/63 participants was not analysed, but was accounted for.

(attrition bias)

All outcomes

Selective reporting (re- Low risk $\quad$ Results of all outcome measures were reported.
porting bias)

Other bias Low risk No other sources of bias identified.




\begin{tabular}{|c|c|}
\hline Methods & $\begin{array}{l}\text { Study: RCT } \\
\text { Exclusion to postrandomisation: } 5 \\
\text { Losses to follow-up: } 0 \\
\text { DVT diagnosis: FUT on first, second, third, fifth, and seventh postoperative days } \\
\text { Follow-up: } 7 \text { days } \\
\text { Statistical analysis: Fisher's exact test }\end{array}$ \\
\hline Participants & $\begin{array}{l}\text { Country: UK } \\
\text { Total number of participants: } 75 \\
\text { Total available for analysis: } 70 \\
\text { Age: }>42 \text { years } \\
\text { Sex: male and female } \\
\text { Inclusion criteria: all patients admitted for major abdominal surgery } \\
\text { Exclusion criteria: none mentioned. }\end{array}$ \\
\hline Interventions & $\begin{array}{l}\text { Type of treatment: GCS thigh length } \\
\text { Control: } 70 \text { ( } 32 \text { right leg, } 38 \text { left leg) } \\
\text { Treatment: } 70 \text { (38 right leg, } 32 \text { left leg) } \\
\text { Duration: wore the stockings on the evening before the operation until the ninth postoperative day }\end{array}$ \\
\hline Outcomes & $\begin{array}{l}\text { DVT } \\
\text { Control: } 26 \\
\text { Treatment: } 8 \\
P<0.0003\end{array}$ \\
\hline Notes & $\begin{array}{l}\text { Incidences of proximal DVT, PE, and adverse events were not mentioned. } \\
\text { Stockings were supplied by The Kendall Company. }\end{array}$ \\
\hline
\end{tabular}

\section{Risk of bias}

\begin{tabular}{|c|c|c|}
\hline Bias & Authors' judgement & Support for judgement \\
\hline $\begin{array}{l}\text { Random sequence genera- } \\
\text { tion (selection bias) }\end{array}$ & Low risk & By "tossing a coin" \\
\hline $\begin{array}{l}\text { Allocation concealment } \\
\text { (selection bias) }\end{array}$ & Unclear risk & Not mentioned \\
\hline $\begin{array}{l}\text { Blinding (performance } \\
\text { bias and detection bias) } \\
\text { All outcomes }\end{array}$ & Unclear risk & Not mentioned \\
\hline $\begin{array}{l}\text { Incomplete outcome data } \\
\text { (attrition bias) } \\
\text { All outcomes }\end{array}$ & Low risk & 5/75 participants were not analysed, but were accounted for. \\
\hline $\begin{array}{l}\text { Selective reporting (re- } \\
\text { porting bias) }\end{array}$ & Low risk & Results of all outcome measures were reported. \\
\hline Other bias & Low risk & No other sources of bias identified. \\
\hline
\end{tabular}




\begin{tabular}{|c|c|}
\hline Methods & $\begin{array}{l}\text { Study: RCT } \\
\text { Exclusions postrandomisation: } 0 \\
\text { Losses to follow-up: } 0 \\
\text { DVT diagnosis: FUT on first, third, fifth, and seventh postoperative day and phlebography if FUT was } \\
\text { positive } \\
\text { Follow-up: } 7 \text { days } \\
\text { Statistical analysis: McNemar's exact test }\end{array}$ \\
\hline Participants & $\begin{array}{l}\text { Country: UK } \\
\text { Total number of participants: } 78 \\
\text { Total available for analysis: } 78 \\
\text { Age: }>43 \text { years } \\
\text { Sex: male and female } \\
\text { Inclusion criteria: all patients admitted for abdominal operations } \\
\text { Exclusion criteria: anyone with preoperative evidence of DVT on Doppler ultrasound and strain-gauge } \\
\text { plethysmography methods }\end{array}$ \\
\hline Interventions & $\begin{array}{l}\text { Type of treatment: GCS thigh length } \\
\text { Additional background thromboprophylaxis: sequential compression device } \\
\text { Control: } 78 \text { (legs, sequential compression device only) } \\
\text { Treatment: } 78 \text { (legs, sequential compression device and GCS) } \\
\text { Duration: until ambulatory }\end{array}$ \\
\hline Outcomes & $\begin{array}{l}\text { DVT } \\
\text { Control: } 7 \\
\text { Treatment: } 1 \\
\text { P<0.016 } \\
\text { Proximal DVT } \\
\text { Control: } 0 \\
\text { Treatment: } 0 \\
\text { PE } \\
\text { Control: } 0 \\
\text { Treatment: } 0\end{array}$ \\
\hline Notes & $\begin{array}{l}\text { Left and right legs were randomised to receive either treatment or control. The control group only had } \\
\text { a sequential compression device fitted on the day of the operation. The treatment group had both GCS } \\
\text { and sequential compression devices fitted. } \\
\text { Incidence of symptomatic DVT not reported. } \\
\text { Incidence of adverse events was not mentioned. All participants wore stockings for the whole study pe- } \\
\text { riod. }\end{array}$ \\
\hline
\end{tabular}

\section{Risk of bias}

\begin{tabular}{lll}
\hline Bias & Authors' judgement & Support for judgement \\
\hline $\begin{array}{l}\text { Random sequence genera- } \\
\text { tion (selection bias) }\end{array}$ & Unclear risk & Method of randomisation not mentioned. \\
\hline $\begin{array}{l}\text { Allocation concealment } \\
\text { (selection bias) }\end{array}$ & Unclear risk & Not mentioned \\
\hline $\begin{array}{l}\text { Blinding (performance } \\
\text { bias and detection bias) }\end{array}$ & Unclear risk & Not mentioned \\
\hline
\end{tabular}


Scurr 1987 (Continued)

All outcomes

Incomplete outcome data Low risk All 78 participants were accounted for.
(attrition bias)

All outcomes

\begin{tabular}{lll}
\hline $\begin{array}{l}\text { Selective reporting (re- } \\
\text { porting bias) }\end{array}$ & Low risk & Results of all outcome measures were reported. \\
\hline Other bias & Unclear risk & The study was supported in part by the Kendall Research Center. \\
\hline
\end{tabular}

\section{Shirai 1985}

\begin{tabular}{ll}
\hline Methods & Study: RCT \\
& Losses to follow-up: not reported \\
& DVT diagnosis: FUT and measurement of leg diameter preoperatively, immediately after surgery, and \\
& on postoperative days $1,3,5$, and 7 \\
& Follow-up: 7 days \\
Statistical analysis: unknown
\end{tabular}

\begin{tabular}{ll}
\hline Participants & Country: Japan \\
& Total number of participants: 126 \\
& Total available for analysis: 126 \\
& Age: 18 to 81 years (mean 54.8 years) \\
& Sex: male and female \\
& Inclusion criteria: heart surgery and vein surgery patients \\
& Exclusion criteria: complications with swellings on the veins of the legs and previous history of venous \\
& thrombosis in the legs \\
\hline Interventions & Type of treatment: thigh-length GCS \\
& Control: 126 (legs with stockings) \\
& Treatment: 126 (legs without stockings) \\
& Duration: not mentioned \\
& DVT \\
Outcomes & Control: 17 \\
& Preatment: 5 \\
& This trial was published in Japanese, which made accurate extraction of information about methodolo- \\
gy difficult.
\end{tabular}

\section{Risk of bias}

\begin{tabular}{lll}
\hline Bias & Authors' judgement & Support for judgement \\
\hline $\begin{array}{l}\text { Random sequence genera- } \\
\text { tion (selection bias) }\end{array}$ & Unclear risk & Method of randomisation not stated. \\
\hline $\begin{array}{l}\text { Allocation concealment } \\
\text { (selection bias) }\end{array}$ & Unclear risk & Method of allocation concealment was not stated. \\
\hline $\begin{array}{l}\text { Blinding (performance } \\
\text { bias and detection bias) }\end{array}$ & Unclear risk & No mention of blinding \\
& &
\end{tabular}


Shirai 1985 (Continued)

All outcomes

\begin{tabular}{lll}
\hline $\begin{array}{l}\text { Incomplete outcome data } \\
\text { (attrition bias) } \\
\text { All outcomes }\end{array}$ & Unclear risk & Japanese study, difficult to determine \\
\hline $\begin{array}{l}\text { Selective reporting (re- } \\
\text { porting bias) }\end{array}$ & Unclear risk & Japanese study, difficult to determine \\
\hline Other bias & Unclear risk & Japanese study, difficult to determine \\
\hline
\end{tabular}

\section{Torngren 1980}

\begin{tabular}{ll}
\hline Methods & Study: RCT \\
Exclusions postrandomisation: 12 \\
Losses to follow-up: 0 \\
DVT diagnosis: FUT started the day before the operation up to the seventh day \\
Follow-up: 7 days \\
Statistical analysis: sign test
\end{tabular}

\begin{tabular}{ll}
\hline Participants & Country: Sweden \\
& Total number of participants: 110 \\
& Total available for analysis: 98 \\
& Age: $>42$ years \\
& Sex: male and female \\
Inclusion criteria: all patients admitted for major abdominal operation \\
Exclusion criteria: those positive for preoperative FUT \\
Type of treatment: GCS thigh length \\
Additional background thromboprophylaxis: subcutaneous heparin sodium (UFH) \\
Control: 98 \\
Treatment: 98 \\
Duration: GCS applied the day of the operation and continued up to sixth postoperative day. \\
DVT \\
Control: 12 \\
Treatment: 4 \\
P $<0.004$ \\
Incidence of proximal DVT not reported. \\
Incidence of PE was not routinely assessed. \\
\hline \multirow{2}{*}{ Outcomes }
\end{tabular}

Notes All participants received heparin $5000 \mathrm{IU} 12$ hourly.

No participants developed fatal PE or reported side effects. However, bleeding complications were reported, likely associated with the use of heparin.

Study supported by Karolinska Institutet, Stockholm.

\section{Risk of bias}

\begin{tabular}{lll} 
Bias & Authors' judgement & Support for judgement \\
\hline $\begin{array}{l}\text { Random sequence genera- } \\
\text { tion (selection bias) }\end{array}$ & High risk & $\begin{array}{l}\text { Randomisation was achieved "...depending on the date of birth of the pa- } \\
\text { tient". }\end{array}$
\end{tabular}


Torngren 1980 (Continued)

\begin{tabular}{lll}
$\begin{array}{l}\text { Allocation concealment } \\
\text { (selection bias) }\end{array}$ & Unclear risk & Not mentioned \\
\hline $\begin{array}{l}\text { Blinding (performance } \\
\text { bias and detection bias) } \\
\text { All outcomes }\end{array}$ & Unclear risk & Not mentioned \\
\hline
\end{tabular}

Incomplete outcome data Low risk
(attrition bias)

All outcomes

Selective reporting (re- Low risk $\quad$ Frequency of DVT in both groups was reported.
porting bias)

\begin{tabular}{ll}
\hline Other bias $\quad$ Low risk $\quad$ No other sources of bias identified. \\
\hline
\end{tabular}

Tsapogas 1971

$\begin{array}{ll}\text { Methods } & \text { Study: RCT } \\ & \text { Exclusions postrandomisation: } 0 \\ & \text { Losses to follow-up: } 0 \\ & \text { DVT diagnosis: Initially, FUT on first, third, fifth, and seventh day. Phlebography at the end of } 1 \text { week } \\ \text { postoperatively for all participants (including those with previously negative FUT) } \\ \text { Follow-up: } 7 \text { days } \\ \text { Statistical analysis: not given }\end{array}$

\begin{tabular}{ll}
\hline Participants & Country: USA \\
& Total number of participants: 95 \\
& Total available for analysis: 95 \\
& Age: $>40$ years \\
& Sex: male and female \\
& Inclusion criteria: all major abdominal surgery and those who were negative to preoperative phlebog- \\
& raphy \\
& Exclusion criteria: lower limb operations, thyroid diseases \\
\hline Interventions & Type of treatment: GCS thigh length \\
& Control: 44 \\
& Treatment: 51 \\
& Duration: stockings worn on the day of surgery until discharge \\
\hline Outcomes & DVT \\
Control: 6 \\
Treatment: 2 \\
P not reported \\
\hline
\end{tabular}

2 of 6 participants who developed DVT in the control arm were noted as developing clinical signs of DVT.

1 participant developed a proximal DVT, however group allocation for this participant was not reported.

Incidences of PE and adverse events were not mentioned. Participants were not routinely assessed for presence of $P E$. 
Tsapogas 1971 (Continued)

Risk of bias

\begin{tabular}{|c|c|c|}
\hline Bias & Authors' judgement & Support for judgement \\
\hline $\begin{array}{l}\text { Random sequence genera- } \\
\text { tion (selection bias) }\end{array}$ & Low risk & By a random allocation table \\
\hline $\begin{array}{l}\text { Allocation concealment } \\
\text { (selection bias) }\end{array}$ & Unclear risk & $\begin{array}{l}\text { Not mentioned. However, there was a discrepancy between the number of } \\
\text { participants randomised to the treatment and control groups. }\end{array}$ \\
\hline $\begin{array}{l}\text { Blinding (performance } \\
\text { bias and detection bias) } \\
\text { All outcomes }\end{array}$ & Unclear risk & Not mentioned \\
\hline $\begin{array}{l}\text { Incomplete outcome data } \\
\text { (attrition bias) } \\
\text { All outcomes }\end{array}$ & Low risk & All 95 participants were accounted for and analysed. \\
\hline $\begin{array}{l}\text { Selective reporting (re- } \\
\text { porting bias) }\end{array}$ & Low risk & Results of all outcome measures were reported. \\
\hline Other bias & Unclear risk & $\begin{array}{l}\text { In addition to receiving stockings, participants in the treatment group were } \\
\text { given extra recommendations regarding exercise that were not given to partic- } \\
\text { ipants in the control group. }\end{array}$ \\
\hline
\end{tabular}

Turner 1984

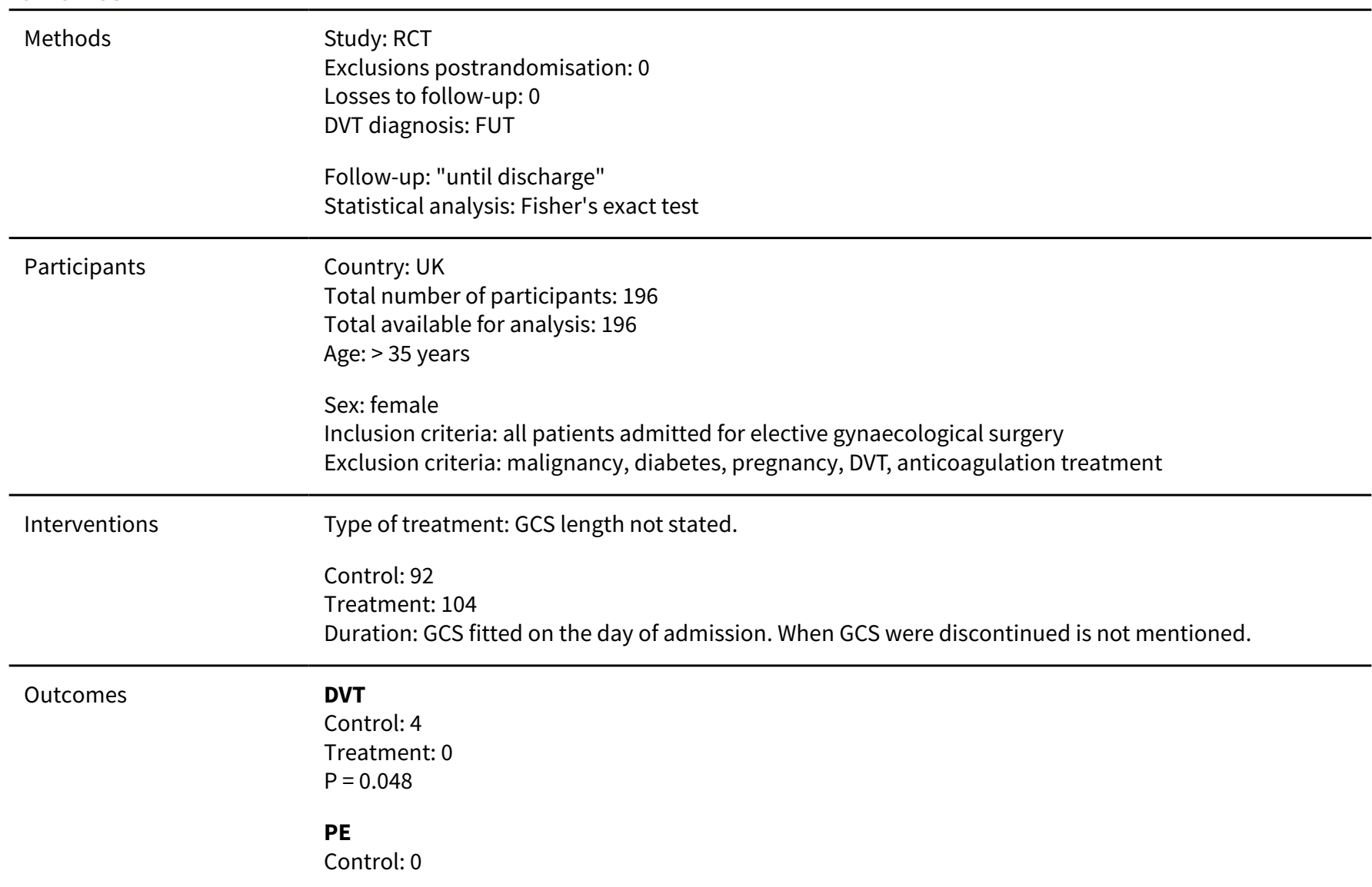


Turner 1984 (Continued)

\section{Treatment: 0}

Stated as randomised, however method not made explicit. Losses to follow-up or loss to randomisation not explicit.

Incidence of proximal DVT was not reported.

Method of diagnosis of PE was not reported.

No adverse events were mentioned, and stockings were acceptable to participants, the only adverse comment being that the stockings were hot.

Stockings were supplied by The Kendall Company.

\title{
Risk of bias
}

\begin{tabular}{lll}
\hline Bias & Authors' judgement & Support for judgement \\
\hline $\begin{array}{l}\text { Random sequence genera- } \\
\text { tion (selection bias) }\end{array}$ & Low risk & Random number chart was used. \\
\hline $\begin{array}{l}\text { Allocation concealment } \\
\text { (selection bias) }\end{array}$ & Unclear risk & Not mentioned \\
\hline $\begin{array}{l}\text { Blinding (performance } \\
\text { bias and detection bias) } \\
\text { All outcomes }\end{array}$ & Low risk & "The scans were assessed blindly" \\
\hline $\begin{array}{l}\text { Incomplete outcome data } \\
\text { (attrition bias) } \\
\text { All outcomes }\end{array}$ & Low risk & All 196 participants who entered the study were analysed and accounted for. \\
\hline $\begin{array}{l}\text { Selective reporting (re- } \\
\text { porting bias) }\end{array}$ & Low risk & Results of all outcome measures were reported. \\
\hline \begin{tabular}{l} 
Other bias \\
\hline
\end{tabular} & Low risk & No other sources of bias were identified. \\
\hline
\end{tabular}

Turpie 1989

$\begin{array}{ll}\text { Methods } & \text { Study: RCT } \\ & \text { Exclusions postrandomisation: } 0 \\ & \text { Losses to follow-up: } 0 \\ & \text { DVT diagnosis: FUT daily for } 14 \text { days or until discharge. Impedance plethysmography before study and } \\ & \text { day 3, 5, 7, } 9,11 \text { and } 14 \text { days or on the day of discharge. If FUT or IPG was abnormal, phlebogram was } \\ \text { carried out. } & \\ & \text { Follow-up: } 14 \text { days or until discharge (if earlier) } \\ \text { Statistical analysis: Fisher's exact or 1-sided Chi } 2\end{array}$

\section{Participants}

\author{
Country: USA \\ Total number of participants: 239 \\ Total available for analysis: 239 \\ Age: $>16$ years
}

Sex: male and female

Inclusion criteria: all patients with head or spinal pathology including trauma 
Turpie 1989 (Continued)

Exclusion criteria: history of iodine allergy, trauma to legs, mild head injury that needed only 24-hour surgery, those that needed anticoagulant treatment, or initial abnormal IPG

\begin{tabular}{ll}
\hline Interventions & Type of treatment: GCS thigh length (1 participant had knee length because of obesity) \\
Control: 81 \\
Treatment: 80 \\
Duration: applied 12 hours before surgery, and removed after participant fully mobile (4 to 5 days lat- \\
er). Participants encouraged to mobilise early. \\
\hline DVT (all) \\
Control: 16 \\
Treatment: 7 \\
P 0.023 \\
Proximal DVT \\
Control: 2 \\
Treatment: 1 \\
P not reported \\
Losses to follow-up: 1 unavailable for follow-up and 19 deaths during the follow-up period (none due to \\
PE). It is not explicit if these participants were included in or excluded from the study. \\
1 participant developed PE. \\
Source of funding not stated. \\
\hline Notes
\end{tabular}

\section{Risk of bias}

\begin{tabular}{|c|c|c|}
\hline Bias & Authors' judgement & Support for judgement \\
\hline $\begin{array}{l}\text { Random sequence genera- } \\
\text { tion (selection bias) }\end{array}$ & Unclear risk & By "...a prescribed randomised arrangement" \\
\hline $\begin{array}{l}\text { Allocation concealment } \\
\text { (selection bias) }\end{array}$ & Low risk & "Using sealed envelopes" \\
\hline $\begin{array}{l}\text { Blinding (performance } \\
\text { bias and detection bias) } \\
\text { All outcomes }\end{array}$ & Low risk & $\begin{array}{l}\text { "The results of the tests were interpreted independently by a panel of experts } \\
\text { blinded to the patient's treatment group." }\end{array}$ \\
\hline $\begin{array}{l}\text { Incomplete outcome data } \\
\text { (attrition bias) } \\
\text { All outcomes }\end{array}$ & Low risk & All 236 participants accounted for. \\
\hline $\begin{array}{l}\text { Selective reporting (re- } \\
\text { porting bias) }\end{array}$ & Low risk & Results of all outcomes measures were reported. \\
\hline Other bias & Low risk & No other sources of bias identified. \\
\hline
\end{tabular}

$\begin{array}{ll}\text { Methods } & \text { Study: RCT } \\ & \text { Exclusions postrandomisation: } 20 \\ & \text { Losses to follow-up: } 0 \\ & \text { DVT diagnosis: FUT preoperatively and on first, third, fifth, and seventh day postoperatively. Those } \\ & \text { who are FUT positive also had phlebography and perfusion lung scan. }\end{array}$


Wille-Jorgensen 1985 (Continued)

Follow-up: 7 days postoperatively for DVT, participants with suspected DVT also had V/Q scan at this time, follow-up for death at 30 days. 64 participants were observed for a median of 7 days due to early discharge (60), removing stockings early (2), or death (2).

Statistical analysis: Mann-Whitney $\mathrm{U}$ test

\begin{tabular}{ll}
\hline Participants & Country: Denmark \\
& Total number of participants: 196 \\
& Total available for analysis: 176 \\
& Age: $>39$ years \\
& Sex: male and female \\
Inclusion criteria: all patients for abdominal surgery \\
Exclusion criteria: those with hepatic diseases with coagulation defects, anticoagulant treatment, PAD, \\
and allergy to iodine \\
Treatment: GCS thigh length \\
Additional background thromboprophylaxis: UFH \\
Control: 90 \\
Treatment: 86 \\
Duration: GCS were fitted on the day of surgery and continued for 7 days or until discharge. \\
Interventions \\
DVT \\
Control: 7 \\
Treatment: 1 \\
P 0.05 \\
PE \\
Control: 6 \\
Treatment: 2 \\
P value: not significant (value not reported)
\end{tabular}

Notes

Heparin $5000 \mathrm{IU}$ was given to all participants every 12 hourly for 7 days or until discharge. Thromboembolic complications are not clear.

Incidence of proximal DVT not reported.

No mention of adverse events

Novo Diagnostics supplied heparin and thrombograph, and Kendall supplied the stockings.

\section{Risk of bias}

\begin{tabular}{|c|c|c|}
\hline Bias & Authors' judgement & Support for judgement \\
\hline $\begin{array}{l}\text { Random sequence genera- } \\
\text { tion (selection bias) }\end{array}$ & Low risk & "by random numbers" \\
\hline $\begin{array}{l}\text { Allocation concealment } \\
\text { (selection bias) }\end{array}$ & Unclear risk & Not mentioned \\
\hline $\begin{array}{l}\text { Blinding (performance } \\
\text { bias and detection bias) } \\
\text { All outcomes }\end{array}$ & Low risk & $\begin{array}{l}\text { "Phlebogram evaluated by radiologist not aware of the patient's treatment } \\
\text { group" and scintigraphy "read blindly" }\end{array}$ \\
\hline $\begin{array}{l}\text { Incomplete outcome data } \\
\text { (attrition bias) } \\
\text { All outcomes }\end{array}$ & Low risk & 20/196 participants withdrew, but all were accounted for. \\
\hline $\begin{array}{l}\text { Selective reporting (re- } \\
\text { porting bias) }\end{array}$ & Low risk & Results of all outcome measures were addressed. \\
\hline
\end{tabular}


Wille-Jorgensen 1985 (Continued)
Other bias
Low risk
No other sources of bias identified.

Wille-Jorgensen 1991

Study: RCT
Exclusions postrandomisation: 31
Losses to follow-up: 0
DVT diagnosis: FUT on the first, third, fifth, and seventh postoperative days and phlebography as indi-
cated
Follow-up: screened for DVT at 7 days, then monitored for death due to fatal PE at 30 days
Statistical analysis: Kruskal-Wallis test, Chi2 test, and Mantel-Haenszel test
Country: Denmark
Total number of participants: 276
Total available for analysis: 245
Age: $>39$
Participants
Sex: male and female
Inclusion criteria: all patients admitted for abdominal operations lasting over 1 hour
Exclusion criteria: allergy to iodine, dextran. Severe peripheral vascular disease, pregnancy, GI bleed-
ing

\begin{tabular}{ll}
\hline Interventions & Type of treatment: GCS length not stated. \\
Additional background thromboprophylaxis: UFH \\
Control: 81 \\
Treatment: 79 \\
Duration: worn until full mobilisation
\end{tabular}

\begin{tabular}{|c|c|}
\hline Outcomes & $\begin{array}{l}\text { DVT } \\
\text { Control: } 12 \\
\text { Treatment: } 2 \\
P<0.013\end{array}$ \\
\hline \multirow[t]{4}{*}{ Notes } & $\begin{array}{l}\text { On a background of heparin } 5000 \text { IU prophylaxis. } 1 \text { group received dextran and GCS, which we have ex } \\
\text { cluded from our analysis. }\end{array}$ \\
\hline & Incidence of proximal DVT was not reported. \\
\hline & $\begin{array}{l}\text { Participants were not routinely assessed for PE. } 1 \text { participant in the treatment group developed a fatal } \\
\text { PE on the 14th postoperative day, however this participant had been excluded from the study on the } \\
\text { second postoperative day due to poor compliance. }\end{array}$ \\
\hline & $\begin{array}{l}\text { Adverse events: bleeding complications, likely associated with heparin. No complications associated } \\
\text { with the use of GCS were reported. }\end{array}$ \\
\hline
\end{tabular}

Risk of bias

\begin{tabular}{lll}
\hline Bias & Authors' judgement & Support for judgement \\
\hline $\begin{array}{l}\text { Random sequence genera- } \\
\text { tion (selection bias) }\end{array}$ & Low risk & "continuous random numbers" \\
\hline $\begin{array}{l}\text { Allocation concealment } \\
\text { (selection bias) }\end{array}$ & Low risk & Sealed envelopes were used. \\
\hline
\end{tabular}


Wille-Jorgensen 1991 (Continued)
Blinding (performance
Unclear risk
Not mentioned
bias and detection bias)
All outcomes

\begin{tabular}{lll}
\hline $\begin{array}{l}\text { Incomplete outcome data } \\
\text { (attrition bias) } \\
\text { All outcomes }\end{array}$ & Low risk & 31 participants withdrew, but all were accounted for. \\
\hline $\begin{array}{l}\text { Selective reporting (re- } \\
\text { porting bias) }\end{array}$ & Low risk & Results of all outcome measures were reported. \\
\hline Other bias & Unclear risk & $\begin{array}{l}\text { Supported in part by grants from Novo A/S, Kabi Vitrum A/S, and The Kendall } \\
\text { Company }\end{array}$ \\
\hline
\end{tabular}

BMI: body mass index

CVI: chronic venous insufficiency

DHE-LDH: dihydroergotamine + low-dose heparin

DVT: deep vein thrombosis

FUT: 125 fibrinogen uptake test. A sustained difference of more than $20 \%$ between consecutive or opposite points or a raising count were considered diagnostic of DVT.

GCS: graduated compression stockings (also known as thrombo-embolic deterrent (TED) stockings). Compression is graduated, $18 \mathrm{mmHg}$, $14 \mathrm{mmHg}, 8 \mathrm{mmHg}, 10 \mathrm{mmHg}$, and $8 \mathrm{mmHg}$ from ankle to upper thigh.

$\mathrm{GI}$ : gastrointestinal

IPC: intermittent pneumatic compression device

IPCC: intermittent pneumatic calf compression

IPG: impedance plethysmography

IU: international units

LMWH: low molecular weight heparin

NSAIDs: non-steroidal anti-inflammatory drugs

PAD: peripheral arterial disease

PE: pulmonary embolism

PVD: peripheral vascular disease

$\mathrm{RCT}$ : randomised controlled trial

UFH: unfractionated heparin

V/Q: ventilation/perfusion

VTE: venous thromboembolism

Characteristics of excluded studies [ordered by study ID]

\begin{tabular}{ll}
\hline Study & Reason for exclusion \\
\hline Ayhan 2013 & $\begin{array}{l}\text { Lacks appropriate control group. Compares the following groups of patients: low-pressure knee- } \\
\text { length stockings, low-pressure thigh-length stockings, and moderate-pressure knee-length stock- } \\
\text { ings }\end{array}$ \\
\hline Barinov 2014 & $\begin{array}{l}\text { Lacks appropriate control arm. Compared low- vs moderate-pressure GCS, and knee-length vs } \\
\text { thigh-length GCS }\end{array}$ \\
\hline Belcaro 1993 & $\begin{array}{l}\text { Unclear whether participants were hospitalised, therefore study did not meet our inclusion crite- } \\
\text { ria. Focused on patients with recurrent DVTs, including those with chronic DVT. Method of randomi- } \\
\text { sation unclear. Reasons for dropouts unclear. The duration that stockings were worn is not men- } \\
\text { tioned. Method of monitoring the occurrence of DVT in the study is unclear. }\end{array}$ \\
\hline Bolton 1978 & $\begin{array}{l}\text { Not randomised and not published as a paper. High-risk group of patients were involved (malig- } \\
\text { nant diseases). A significant reduction in DVT was noted in the treatment group compared with the } \\
\text { control group. The method of analysis seems appropriate. }\end{array}$
\end{tabular}




\begin{tabular}{ll}
\hline Study & Reason for exclusion \\
\hline Brunkwall 1991 & $\begin{array}{l}\text { Not published as a full paper. Abstract does not mention number of legs in each group (transplant- } \\
\text { ed side versus non-transplanted side). }\end{array}$ \\
\hline Caprini 1983 & Control group is retrospective. \\
\hline Chandhoke 1991 & $\begin{array}{l}\text { Lacks appropriate control group. Compares patients given warfarin (Coumadin) only to those given } \\
\text { compression stockings only }\end{array}$ \\
\hline CLOTS 2009 & $\begin{array}{l}\text { Included only stroke patients } \\
\text { Cohen } 2007\end{array}$ \\
$\begin{array}{l}\text { Proximal asymptomatic DVT was diagnosed using venography, however it was unclear whether } \\
\text { symptomatic DVT was also confirmed objectively using this method, and whether this was stan- } \\
\text { dardised throughout the study. It appears that some participants were scanned using ultrasound } \\
\text { and some using venography. If this was the case, the split between the two methodologies is un- } \\
\text { clear. Furthermore, participants with asymptomatic DVT seem only to have been assessed proxi- } \\
\text { mally; it was unclear whether they were also examined for more distal DVTs. It was not clear which } \\
\text { veins were examined for proximal DVTs and whether this was standardised throughout the study. } \\
\text { We contacted the authors seeking clarification, however these queries remained unanswered at } \\
\text { the time of publication. }\end{array}$
\end{tabular}

Fasting $1985 \begin{aligned} & \text { Lacks appropriate control group. Compares patients given heparin only to those given compres- } \\ & \text { sion stockings only }\end{aligned}$

\begin{tabular}{ll}
\hline Flanc 1969 & Thick elastic compression stockings used, not TED stockings. This study was randomised and \\
would have been suitable for analysis.
\end{tabular}

\begin{tabular}{ll}
\hline Gao 2012 & Lacks appropriate control group. 2 groups: GCS only versus GCS + intermittent pneumatic com- \\
pression
\end{tabular}

\begin{tabular}{ll}
\hline Hansberry 1991 & Lacks appropriate control group. 3 groups: thromboembolic stocking only versus external sequen- \\
tial pneumatic compression stockings only versus heparin + dihydroergotamine
\end{tabular}

\begin{tabular}{ll}
\hline Ibegbuna 1997 & Incidence of DVT not assessed. Studies venous haemodynamics \\
\hline Ido 1995 & $\begin{array}{l}\text { Haemodynamic study of mean blood flow velocity in participants wearing GCS versus those not } \\
\text { wearing GCS. Incidence of GCS in these patient groups not reported. }\end{array}$ \\
\hline KANT study & $\begin{array}{l}\text { Lacks appropriate control group. Compares } 3 \text { groups: stockings only versus LMWH } 7 \text { days versus } \\
\text { LMWH 14 days }\end{array}$ \\
\hline Koopmann 1985 & $\begin{array}{l}\text { Lacks appropriate control group. Compares patients given heparin only to those given stockings } \\
\text { only }\end{array}$ \\
\hline Lacut 2005 & $\begin{array}{l}\text { Lacks appropriate control group. All participants wore elastic compression stockings (stockings on- } \\
\text { ly versus stockings + intermittent pneumatic compression). }\end{array}$ \\
\hline Lee 1989 & $\begin{array}{l}\text { Lacks appropriate control group. Compares 3 groups: sodium heparin versus calcium heparin ver- } \\
\text { sus stockings }\end{array}$ \\
\hline Lobastov 2013 & $\begin{array}{l}\text { Lacks appropriate control group. Compares the following } 2 \text { experimental groups: electrical calf } \\
\text { stimulation + low-dose unfractionated heparin + elastic compression versus low-dose unfraction- } \\
\text { ated heparin + elastic compression }\end{array}$ \\
\hline Maksimovic 1996 & $\begin{array}{l}\text { Lacks appropriate control group. All participants wore stockings: GCS + standard heparin versus } \\
\text { GCS + dipyridamole + acetylsalicylic acid versus GCS + placebo }\end{array}$ \\
\hline
\end{tabular}




\begin{tabular}{|c|c|}
\hline Study & Reason for exclusion \\
\hline Manella 1981 & Incidence of DVT not assessed. Measures residual limb volume \\
\hline Marston 1995 & $\begin{array}{l}\text { Lacks appropriate control group. All participants wore stockings. Compares LMWH + stockings ver- } \\
\text { sus stockings alone }\end{array}$ \\
\hline Maxwell 2000 & $\begin{array}{l}\text { Lacks appropriate control group. Compares intermittent pneumatic compression stockings versus } \\
\text { LMWH }\end{array}$ \\
\hline Muir 2000 & RCT based on stroke patients \\
\hline NCT00333021 & $\begin{array}{l}\text { Lacks appropriate control group, based on reported clinical protocol. Formal methodology not } \\
\text { published. No mention of use of mechanical method of thromboprophylaxis in this trial }\end{array}$ \\
\hline NCT01234064 & $\begin{array}{l}\text { Substudy of Perioperative Ischemic Evaluation } 2 \text { (POISE-2) trial (evaluating efficacy of aspirin in } \\
\text { preventing venous thromboembolism); results for GCS vs no GCS arms not published }\end{array}$ \\
\hline NCT01935414 & Lacks appropriate control group. Compared neuromuscular stimulation versus TED stockings \\
\hline Necioglu 2008 & Lacks appropriate control group. LMWH versus GCS \\
\hline Norgren 1996 & $\begin{array}{l}\text { Compares patients wearing intermittent pneumatic compression stockings + GCS to patients on } \\
\text { enoxaparin, rather than to a control group of patients wearing intermittent pneumatic compres- } \\
\text { sion stockings only }\end{array}$ \\
\hline Nurmohamed 1996 & $\begin{array}{l}\text { All participants wore stockings. Compares patients wearing stockings and taking nadroparin to pa- } \\
\text { tients wearing stockings alone, rather than to a control group of patients not wearing stockings } \\
\text { and on nadroparin as background prophylaxis }\end{array}$ \\
\hline Orken 2009 & Lacks appropriate control group. LMWH versus GCS \\
\hline Patel 1988 & Antithrombotic stockings, but does not state if compression graduated stockings. French paper \\
\hline Perkins 1999 & Difficult to analyse as not published as a full paper \\
\hline Porteous 1989 & $\begin{array}{l}\text { This study compared above-knee stockings to below-knee stockings, rather than to a control group } \\
\text { of no stockings or another method of prophylaxis. }\end{array}$ \\
\hline
\end{tabular}

Rabe 2013 This study aimed to assess the effectiveness of thigh-length vs lower-leg compression in preventing post-thrombotic syndrome in people known to have proximal DVT.

Ramos 1996 This study used pneumatic compression stockings rather than graduated compression stockings.

Rasmussen 1988 This study relied solely on the Tc $99 \mathrm{~m}$ plasmin test, which is associated with a high frequency of false positives. Diagnosis of DVT was not confirmed using another objective test. Furthermore, the method of randomisation used in this trial does not appear to be reliable, due to substantial difference in number of participants allocated to the GCS-only group (74 participants) and the GCS + heparin group (89 participants).

Rocca 2012 This study aimed to assess the effectiveness of 2 different types of stockings in the treatment and prevention of venous ulcers. Does not assess incidence of DVT

Rosengarten $1970 \quad$ This trial used Tubigrip rather than graduated compression stockings.

Ryan 2002

This study compared 2 groups: mechanical compression + aspirin versus GCS + aspirin. Lacks a control group with participants on aspirin with no stockings 


\begin{tabular}{|c|c|}
\hline Study & Reason for exclusion \\
\hline Sakon 2012 & Lacks appropriate control group. Compares incidence of DVT in 2 groups: darexaban versus GCS \\
\hline Serin 2010 & Lacks appropriate control group. Compares incidence of DVT in 2 groups: LMWH versus GCS + IPC \\
\hline Shilpa 2013 & Lacks appropriate control group. Compared TED stockings versus crepe bandage \\
\hline Silbersack 2004 & $\begin{array}{l}\text { This study compared } 2 \text { groups: LMWH + IPC versus LMWH + GCS. Lacks a control group of partici- } \\
\text { pants on LMWH with no stockings }\end{array}$ \\
\hline Sobieraj-Teague 2012 & $\begin{array}{l}\text { Lacks appropriate control group. Compares incidence of DVT in } 2 \text { groups: GCS versus Venowave + } \\
\text { GCS }\end{array}$ \\
\hline Sultan 2011 & $\begin{array}{l}\text { This study compared the effectiveness of engineered compression stockings in the prevention of } \\
\text { DVT following ankle fractures. We sought further information from trialists as results were only } \\
\text { published as a conference abstract. Not all trial participants had been hospitalised, therefore the } \\
\text { trial did not meet our inclusion criteria. }\end{array}$ \\
\hline Sultan 2014 & $\begin{array}{l}\text { Lacks appropriate control group. Compared ankle injury stockings versus Tubigrip in participants } \\
\text { with ankle fractures }\end{array}$ \\
\hline Vignon 2013 & $\begin{array}{l}\text { Lacks appropriate control group. Compared the following } 2 \text { experimental groups: IPC + GCS versus } \\
\text { GCS alone }\end{array}$ \\
\hline Westrich 1996 & $\begin{array}{l}\text { This study used a pneumatic plantar compression device rather than graduated compression } \\
\text { stockings. }\end{array}$ \\
\hline Wilkins 1952 & $\begin{array}{l}\text { Based solely on clinical diagnosis of DVT instead of using Doppler/venography for confirmation, as } \\
\text { set out in the criteria for this review }\end{array}$ \\
\hline Wille-Jorgensen 1986 & $\begin{array}{l}\text { Lacks appropriate control group. Compared the following } 2 \text { experimental groups: heparin + GCS } \\
\text { versus heparin + dihydroergotamine }\end{array}$ \\
\hline Wilson 1994 & Studies venous haemodynamics. Does not assess the incidence of DVT \\
\hline Yang 2009 & $\begin{array}{l}\text { Lacks appropriate experimental groups. Compared the following } 3 \text { groups: IPC versus LMWH versus } \\
\text { no thromboprophylaxis }\end{array}$ \\
\hline Zhang 2011 & $\begin{array}{l}\text { Lacks appropriate experimental groups. Compared the following } 2 \text { groups: IPC versus no thrombo- } \\
\text { prophylaxis }\end{array}$ \\
\hline Zheng 2014 & Lacks appropriate control group. Compared GCS + LMWH versus GCS alone \\
\hline
\end{tabular}

DVT: deep vein thrombosis

GCS: graduated compression stockings

IPC: intermittent pneumatic compression

LMWH: low molecular weight heparin

TED: thrombo-embolic deterrent

Characteristics of studies awaiting assessment [ordered by study ID]

Celebi 2001

Methods

Study: randomised controlled trial

Losses to follow-up: 2 participants in control group died during treatment.

DVT diagnosis: deep venous Doppler ultrasonography 
Celebi 2001 (Continued)

PE diagnosis: pulmonary scintigraphy

\begin{tabular}{ll}
\hline Participants & Country: Turkey \\
& Total number of participants: 274 \\
& Total available for analysis: 274 \\
& Sex: male and female \\
& Inclusion criteria: patients undergoing major abdominal surgery \\
\hline Interventions & Type of treatment: compression stockings \\
& Control: 91 (LMWH only) \\
& Treatment: 92 (LMWH and compression stockings) \\
& Duration: not specified in abstract \\
\hline Outcomes & DVT \\
Control: 8 \\
Treatment: 3 \\
P > 0.05 (not significant) \\
Turkish paper \\
Low molecular weight heparin (nadroparin calcium 0.3 mL 2850 IU anti-factor Xa) was given to both \\
control and treatment groups. \\
This study included an additional group of patients who wore stockings but were not administered \\
LMWH that is not relevant to this review. \\
Awaiting translation
\end{tabular}

DVT: deep vein thrombosis

FUT: |125 fibrinogen uptake test

GCS: graduated compression stockings

LMWH: low molecular weight heparin

PE: pulmonary embolism

Characteristics of ongoing studies [ordered by study ID]

\section{ChiCTR1800014257}

\section{Trial name or title}

The strategies of risk-stratified prophylaxis of deep venous thrombosis after gynaecologic pelvic surgery in patients at different levels of risk: a prospective multicenter randomised controlled trial

\begin{tabular}{ll}
\hline Methods & Multicentre RCT \\
\hline Participants & Inclusion criteria \\
- & aged $\geq 50$ years \\
- hypertension & varicose vein of lower extremity \\
- pelvic laparotomy \\
- expected surgery time $\geq 1 \mathrm{~h}$ \\
- postsurgery bedridden time $\geq 48 \mathrm{~h}$ \\
Patients are risk stratified into high- (at least 2 criteria met) and very high-risk groups (3 or more \\
criteria met).
\end{tabular}

$\begin{array}{ll}\text { Interventions } & 4 \text { arms based on risk of DVT: } \\ & -\mathrm{GCS} \text { only (high-risk group, } \mathrm{n}=404) \\ & -\mathrm{GCS}+\text { LMWH (high-risk group, } \mathrm{n}=404)\end{array}$


ChiCTR1800014257 (Continued)

- $\mathrm{GCS}+\mathrm{IPC}$ (very high-risk group, $\mathrm{n}=102$ )

- $\mathrm{GCS}+\mathrm{LMWH}+$ IPC (very high-risk group, $\mathrm{n}=102$ )

\begin{tabular}{ll}
\hline Outcomes & Primary outcome: DVT diagnosed using colour Doppler ultrasound \\
\hline Starting date & 1 January 2018 \\
\hline Contact information & Zhengyu Zhang \\
& 8 Gongti Road South, Chaoyang District, Beijing, China \\
& Telephone: +86 13801237287 \\
& Email: zhangzhenyu@coga.org.cn \\
\hline Notes & Trial information from www.chictr.org.cn/showproj.aspx?proj=24115 \\
& Trial end date: 31 December 2020 \\
\hline
\end{tabular}

GAPS

Trial name or title Graduated compression as an Adjunct to Pharmacoprophylaxis in Surgery (GAPS). Examining the benefit of GCS as an adjunct to low dose LMWH in the prevention of VTE in elective surgical inpatients identified as moderate or high risk for VTE

\begin{tabular}{ll}
\hline Methods & Multicentre RCT \\
\hline Participants & Elective surgical inpatients assessed as being at moderate or high risk of VTE \\
& Planned sample size: 2236 \\
\hline Interventions & 2 arms: GCS only vs GCS + LMWH \\
\hline Outcomes & $\begin{array}{l}\text { Primary outcome: VTE within } 90 \text { days (composite endpoint of duplex ultrasound-proven new low- } \\
\text { er-limb DVT up to } 90 \text { days postsurgery (symptomatic or asymptomatic) and symptomatic PE (imag- } \\
\text { ing confirmed) up to 90 days postsurgery) }\end{array}$ \\
\hline Starting date & 1 May 2016 \\
\hline Contact information & $\begin{array}{l}\text { Professor Alun Davies } \\
\text { Section of Vascular Surgery, Room 3E, 4th Floor East Wing, Charing Cross Hospital, Fulham Palace } \\
\text { Road, London W6 } 8 \text { RF. }\end{array}$ \\
Telephone: 02088467320 \\
Email: a.h.davies@imperial.ac.uk
\end{tabular}

Notes ISRCTN: 13911492

Trial website: w3.abdn.ac.uk/hsru/gaps/

Overall trial end date: 30 November 2019 


\section{IRCT2017080935594N1}

Trial name or title

Comparison of efficacy compressive stocking with heparin and enoxaparin in prevention of deep vein thrombosis of lower extremities in hysterectomized patients

\begin{tabular}{ll}
\hline Methods & Randomised trial \\
\hline Participants & Women under 60 years old undergoing hysterectomy for indications other than malignancy \\
\hline Interventions & Participants were randomised to 1 of 4 groups: \\
& - heparin subcutaneously 5000 units every 12 hours for 3 days plus compressive socks; \\
& - heparin without compressive socks; \\
& - prophylaxis with subcutaneous enoxaparin 40 mg daily for 3 days plus compressive socks;
\end{tabular}

The presence or absence of thrombosis on Doppler ultrasonography of the deep veins of the lower limb at 2 weeks follow-up

\begin{tabular}{ll}
\hline Starting date & 23 August 2017 \\
\hline Contact information & Ahmad Enhesari \\
& Kerman University of Medical Sciences \\
& Afzalipour Pardis, Early axis of seven Alavi Gardens, Kerman, Iran 7916913555 \\
& Telephone: +983431325700 \\
& Fax: +9831325605 \\
& Email: Enhesari@Kmu.ac.ir \\
& Web address: www.kmu.ac.ir/ \\
\hline Notes & Trial information from en.irct.ir/trial/26850 \\
& Expected recruitment end date: 23 August 2018 \\
\hline
\end{tabular}

DVT: deep vein thrombosis

GCS: graduated compression stockings

IPC: intermittent pneumatic compression

LMWH: low molecular weight heparin

$\mathrm{RCT}$ : randomised controlled trial

VTE: venous thromboembolism

\section{DATA AND ANALYSES}

Comparison 1. Incidence of DVT with stockings and without stockings

\begin{tabular}{llllll}
\hline $\begin{array}{l}\text { Outcome or subgroup } \\
\text { title }\end{array}$ & No. of studies & $\begin{array}{l}\text { No. of partici- } \\
\text { pants }\end{array}$ & Statistical method & Effect size \\
\hline 1 All specialties & 20 & 2853 & Peto Odds Ratio (Peto, Fixed, 95\% Cl) & $0.35[0.28,0.43]$ \\
\hline 1.1 General surgery & 10 & 1486 & Peto Odds Ratio (Peto, Fixed, 95\% Cl) & $0.30[0.22,0.41]$ \\
\hline 1.2 Orthopaedic surgery & 6 & 598 & Peto Odds Ratio (Peto, Fixed, 95\% Cl) & $0.47[0.32,0.68]$ \\
\hline
\end{tabular}




\begin{tabular}{llllll}
\hline $\begin{array}{l}\text { Outcome or subgroup } \\
\text { title }\end{array}$ & No. of studies & $\begin{array}{l}\text { No. of partici- } \\
\text { pants }\end{array}$ & Statistical method & Effect size \\
\hline 1.3 Other specialties & 4 & 769 & Peto Odds Ratio (Peto, Fixed, 95\% Cl) & $0.28[0.16,0.48]$ \\
\hline $\begin{array}{l}\text { 2 All specialties - surgical } \\
\text { vs medical }\end{array}$ & 20 & 2853 & Peto Odds Ratio (Peto, Fixed, 95\% Cl) & $0.35[0.28,0.43]$ \\
\hline 2.1 Surgery & 19 & 2693 & Peto Odds Ratio (Peto, Fixed, 95\% Cl) & $0.35[0.28,0.44]$ \\
\hline 2.2 Medicine & 1 & 160 & Peto Odds Ratio (Peto, Fixed, 95\% Cl) & $0.12[0.03,0.51]$ \\
\hline
\end{tabular}

Analysis 1.1. Comparison 1 Incidence of DVT with stockings and without stockings, Outcome 1 All specialties.

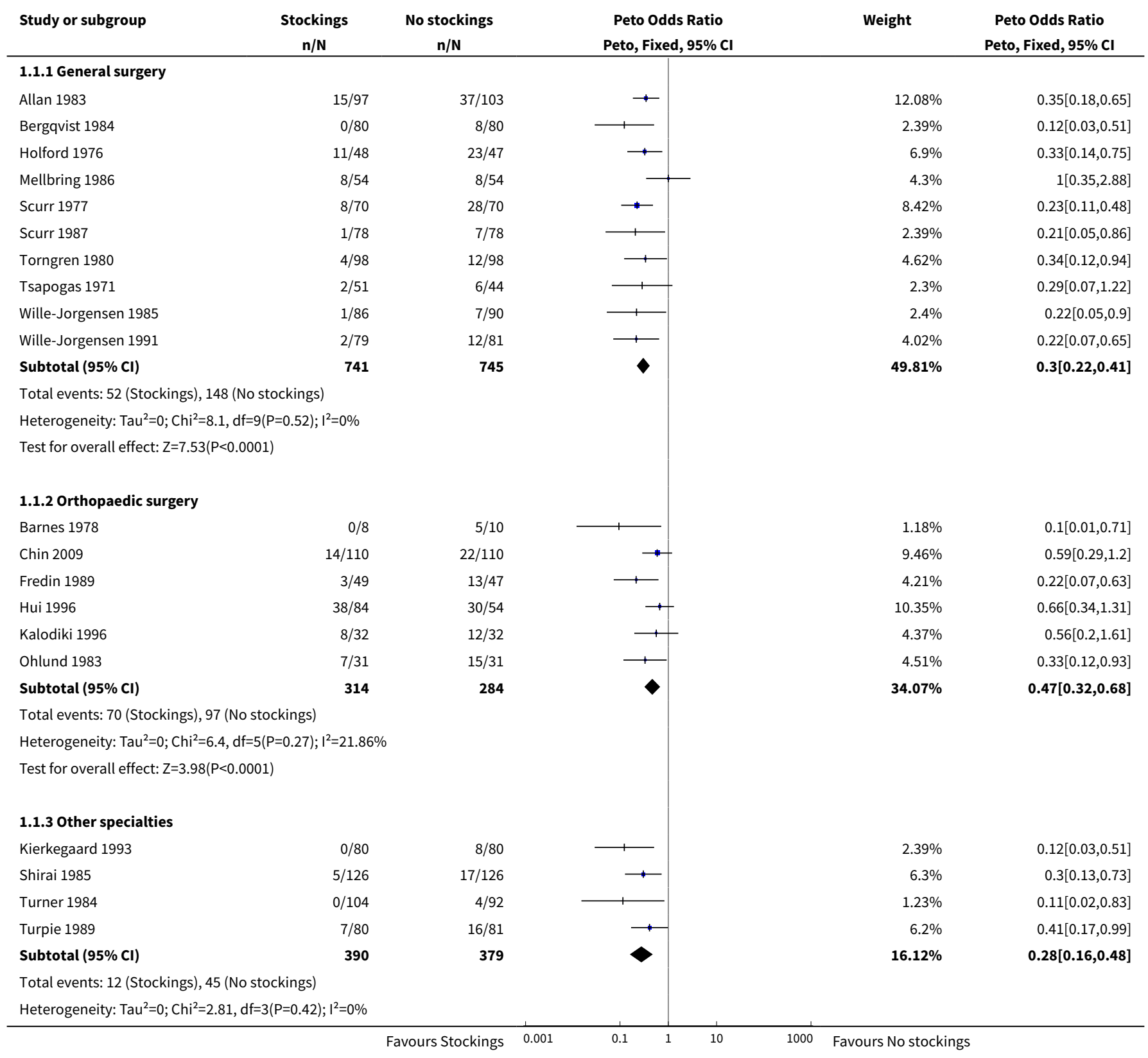




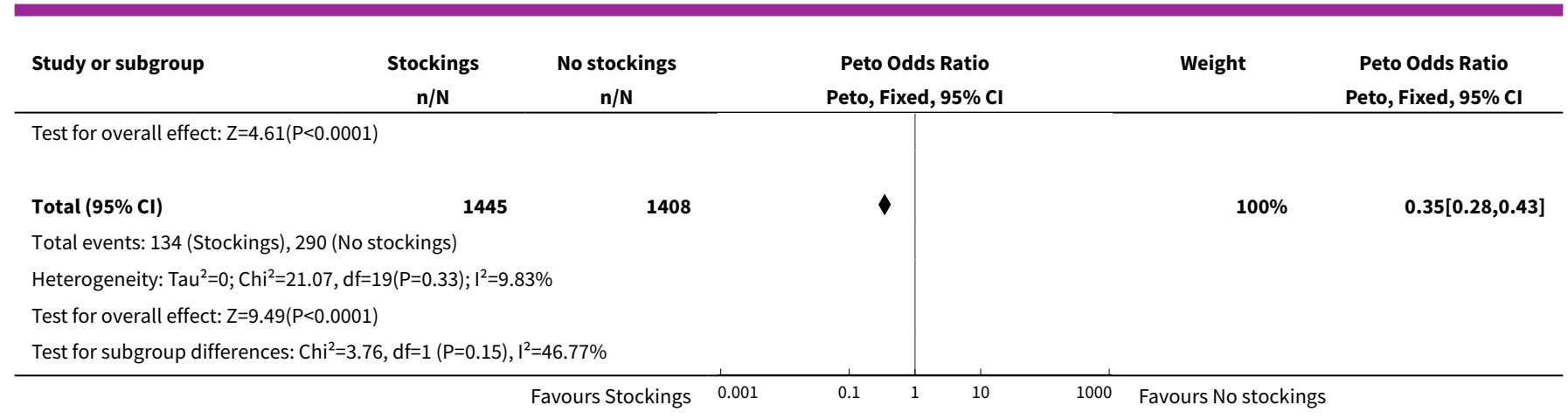

Analysis 1.2. Comparison 1 Incidence of DVT with stockings and without stockings, Outcome 2 All specialties - surgical vs medical.

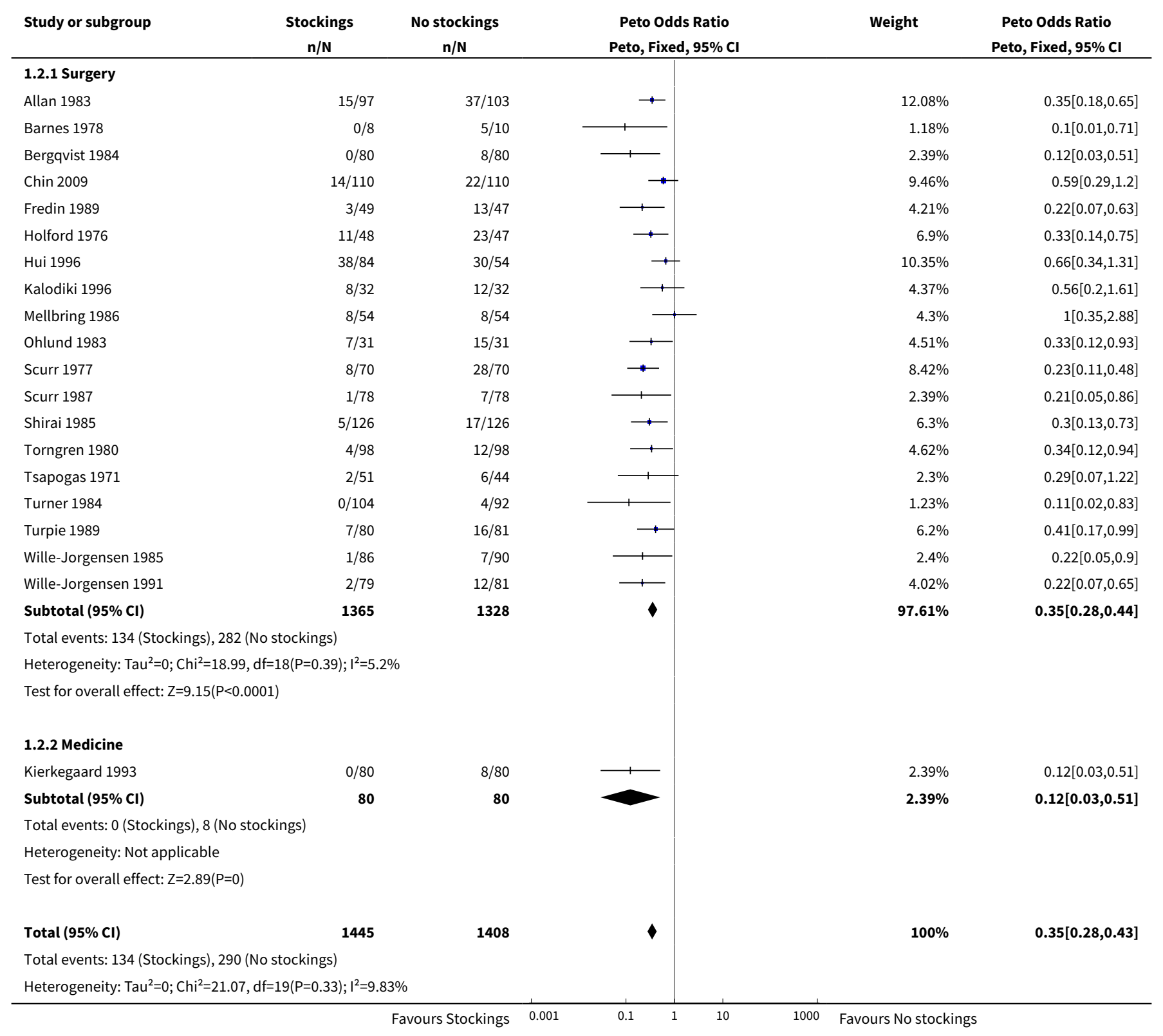




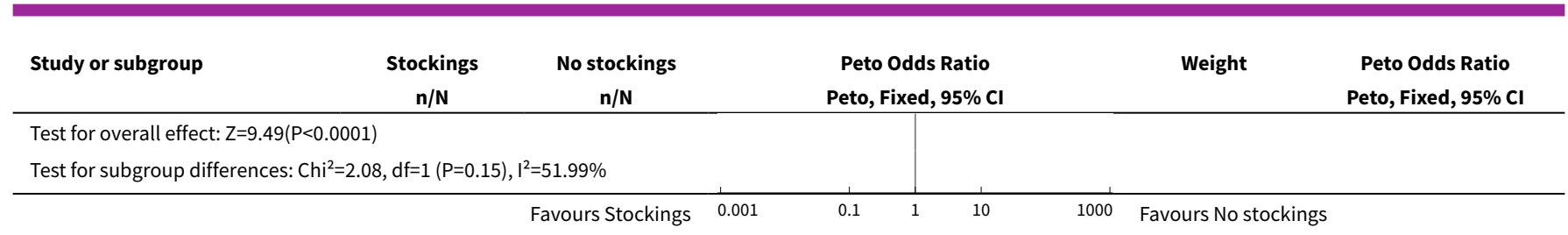

\section{Comparison 2. Incidence of proximal DVT with stockings and without stockings}

\begin{tabular}{lllll}
\hline $\begin{array}{l}\text { Outcome or subgroup } \\
\text { title }\end{array}$ & No. of studies & $\begin{array}{l}\text { No. of partici- } \\
\text { pants }\end{array}$ & Statistical method & Effect size \\
\hline 1 All specialties & 8 & 1035 & Peto Odds Ratio (Peto, Fixed, 95\% Cl) & $0.26[0.13,0.53]$ \\
\hline 1.1 General surgery & 2 & 316 & Peto Odds Ratio (Peto, Fixed, 95\% Cl) & $0.14[0.00,6.82]$ \\
\hline 1.2 Orthopaedic surgery & 4 & 398 & Peto Odds Ratio (Peto, Fixed, 95\% Cl) & $0.25[0.12,0.53]$ \\
\hline 1.3 Other specialties & 2 & 321 & Peto Odds Ratio (Peto, Fixed, 95\% Cl) & $0.52[0.05,5.03]$ \\
\hline $\begin{array}{l}\text { 2 All specialties - surgical } \\
\text { vs medical }\end{array}$ & 8 & 1035 & Peto Odds Ratio (Peto, Fixed, 95\% Cl) & $0.26[0.13,0.53]$ \\
\hline 2.1 Surgery & 7 & 875 & Peto Odds Ratio (Peto, Fixed, 95\% Cl) & $0.26[0.13,0.53]$ \\
\hline 2.2 Medicine & 1 & 160 & Peto Odds Ratio (Peto, Fixed, 95\% Cl) & $0.0[0.0,0.0]$ \\
\hline
\end{tabular}

Analysis 2.1. Comparison 2 Incidence of proximal DVT with stockings and without stockings, Outcome 1 All specialties.

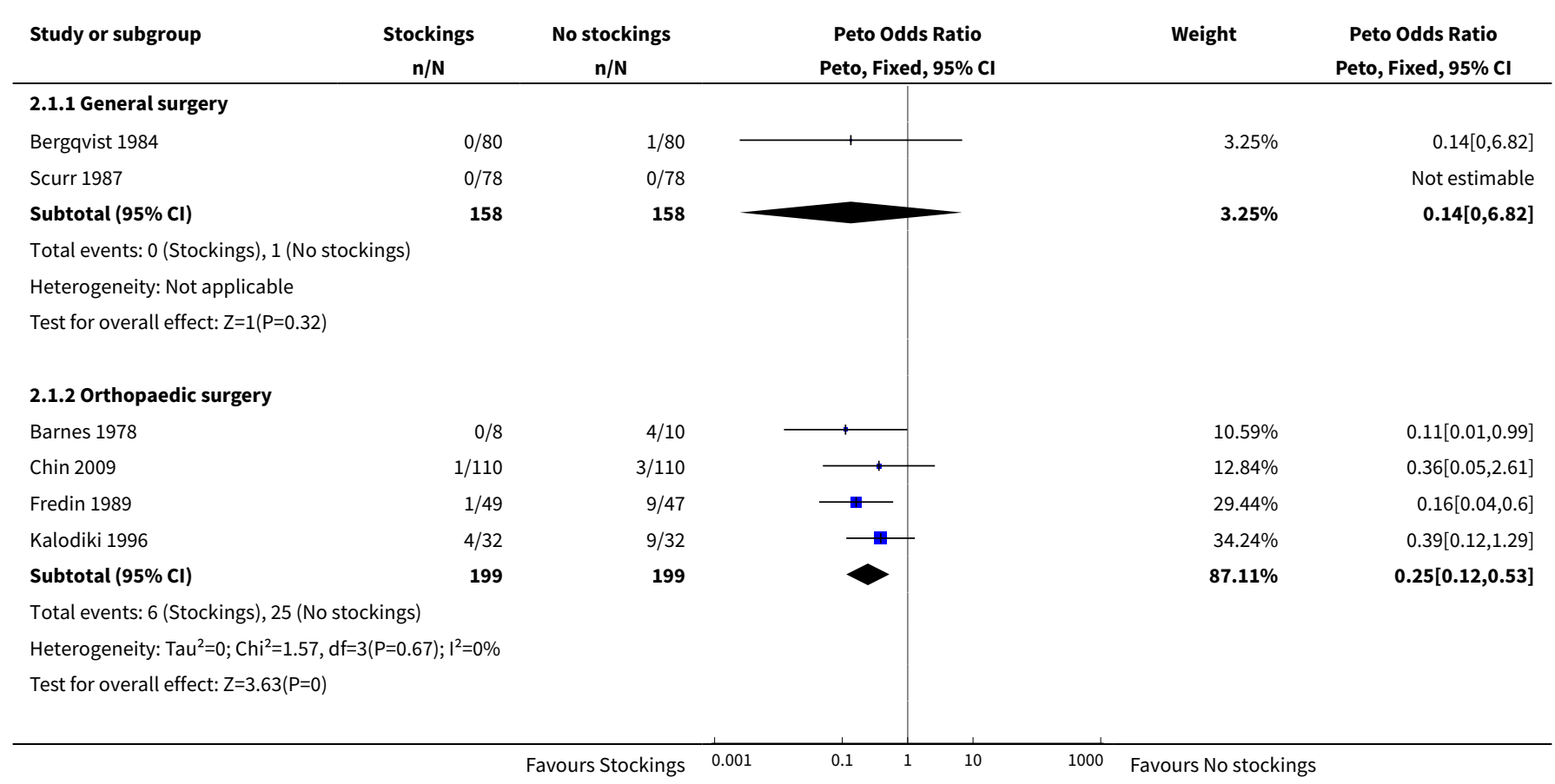




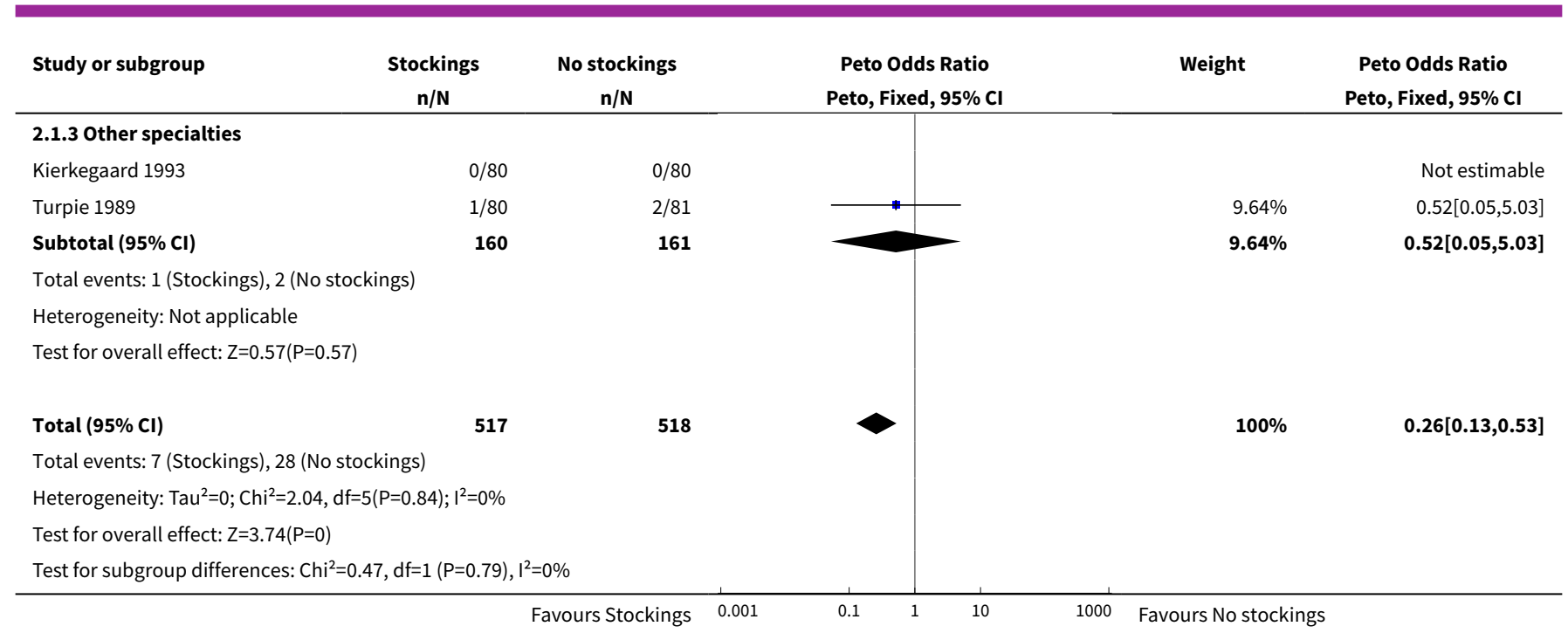

Analysis 2.2. Comparison 2 Incidence of proximal DVT with stockings and without stockings, Outcome 2 All specialties - surgical vs medical.

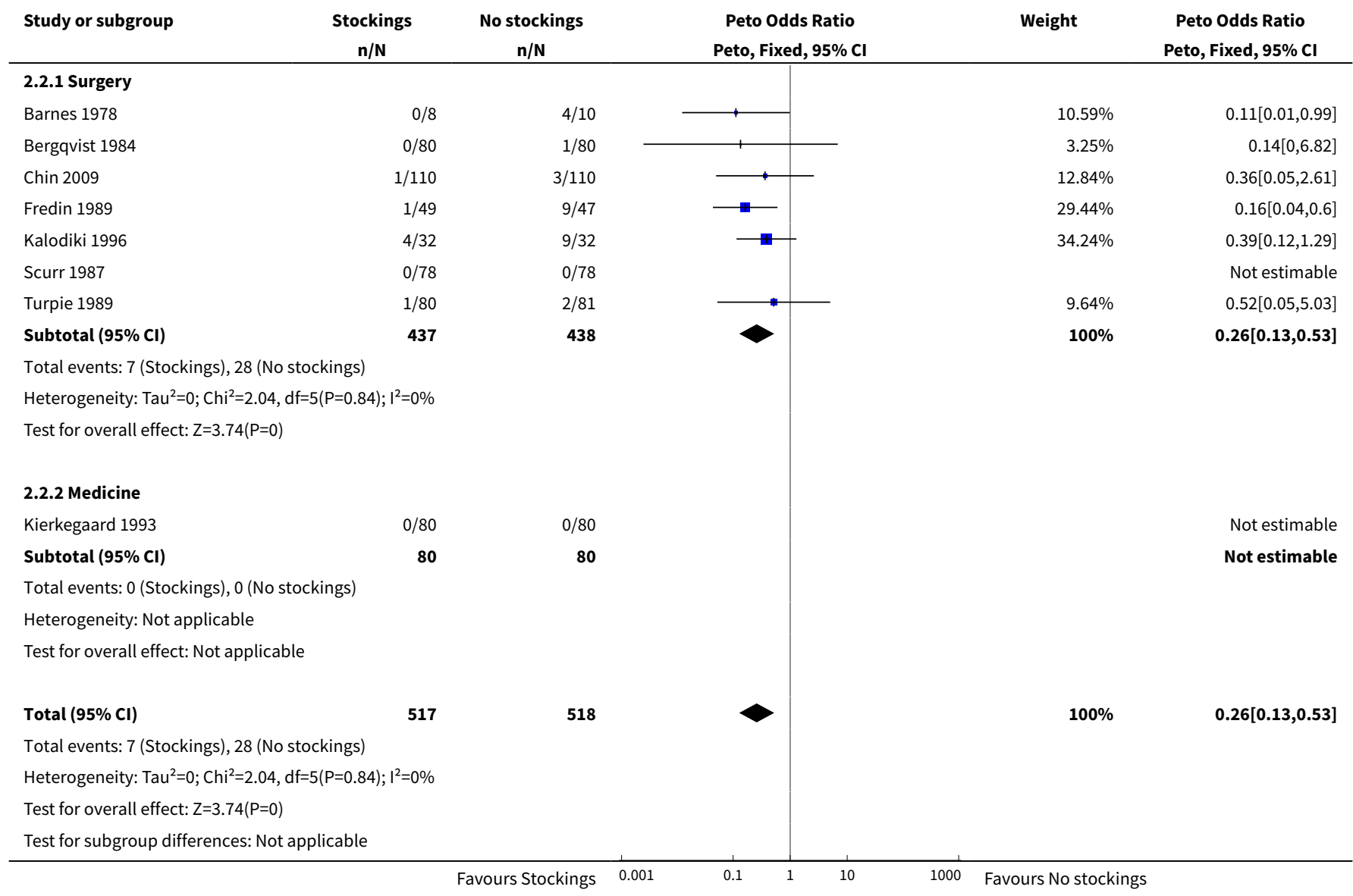


Comparison 3. Incidence of PE with stockings and without stockings

\begin{tabular}{llllll}
\hline $\begin{array}{l}\text { Outcome or subgroup } \\
\text { title }\end{array}$ & No. of studies & $\begin{array}{l}\text { No. of partici- } \\
\text { pants }\end{array}$ & Statistical method & Effect size \\
\hline 1 All specialties & 5 & 569 & Peto Odds Ratio (Peto, Fixed, 95\% Cl) & $0.38[0.15,0.96]$ \\
\hline 1.1 General surgery & 2 & 271 & Peto Odds Ratio (Peto, Fixed, 95\% Cl) & $0.33[0.09,1.24]$ \\
\hline $\begin{array}{l}1.2 \text { Orthopaedic surgery } \\
1.3 \text { Other specialties }\end{array}$ & 0 & 298 & Peto Odds Ratio (Peto, Fixed, 95\% Cl) & $0.44[0.12,1.58]$ \\
\hline $\begin{array}{l}2 \text { All specialties - surgical } \\
\text { vs medical }\end{array}$ & 5 & 0 & Peto Odds Ratio (Peto, Fixed, 95\% Cl) & $0.0[0.0,0.0]$ \\
\hline $\begin{array}{l}2.1 \text { Surgery } \\
2.2 \text { Medicine }\end{array}$ & 5 & 569 & Peto Odds Ratio (Peto, Fixed, 95\% Cl) & $0.38[0.15,0.96]$ \\
\hline
\end{tabular}

Analysis 3.1. Comparison 3 Incidence of PE with stockings and without stockings, Outcome 1 All specialties.

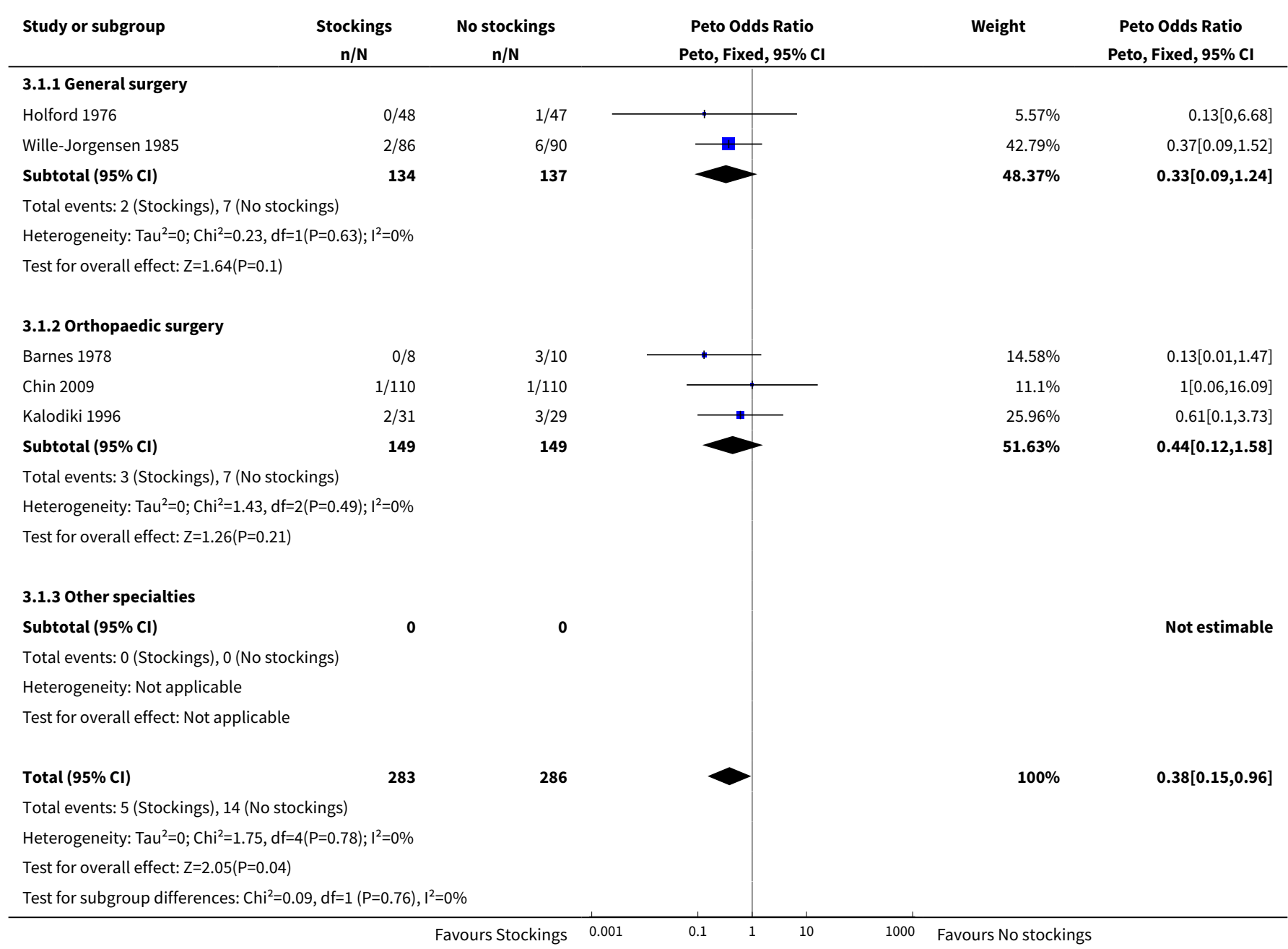


Analysis 3.2. Comparison 3 Incidence of PE with stockings and without stockings, Outcome 2 All specialties - surgical vs medical.

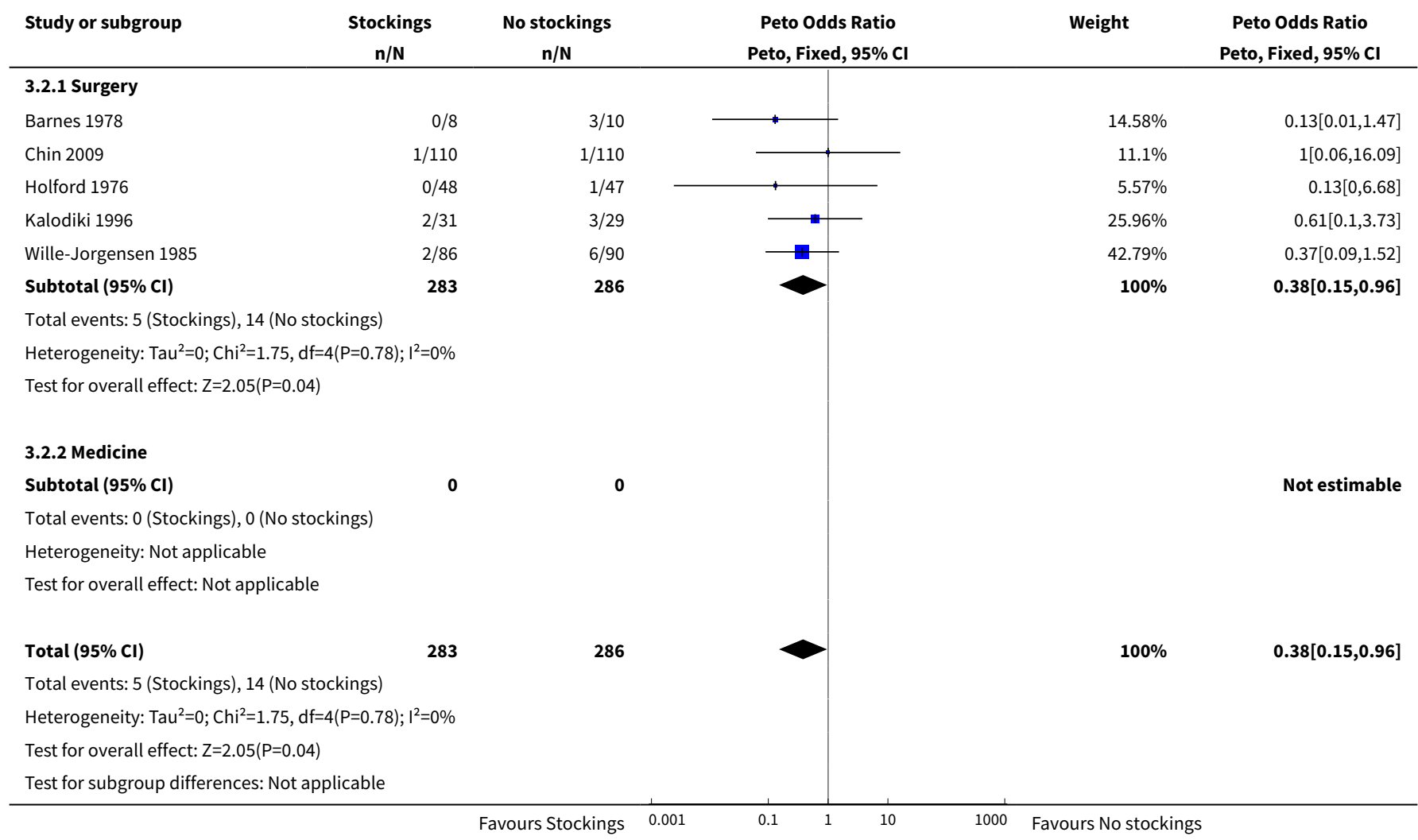

\section{Comparison 4. Sensitivity analysis}

\begin{tabular}{|c|c|c|c|c|}
\hline Outcome or subgroup title & No. of studies & $\begin{array}{l}\text { No. of partici- } \\
\text { pants }\end{array}$ & Statistical method & Effect size \\
\hline 1 Method of randomisation & 20 & 2853 & $\begin{array}{l}\text { Peto Odds Ratio (Peto, Fixed, 95\% } \\
\mathrm{Cl} \text { ) }\end{array}$ & $0.35[0.28,0.43]$ \\
\hline $\begin{array}{l}\text { 1.1 Method of randomisation in- } \\
\text { appropriate or not reported }\end{array}$ & 12 & 1565 & $\begin{array}{l}\text { Peto Odds Ratio (Peto, Fixed, 95\% } \\
\mathrm{Cl} \text { ) }\end{array}$ & $0.34[0.25,0.45]$ \\
\hline $\begin{array}{l}\text { 1.2 Appropriate method of ran- } \\
\text { domisation }\end{array}$ & 8 & 1288 & $\begin{array}{l}\text { Peto Odds Ratio (Peto, Fixed, 95\% } \\
\mathrm{Cl} \text { ) }\end{array}$ & $0.36[0.26,0.50]$ \\
\hline $\begin{array}{l}2 \text { Unit of analysis for randomisa- } \\
\text { tion }\end{array}$ & 20 & 2853 & $\begin{array}{l}\text { Peto Odds Ratio (Peto, Fixed, 95\% } \\
\mathrm{Cl} \text { ) }\end{array}$ & $0.35[0.28,0.43]$ \\
\hline 2.1 Individual participants & 13 & 1681 & $\begin{array}{l}\text { Peto Odds Ratio (Peto, Fixed, 95\% } \\
\mathrm{Cl} \text { ) }\end{array}$ & $0.38[0.29,0.49]$ \\
\hline 2.2 Individual legs & 7 & 1172 & $\begin{array}{l}\text { Peto Odds Ratio (Peto, Fixed, 95\% } \\
\mathrm{Cl} \text { ) }\end{array}$ & $0.28[0.19,0.42]$ \\
\hline
\end{tabular}




\begin{tabular}{|c|c|c|c|c|}
\hline Outcome or subgroup title & No. of studies & $\begin{array}{l}\text { No. of partici- } \\
\text { pants }\end{array}$ & Statistical method & Effect size \\
\hline $\begin{array}{l}3 \text { Use of background method of } \\
\text { thromboprophylaxis }\end{array}$ & 20 & 2853 & $\begin{array}{l}\text { Peto Odds Ratio (Peto, Fixed, 95\% } \\
\text { Cl) }\end{array}$ & $0.35[0.28,0.43]$ \\
\hline $\begin{array}{l}3.1 \text { Trials without background } \\
\text { thromboprophylaxis }\end{array}$ & 9 & 1497 & $\begin{array}{l}\text { Peto Odds Ratio (Peto, Fixed, 95\% } \\
\text { Cl) }\end{array}$ & $0.38[0.29,0.50]$ \\
\hline $\begin{array}{l}3.2 \text { Trials with background } \\
\text { thromboprophylaxis }\end{array}$ & 11 & 1356 & $\begin{array}{l}\text { Peto Odds Ratio (Peto, Fixed, 95\% } \\
\text { Cl) }\end{array}$ & $0.29[0.20,0.42]$ \\
\hline 4 Method of diagnosis & 20 & 2853 & $\begin{array}{l}\text { Peto Odds Ratio (Peto, Fixed, 95\% } \\
\text { Cl) }\end{array}$ & $0.35[0.28,0.43]$ \\
\hline 4.1 Fibrogen uptake test alone & 8 & 1209 & $\begin{array}{l}\text { Peto Odds Ratio (Peto, Fixed, 95\% } \\
\text { Cl) }\end{array}$ & $0.31[0.22,0.44]$ \\
\hline $\begin{array}{l}4.2 \text { Fibrinogen uptake test and } \\
\text { phlebography }\end{array}$ & 6 & 1013 & $\begin{array}{l}\text { Peto Odds Ratio (Peto, Fixed, 95\% } \\
\text { Cl) }\end{array}$ & $0.29[0.19,0.43]$ \\
\hline 4.3 Ultrasonography & 2 & 238 & $\begin{array}{l}\text { Peto Odds Ratio (Peto, Fixed, 95\% } \\
\text { Cl) }\end{array}$ & $0.48[0.25,0.94]$ \\
\hline 4.4 Phlebography & 4 & 393 & $\begin{array}{l}\text { Peto Odds Ratio (Peto, Fixed, 95\% } \\
\text { Cl) }\end{array}$ & $0.47[0.29,0.75]$ \\
\hline
\end{tabular}

Analysis 4.1. Comparison 4 Sensitivity analysis, Outcome 1 Method of randomisation.

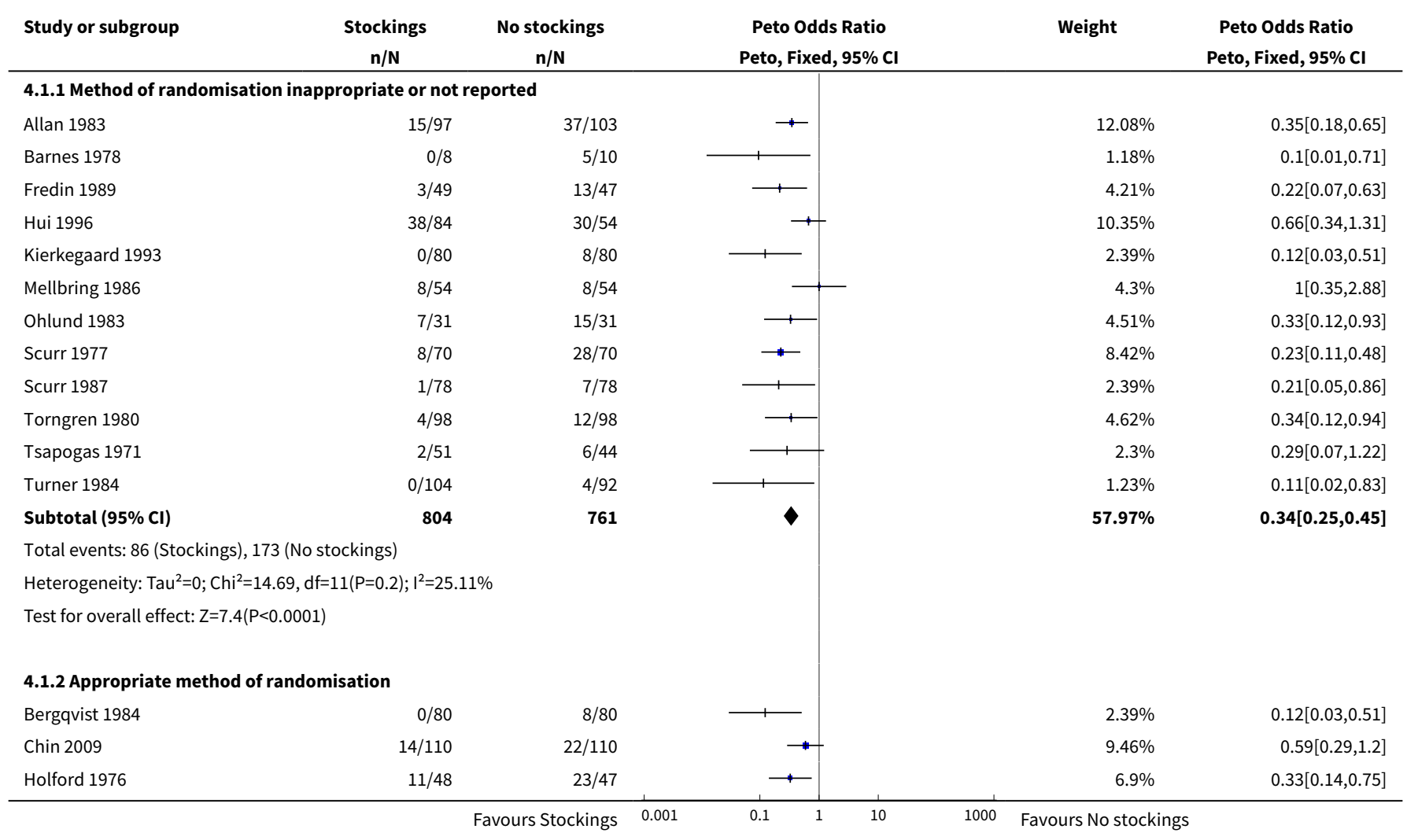




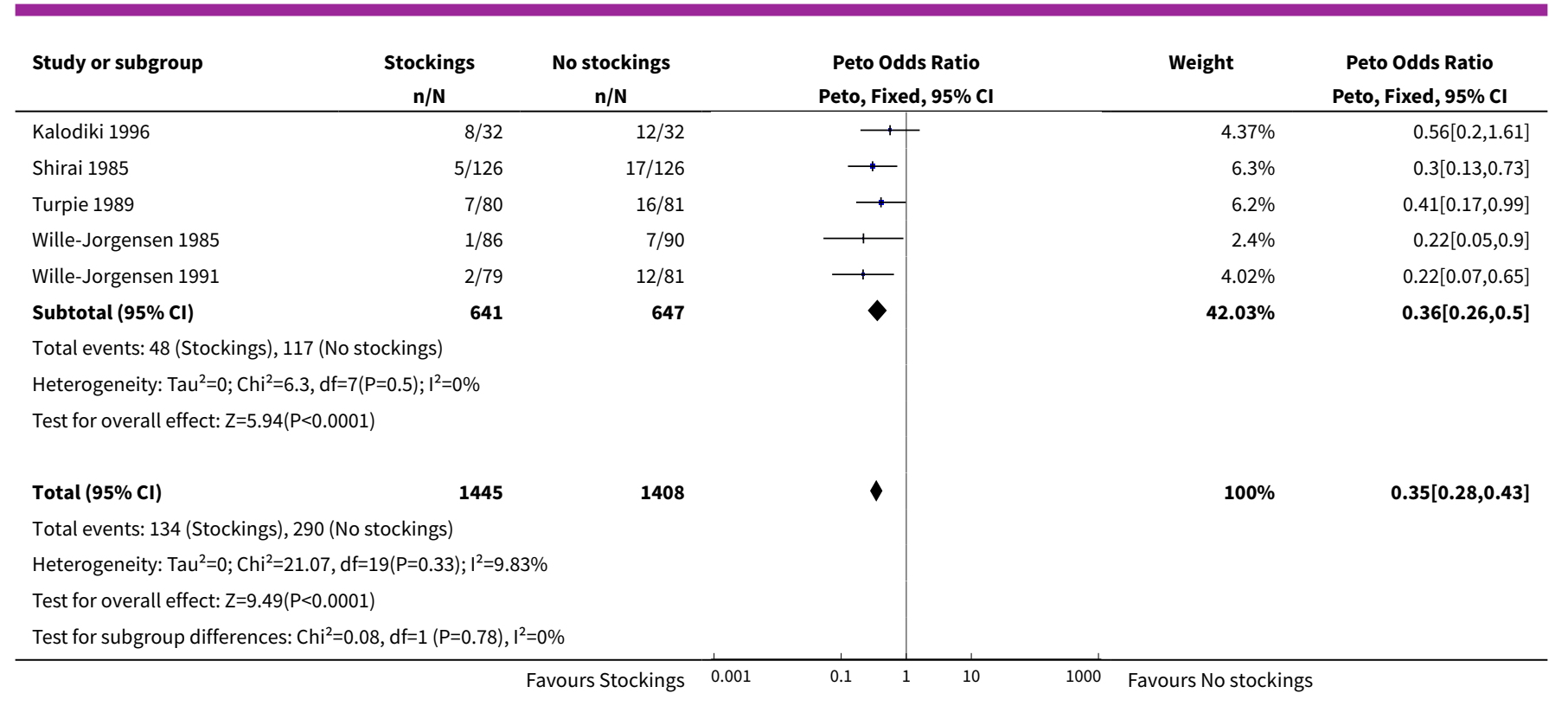

Analysis 4.2. Comparison 4 Sensitivity analysis, Outcome 2 Unit of analysis for randomisation.

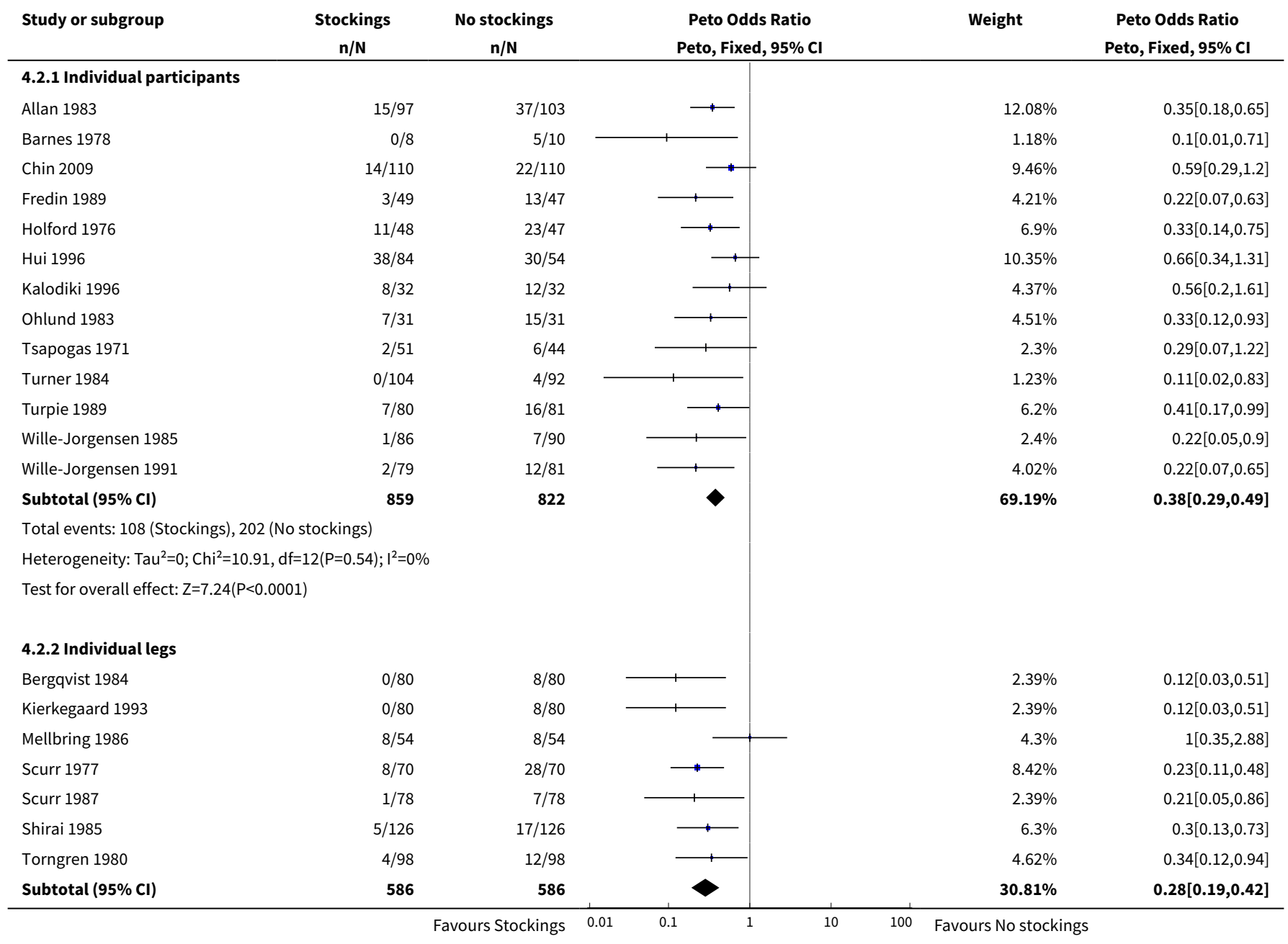




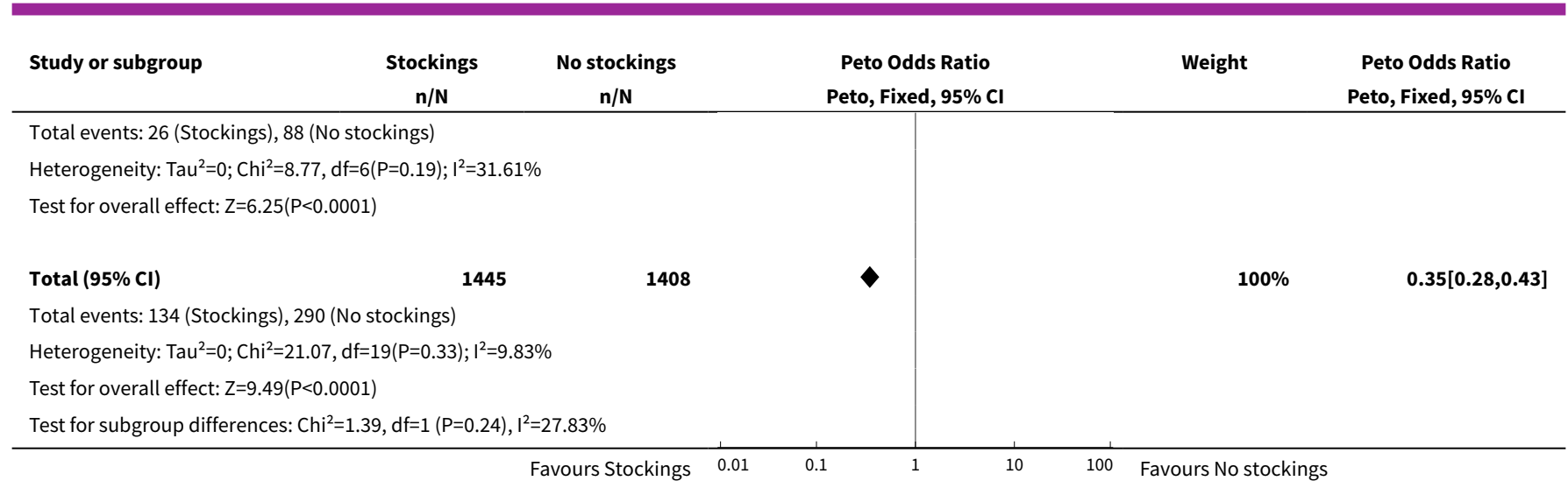

\section{Analysis 4.3. Comparison 4 Sensitivity analysis, Outcome 3 Use of background method of thromboprophylaxis.}

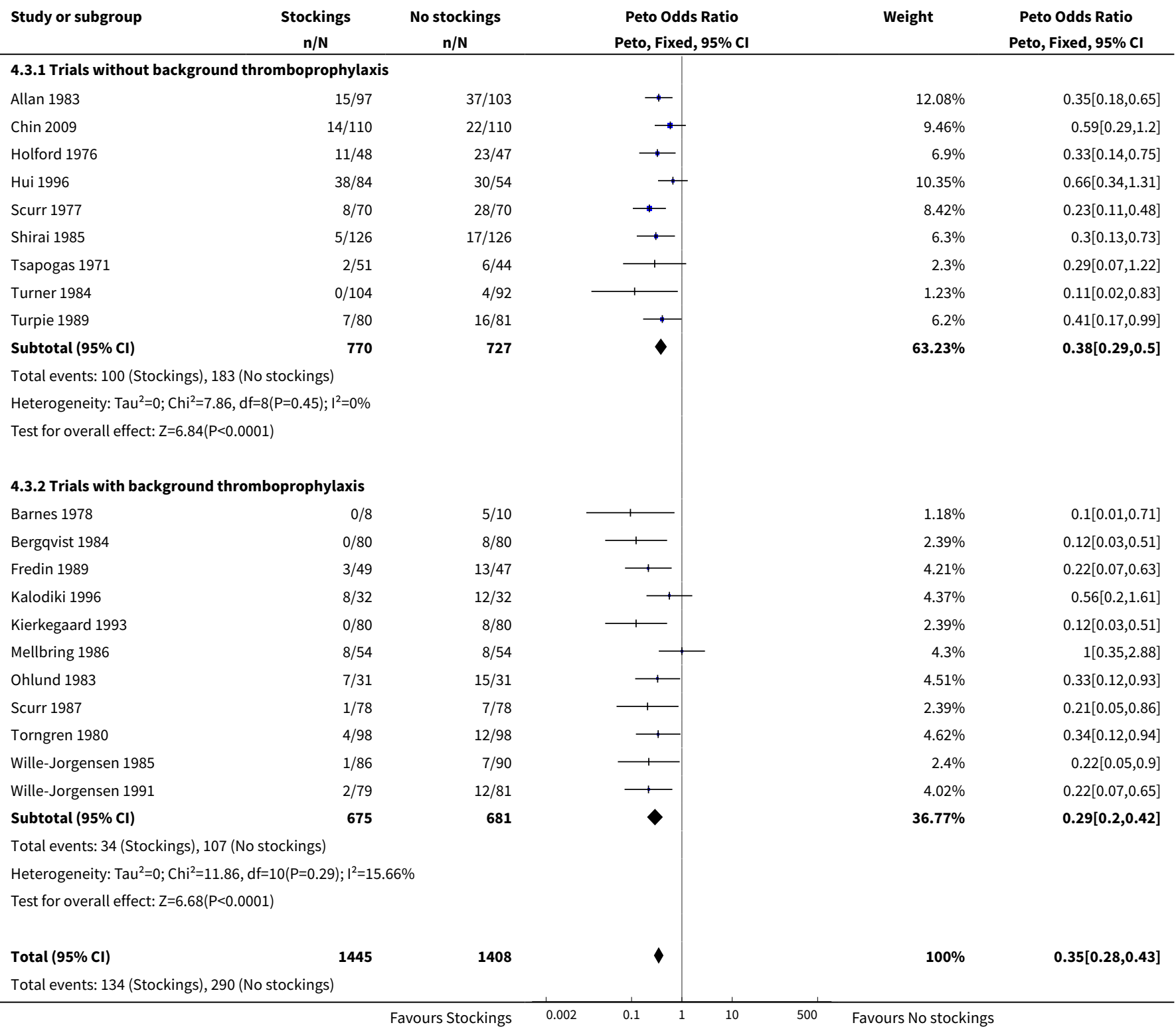




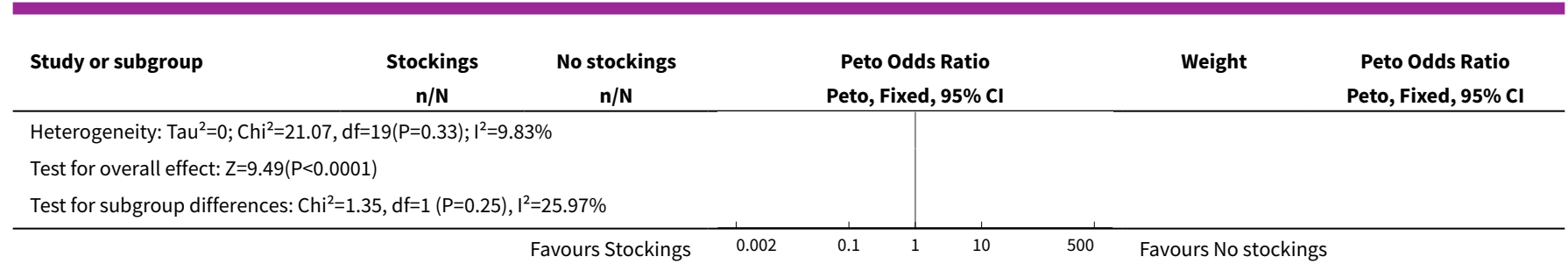

Analysis 4.4. Comparison 4 Sensitivity analysis, Outcome 4 Method of diagnosis.

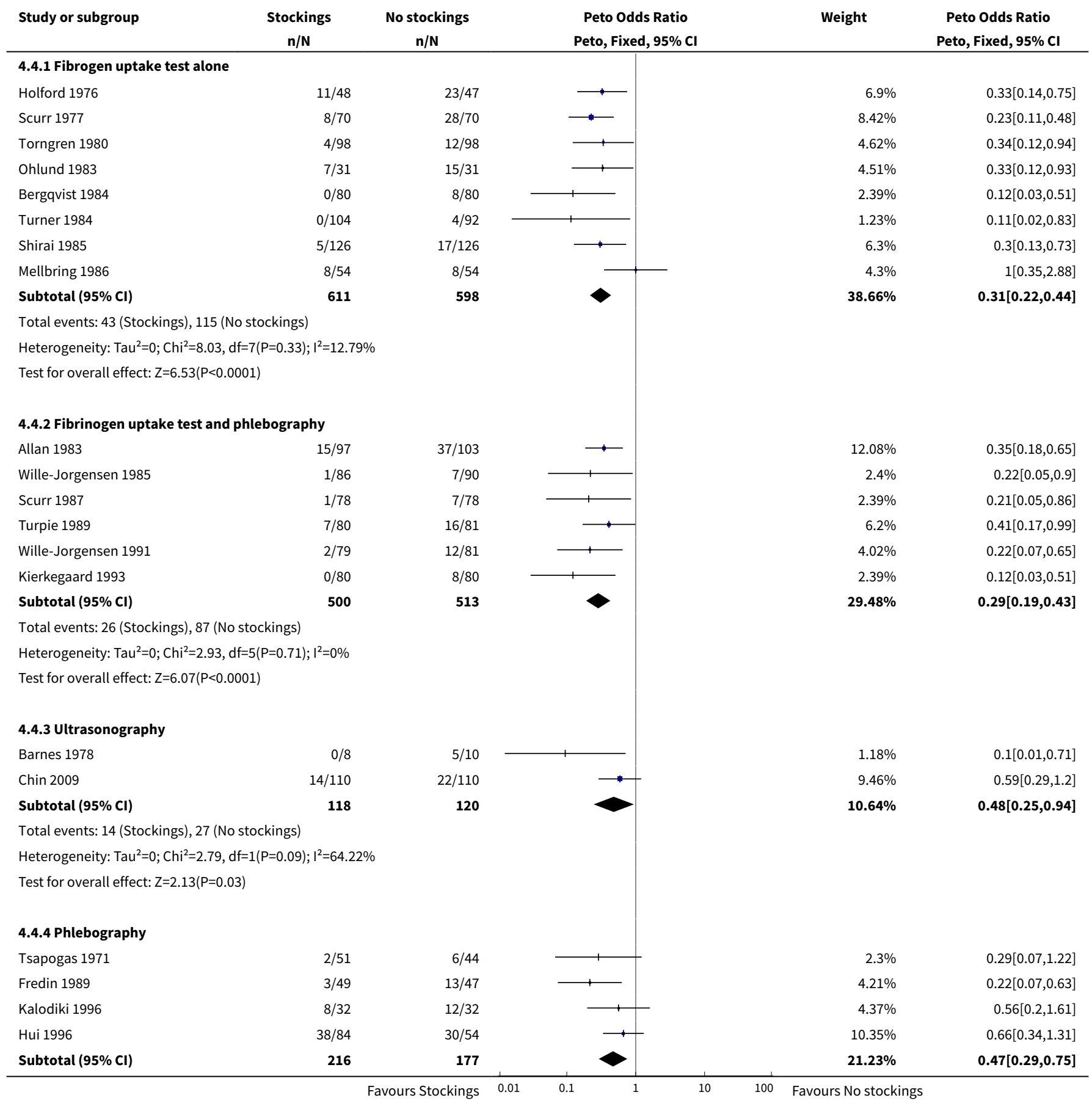




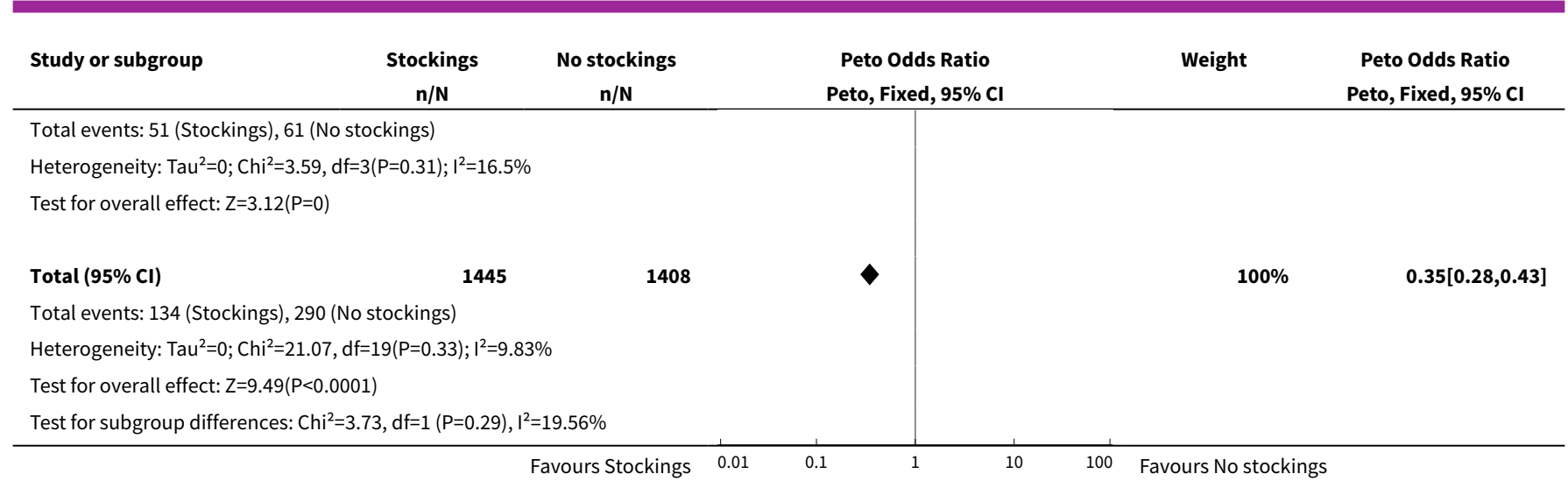

\section{APPENDICES}

\section{Appendix 1. CENTRAL search strategy March 2017}

\begin{tabular}{|c|c|c|}
\hline$\# 1$ & MESH DESCRIPTOR Venous Thrombosis EXPLODE ALL TREES & 2041 \\
\hline \#2 & MESH DESCRIPTOR Thromboembolism EXPLODE ALL TREES & 1433 \\
\hline \#3 & MESH DESCRIPTOR Thrombosis & 1267 \\
\hline \#4 & thrombo*:TI,AB,KY & 31059 \\
\hline \#5 & thrombu*:TI,AB,KY & 1336 \\
\hline \#6 & embol*:TI,AB,KY & 5962 \\
\hline$\# 7$ & (dvt* or PE or VTE):TI,AB,KY & 4996 \\
\hline \#8 & \#1 OR \#2 OR \#3 OR \#4 OR \#5 OR \#6 OR \#7 & 37392 \\
\hline \#9 & MESH DESCRIPTOR Stockings, Compression & 165 \\
\hline$\# 10$ & MESH DESCRIPTOR Compression Bandages & 99 \\
\hline$\# 11$ & (stocking ${ }^{\star}$ or hosiery ${ }^{\star}$ or tights ${ }^{\star}$ or sock ${ }^{\star}$ or bandage ${ }^{\star}$ or compres $\left.{ }^{\star}\right): \mathrm{TI}, \mathrm{AB}, \mathrm{KY}$ & 8388 \\
\hline$\# 12$ & $\begin{array}{l}\text { (VenoTrain* or Ulcertec or SurePress* or ComfortPro or Comfort-Pro or "Ulcer } \\
\text { Kit" or Sigvaris):TI,AB,KY }\end{array}$ & 23 \\
\hline$\# 13$ & \#9 OR \#10 OR \#11 OR \#12 & 8388 \\
\hline$\# 14$ & \#8 AND \#13 & 1023 \\
\hline$\# 15$ & * NOT SR-PVD:CC AND 31/03/2014 TO 31/03/2017:DL & 272119 \\
\hline$\# 16$ & \#14 AND \#15 & 238 \\
\hline
\end{tabular}




\section{Appendix 2. Trials registry searches March 2017}

ClinicalTrials.gov

147 studies found for: compression AND (thrombosis OR embolism OR DVT OR PE)

World Health Organization International Clinical Trials Registry Platform

30 records for 30 trials; compression or stockings in Title and (thrombosis OR embolism OR DVT OR PE) in Condition

27 records for 27 trials; (thrombosis OR embolism OR DVT OR PE) in Condition AND (compression or stockings) Intervention ISRCTN Register

24 results compression stockings

Appendix 3. Database searches June 2018

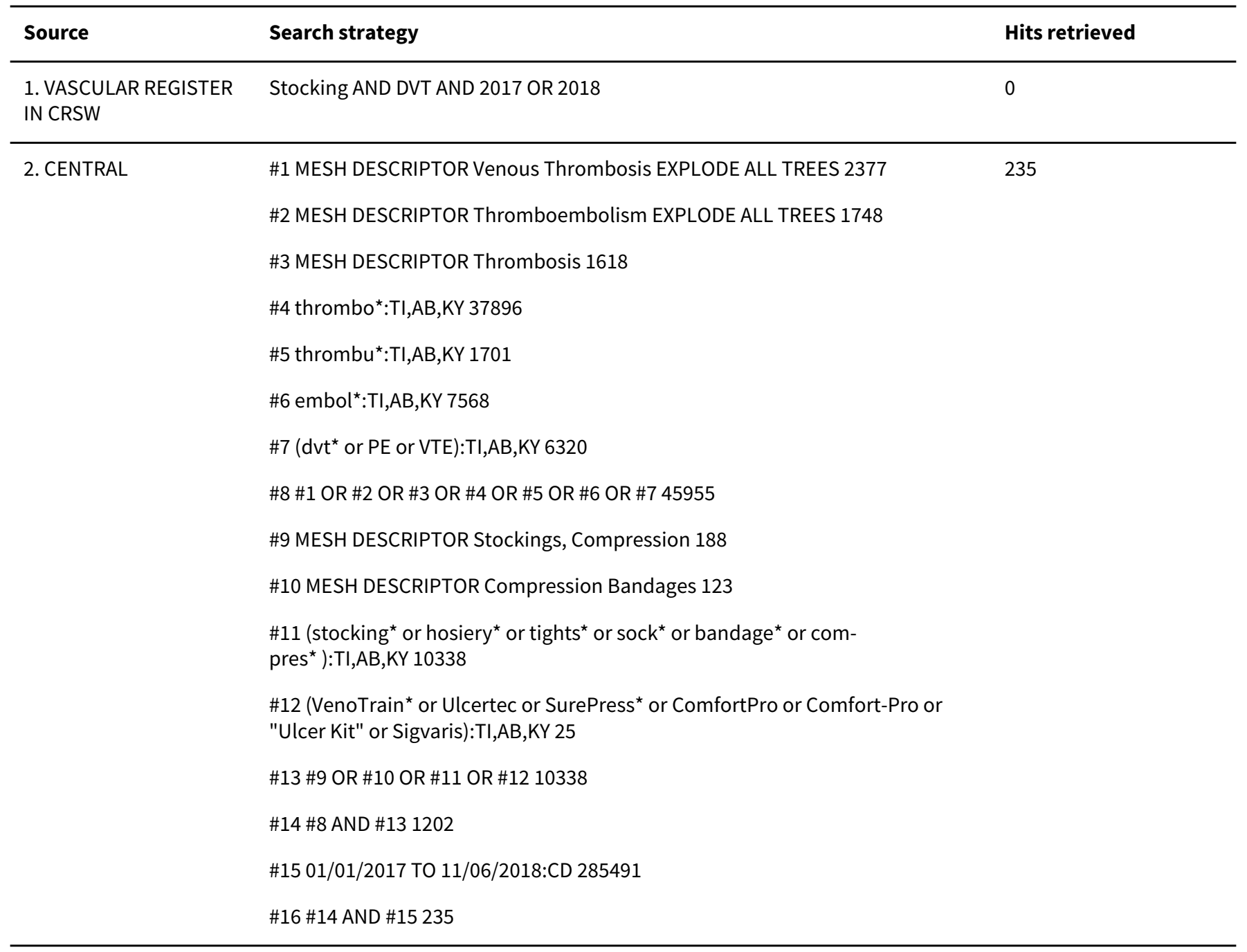

3. ClinicalTrials.gov compression | thrombosis OR embolism OR DVT OR PEO| Start date on or after 22 $01 / 01 / 2017$ | Last update posted on or before 06/12/2018

4. ICTRP Search Portal compression or stockings in Title and (thrombosis OR embolism OR DVT OR 41 $\mathrm{PE})$ 
(thrombosis OR embolism OR DVT OR PE) in Condition AND (compression or stockings) Intervention

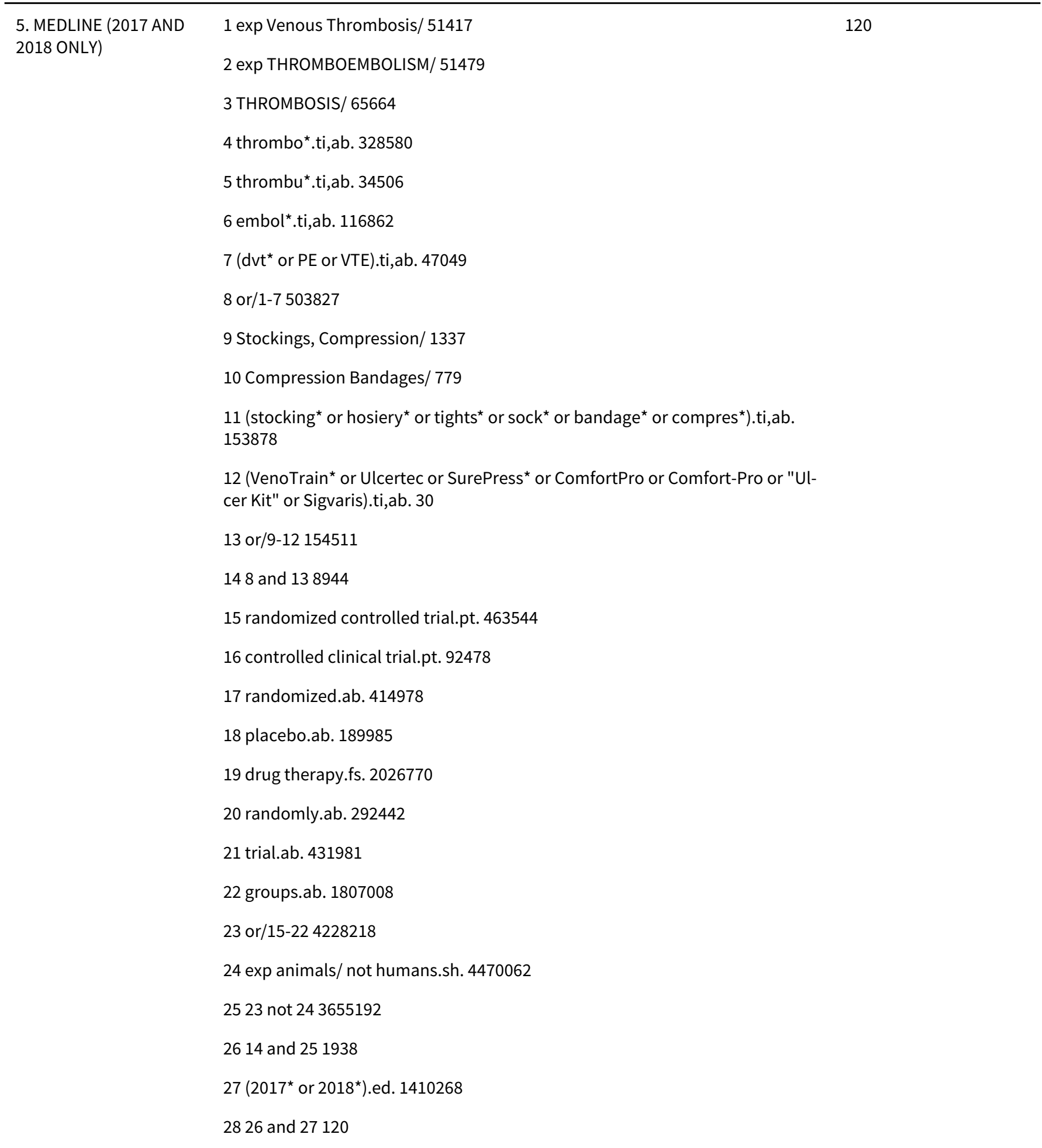

3 thrombosis/ 124510 


\author{
4 thrombo*.ti,ab. 468161 \\ 5 thrombu*.ti,ab. 51801 \\ 6 embol* $^{\star}$.ti,ab. 166543 \\ 7 (dvt* or PE or VTE).ti,ab. 75124 \\ 8 or/1-7 801765 \\ 9 compression stocking/ 2205 \\ 10 compression bandage/ 2132 \\ 11 (stocking* $^{\star}$ or hosiery ${ }^{\star}$ or tights ${ }^{\star}$ or sock ${ }^{\star}$ or bandage ${ }^{\star}$ or compres ${ }^{\star}$ ).ti,ab. \\ 188533 \\ 12 (VenoTrain* or Ulcertec or SurePress* or ComfortPro or Comfort-Pro or "Ul- \\ cer Kit" or Sigvaris).ti,ab. 62
}

13 or/9-12 190524

148 and 1314787

15 randomized controlled trial/ 505723

16 controlled clinical trial/ 460951

17 random\$.ti,ab. 1309942

18 randomization/ 78407

19 intermethod comparison/ 235704

20 placebo.ti,ab. 273502

21 (compare or compared or comparison).ti. 470023

22 ((evaluated or evaluate or evaluating or assessed or assess) and (compare or compared or comparing or comparison)).ab. 1753437

23 (open adj label).ti,ab. 64566

24 ((double or single or doubly or singly) adj (blind or blinded or blindly)).ti,ab. 209146

25 double blind procedure/ 150639

26 parallel group $\$ 1 . t i, a b .21829$

27 (crossover or cross over).ti,ab. 93000

28 ((assign\$ or match or matched or allocation) adj5 (alternate or group $\$ 1$ or intervention $\$ 1$ or patient $\$ 1$ or subject $\$ 1$ or participant $\$ 1)$ ).ti,ab. 283079

29 (assigned or allocated).ti,ab. 332145

30 (controlled adj7 (study or design or trial)).ti,ab. 295234

31 (volunteer or volunteers).ti,ab. 224581

32 trial.ti. 251314

33 or/15-32 4039780

3414 and 332822 
(Continued)

$35\left(2017^{\star}\right.$ or $\left.2018^{\star}\right) \cdot$ em. 3562214

3634 and 35483

37 from 36 keep 1-483 483

7. CINAHL (2017 AND

2018 ONLY)
S31 S29 AND S30 18

18

\section{S29 S14 AND S28 425}

\section{S28 S 15 OR S16 OR S17 OR S18 OR S 19 OR S20 OR S21 OR S22 OR S23 OR S24} OR S25 OR S26 OR S27 341,275

S27 MH "Random Assignment" 38,519

S26 MH "Triple-Blind Studies" 85

S25 MH "Double-Blind Studies" 24,789

S24 MH "Single-Blind Studies" 7,975

S23 MH "Factorial Design" 919

S22 MH "Placebos" 8,349

S21 MH "Clinical Trials" 93,065

S20 TX "multi-centre study" OR "multi-center study" OR "multicentre study" OR "multicenter study" OR "multi-site study" 4,466

S19 TX crossover OR "cross-over" 14,523

S18 AB placebo* 28,225

S17 TX random* 218,477

S16 TX trial $^{*} 249,805$

S15 TX "latin square" 142

S14 S8 AND S13 1,660

S13 S9 OR S10 OR S11 OR S12 25,775

S12 TX VenoTrain* or Ulcertec or SurePress ${ }^{\star}$ or ComfortPro or Comfort-Pro or "Ulcer Kit" or Sigvaris 13

S11 TX stocking* or hosiery * or tights* or sock* or bandage* or compres * 25,772

S10 (MH "Elastic Bandages") 112

S9 (MH "Compression Garments") 1,652

S8 S1 OR S2 OR S3 OR S4 OR S5 OR S6 OR S7 56,491

S7 TX dvt* or PE or VTE 11,032

S6 TX embol* 15,079

S5 TX thrombu* 2,453

S4 TX thrombo* 39,098

S3 (MH "Thrombosis") 4,634 


\section{S2 (MH "Thromboembolism+") 7,488}

S1 (MH "Venous Thrombosis+") 6,387

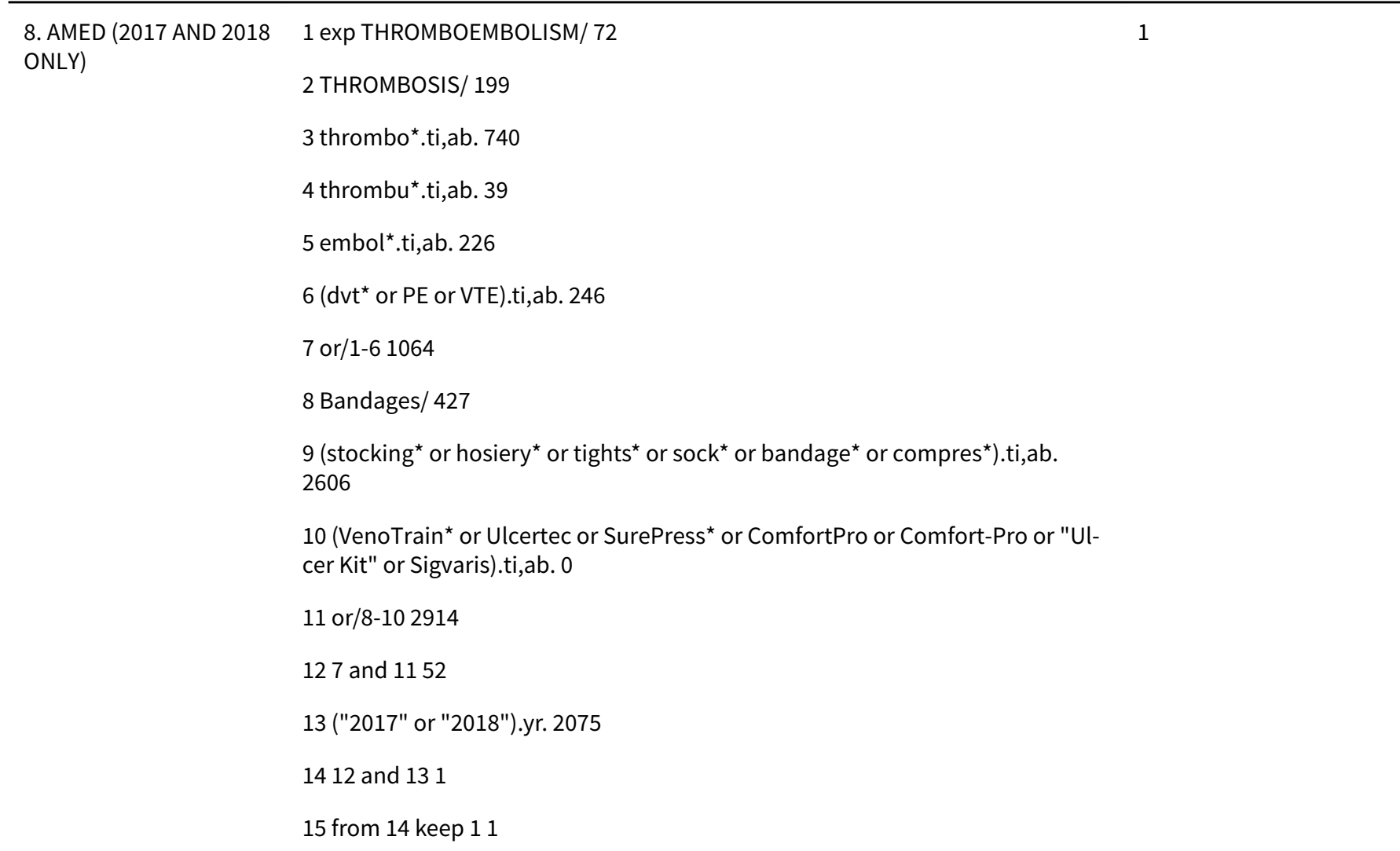

\section{FEE D B A C K}

\section{Excluded studies, 14 September 2015}

\section{Summary}

This study excludes for inadequate reason the two most recent, largest and relevant studies on this topic (CLOTS 2009; Cohen 2007). Both studies showed no benefit to stockings and if included within the review would have meant the conclusions would be changes completely to showing no conclusive benefit of stockings. Most of the included studies are old, small patients numbers and only presented asymptomatic thrombosis events. All of questionable relevance to current practice. Given these studies showing no benefit of stocking and potential for harm I feel the Cochrane review is inaccurate and should not be allowed and if it cannot be immediately updated to included these studies the review should be withdrawn.

\section{Reply}

Mr Parker highlights the exclusion of two trials from this Cochrane review (CLOTS 2009 and Cohen 2007), stating "inadequate reason" for their exclusion. The reasons for excluding both these trials are clearly stated in our review, and revisited below.

The CLOTS 2009 trial was excluded as it focused on patients hospitalised following acute stroke. The authors of this trial have clearly stated that a potential mechanism of action of GCS (i.e. increasing velocity of venous blood flow by improving effectiveness of the calf muscle pump) is lost in patients with severe leg weakness following acute stroke. This patient group, and consequently the CLOTS trial, has therefore been excluded from our review, and is the focus of a separate Cochrane review exclusively focusing on stroke patients (Naccarato 2010).

The Cohen 2007 study was excluded following thorough critical review, as it was unclear whether a standardized protocol was used throughout the study. We noted a number of discrepancies in this trial (such as variation in the use of imaging modalities and how an "objective" diagnosis of symptomatic DVTs was made), and felt it was unclear whether all patients or only selected patients were routinely scanned for DVT. This placed this study at high risk of bias due to lack of consistency in outcome measurement, and it was therefore 
excluded from this review. With regards to adverse events, 7 of 391 patients (2\%) in the Cohen study were stated to have experienced an adverse event related to the wearing of stockings. However, the nature or severity of these events was not reported. Overall, frequency of adverse events was comparable in the fondaparinux-only and fondaparinux+GCS groups. We attempted to contact the authors of this trial to seek further clarification and received no response. Nevertheless, despite the high potential risk for bias associated with this study, its inclusion would not have changed the overall findings on meta-analyses.

Though a number of studies included in this review had small numbers, our conclusions are based upon meta-analyses of 2745 analytic units, making our findings robust and reliable.

In conclusion we see no reason to change the findings of our review.

\section{Contributors}

Feedback: Martyn Parker

MP: I certify that I have no affiliations with or involvement in any organization or entity with a financial interest in the subject matter of my feedback.

Response: Ashwin Sachdeva, Timothy Lees

\section{WHAT'S NEW}

\begin{tabular}{lll}
\hline Date & Event & Description \\
\hline 17 April 2019 & Amended & $\begin{array}{l}\text { Errors in 'anticipated absolute effects' in Summary of Findings } \\
\text { tables corrected. }\end{array}$ \\
\hline
\end{tabular}

\section{H I S T OR Y}

Protocol first published: Issue 2, 1999

Review first published: Issue 3, 2000

\begin{tabular}{lll}
\hline Date & Event & Description \\
\hline 12 June 2018 & New search has been performed & $\begin{array}{l}\text { Searches re-run. One previously excluded study now included. } \\
\text { Six new studies excluded. Three new ongoing studies identified. }\end{array}$
\end{tabular}

12 June $2018 \quad$ New citation required but conclusions

Searches re-run. One previously excluded study now included. have not changed Six new studies excluded. Three new ongoing studies identified. Text amended to reflect current standards. 'Summary of findings' table added. Conclusions not changed.

\begin{tabular}{lll}
\hline 28 October 2015 & Feedback has been incorporated & Feedback and review authors' response to feedback added. \\
\hline 5 April 2014 & New search has been performed & $\begin{array}{l}\text { Searches re-run. One additional trial included. Twenty-three new } \\
\text { studies excluded. }\end{array}$ \\
\hline 5 April 2014 & $\begin{array}{ll}\text { New citation required but conclusions } \\
\text { have not changed }\end{array}$ & $\begin{array}{l}\text { Searches re-run. One additional trial included. Twenty-three } \\
\text { new studies excluded. Trials assessing the effectiveness of stock- } \\
\text { ings and those assessing the effectiveness of stockings over a } \\
\text { background method of thromboprophylaxis were merged in the } \\
\text { analysis. Text updated. No changes to conclusions. }\end{array}$ \\
\hline
\end{tabular}

\begin{tabular}{lll}
\hline 10 May 2010 & $\begin{array}{l}\text { New citation required but conclusions } \\
\text { have not changed }\end{array}$ & Two new authors updated the review. \\
\hline 15 March 2010 & New search has been performed & $\begin{array}{l}\text { The review was updated, and two included studies added. Thir- } \\
\text { ty-five excluded studies added. }\end{array}$ \\
\hline
\end{tabular}




\begin{tabular}{lll}
\hline Date & Event & Description \\
\hline 8 September 2008 & Amended & Converted to new review format. \\
\hline 15 February 2008 & Feedback has been incorporated & $\begin{array}{l}\text { An interim response added to feedback to say that the review is } \\
\text { in the process of being updated. The authors intend to address } \\
\text { the comments and provide a full response with the update. }\end{array}$ \\
\hline 26 November 2003 & New search has been performed & Four excluded studies added. \\
\hline
\end{tabular}

\section{CONTRIBUTIONS OF AUTHORS}

AS: evaluated trials for inclusion; assessed quality of trials; extracted data; updated review

MD: evaluated trials for inclusion; cross-checked and authenticated data extraction; assessed quality of trials; updated review

TL: re-checked and authenticated the selected trials for inclusion; checked the updated review

\section{DECLARATIONS OF INTEREST}

AS: has declared that travel and accommodation expenses were covered by the conference organisers to present the findings of the 2014 version of this review at the 21st European Vascular Course in Maastricht. He has also previously received funding from the following organisations for an unrelated project: National Institute for Health Research, Cancer Research UK, The Urology Foundation, Rosetrees Trust, and JGW Patterson Foundation.

MD: none known

TL: has declared that he is entitled to royalties from Venous Disease Simplified, which are donated to charity. He receives expenses for travel between places of work as part of his normal job and has no known conflicts of interest.

\section{SOURCES OF SUPPORT}

\section{Internal sources}

- No sources of support supplied

\section{External sources}

- Chief Scientist Office, Scottish Government Health Directorates, The Scottish Government, UK.

The Cochrane Vascular editorial base is supported by the Chief Scientist Office.

\section{DIFFERENCES BETWEEN PROTOCOLANDREVIEW}

We excluded two trials including stroke patients, CLOTS 2009; Muir 2000, from this review as they are the subject of another review undertaken by Cochrane Stroke (Naccarato 2010).

Previous versions of this review divided trials into two groups: graduated compression stockings (GCS) as sole method of thromboprophylaxis (i.e. those that compared GCS alone versus no thromboprophylaxis) and GCS as adjuvant method of thromboprophylaxis (i.e. those that compared GCS over a background method of thromboprophylaxis versus background method of thromboprophylaxis alone). Since both these groups of trials test the same treatment effect (i.e. with stockings versus without stockings), we merged all trials in the 2014 update to increase the power of the review.

Since proximal deep vein thrombosis is associated with an increased risk of pulmonary embolism and death (Seinturier 2005), we specifically reported incidence of proximal deep vein thrombosis and pulmonary embolism amongst the included studies (where available).

In keeping with Cochrane's recommendations, we have reassessed studies previously classified as excluded studies for reasons including 'not randomised' as not relevant for this updated version and have removed them from the review. We have reassessed one previously excluded study as an included study. 


\section{N D EX TERMS}

\section{Medical Subject Headings (MeSH)}

*Stockings, Compression; Hospitalization; Orthopedic Procedures; Postoperative Complications [* prevention \& control]; Pulmonary Embolism [* ${ }^{*}$ revention \& control]; Randomized Controlled Trials as Topic; Surgical Procedures, Operative; Venous Thrombosis [*prevention \& control]

\section{MeSH check words}

Humans 